LUCIENE COELHO LOPEZ QUEIROZ

CLASSIFICAÇÃO DAS AMOSTRAS DO ENSAIO DE BAUMANN ATRAVÉS DO PROCESSAMENTO DIGITAL DE IMAGENS

São Paulo 
LUCIENE COELHO LOPEZ QUEIROZ

\title{
CLASSIFICAÇÃO DAS AMOSTRAS DO ENSAIO DE BAUMANN ATRAVÉS DO PROCESSAMENTO DIGITAL DE IMAGENS
}

\author{
Dissertação apresentada à Escola \\ Politécnica da Universidade de São \\ Paulo para obtenção do titulo de \\ Mestre em Ciências.
}

São Paulo 


\title{
CLASSIFICAÇÃO DAS AMOSTRAS DO ENSAIO DE BAUMANN ATRAVÉS DO PROCESSAMENTO DIGITAL DE IMAGENS
}

\author{
Dissertação apresentada à Escola \\ Politécnica da Universidade de São \\ Paulo para obtenção do titulo de \\ Mestre em Ciências.
}

Área de concentração:

Engenharia de Computação.

Orientador:

Prof. Dr. André Riyuiti Hirakawa.

\section{São Paulo}


Este exemplar foi revisado e corrigido em relação à versão original, sob

responsabilidade única do autor e com a anuência de seu orientador.

São Paulo de de

Assinatura do autor:

Assinatura do orientador:

FICHA CATALOGRÁFICA

Queiroz, Luciene Coelho Lopez

Classificação das amostras do ensaio de Baumann através do processamento digital de imagens / L. C. L. Queiroz -- versão corr. -- São Paulo, 2015.

$110 \mathrm{p}$.

Dissertação (Mestrado) - Escola Politécnica da Universidade de São Paulo. Departamento de Engenharia de Computação e Sistemas Digitais.

1.Classificação 2.Defeito 3.Processamento de Imagens 4.Impressão de enxofre 5.Segregação central I.Universidade de São Paulo. Escola Politécnica. Departamento de Engenharia de Computação e Sistemas Digitais II.t. 


\section{DEDICATÓRIA}

Ao meu marido, pelo amor, compreensão e companheirismo incondicionais. Ao meu filho, pela felicidade e pela benção da maternidade. Aos meus pais por todo carinho, apoio e amor que sempre me foi dado, e pelo constante estímulo e incentivo pela educação. À minha irmã e cunhado pelo carinho, amizade e incentivo. 


\section{AGRADECIMENTOS}

À Deus, por tudo. Pelo simples dom da vida, pela esperança, perseverança e amor.

À Escola Politécnica da Universidade de São Paulo por me proporcionar uma evolução profissional e acadêmica.

Ao meu orientador, Prof. Dr. André Riyuiti Hirakawa, pela confiança demonstrada, orientação e apoio ao longo do trabalho.

Aos amigos e líderes, Francisco Roberto Martins de Andrade e Leandro Alcindo de Camargo pelas oportunidades oferecidas, por terem acreditado e incentivado este trabalho.

A todos os colegas, professores e amigos que colaboraram direta ou indiretamente para a realização deste trabalho. 


\section{RESUMO}

O presente trabalho apresenta uma alternativa ao processo de classificação do defeito da segregação central em amostras de aço, utilizando as imagens digitais que são geradas durante o ensaio de Baumann. $O$ algoritmo proposto tem como objetivo agregar as técnicas de processamento digital de imagens e o conhecimento dos especialistas sobre o defeito da segregação central, visando a classificação do defeito de referência. $O$ algoritmo implementado inclui a identificação e a segmentação da linha segregada por meio da aplicação da transformada de Hough e limiar adaptativo. Adicionalmente, $\mathrm{o}$ algoritmo apresenta uma proposta para $\mathrm{O}$ mapeamento dos atributos da segregação central nos diferentes graus de severidade do defeito, em função dos critérios de continuidade e intensidade. $O$ mapeamento foi realizado por meio da análise das características individuais, como comprimento, largura e área, dos elementos segmentados que compõem a linha segregada. A avaliação do desempenho do algoritmo foi realizada em dois momentos específicos, de acordo com sua fase de implementação. Para a realização da avaliação, foram analisadas 255 imagens de amostras reais, oriundas de duas usinas siderúrgicas, distribuídas nos diferentes graus de severidade. Os resultados da primeira fase de implementação mostram que a identificação da linha segregada apresenta acurácia de $93 \%$. As classificações oriundas do mapeamento realizado para as classes de criticidade do defeito, na segunda fase de implementação, apresentam acurácia de $92 \%$ para o critério de continuidade e $68 \%$ para o critério de intensidade.

Palavras-chave: Classificação. Defeito. Processamento de Imagens. Impressão de enxofre. Segregação central. 


\section{ABSTRACT}

This work presents an alternative to the classification process of centerline segregation in steel samples, using the digital images that are generated during the Baumann test. The proposed algorithm aims to aggregate the digital image processing techniques and experts knowledge on centerline segregation to classify the reference defect. The implemented algorithm includes the identification and segmentation of segregation line, applying the Hough transform and adaptive thresholding. Additionally, the algorithm presents a proposal for mapping the centerline segregation attributes on the different defect degrees of severity, according to the intensity and continuity criteria. The mapping was carried out by analyzing the individual characteristics such as length, width and area of the segmented elements that make up the segregation line. The evaluation of the algorithm performance was done in two specific moments, according to implementation phase. In carrying out this evaluation, 255 images of real samples from two steel plants were analyzed, distributed in different degrees of severity. The results of the first phase of implementation show that the identification of the segregation line has $93 \%$ accuracy. The classification results from the attributes mapping realized to the defect severity degrees in the second implementation phase, has accuracy of $92 \%$ for the continuity criteria and $68 \%$ for the intensity criteria.

Keywords: Classification. Defect. Image Processing. Sulphur print. Centerline segregation. 


\section{LISTA DE ILUSTRAÇÕES}

Figura 1 - Tipos de secção das amostras. .....................................................13

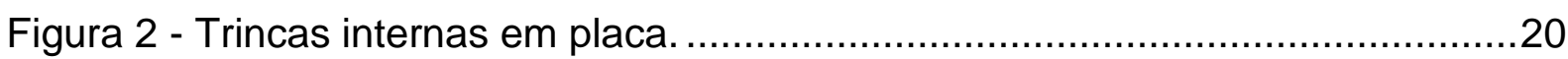

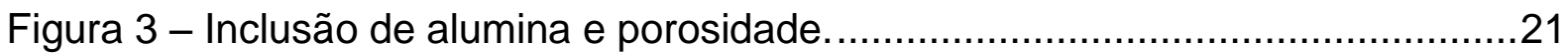

Figura 4 - Etapas de um sistema de processamento de imagens..........................25

Figura 5 - Segregação central: Distribuição das amostras......................................29

Figura 6 - Trincas verticais e internas: Distribuição das amostras. ..........................30

Figura 7 - Trincas horizontais: Distribuição das amostras.....................................31

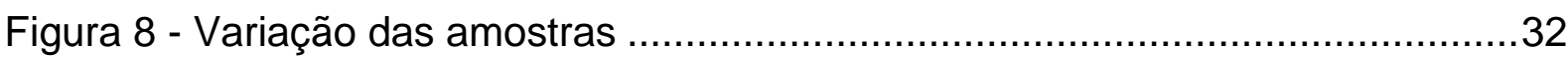

Figura 9 - Imagem digitalizada da impressão de Baumann. ...................................36

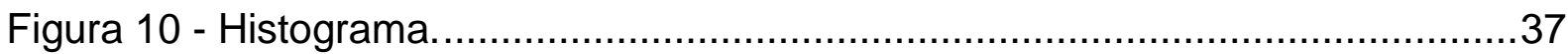

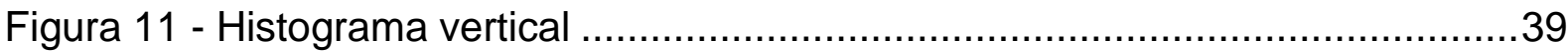

Figura 12 - Histograma vertical após tratamento da imagem ....................................41

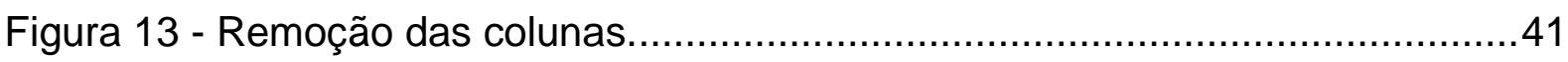

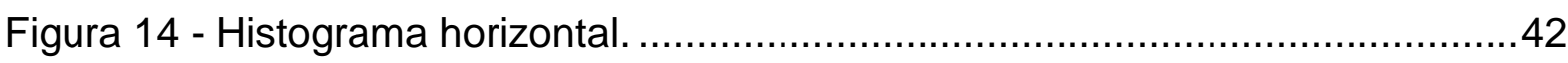

Figura 15 - Histograma horizontal após tratamento da imagem............................43

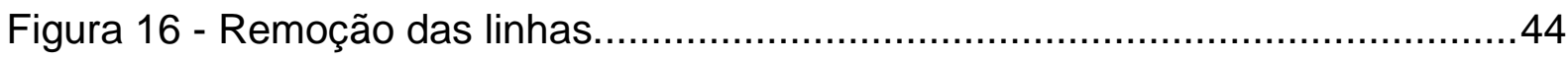

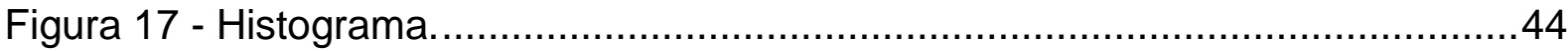

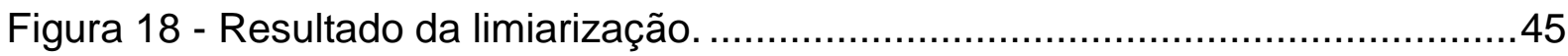

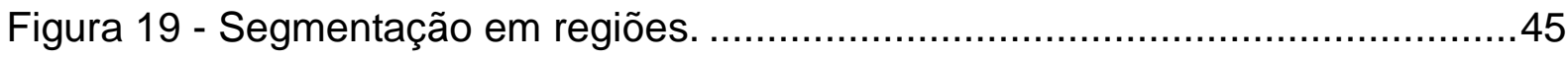

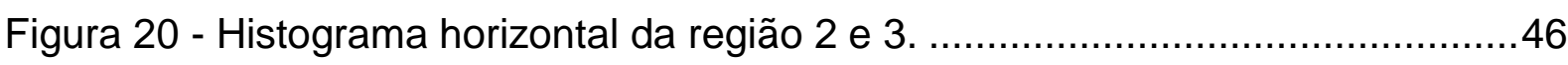

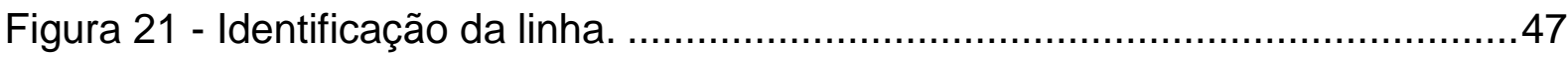

Figura 22 - Intervalo selecionado no histograma horizontal da região 2 e 3 .............47

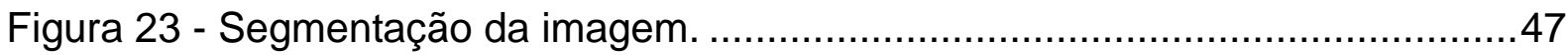

Figura 24 - Resultados da segmentação do algoritmo 1 por grau de severidade. ....49

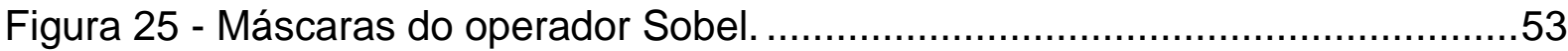

Figura 26 - Estrutura do algoritmo no comparativo de detecção de bordas. .............57

Figura 27 - Implementação dos algoritmos de detecção de bordas........................57

Figura 28 - Estrutura do algoritmo no comparativo entre método Canny tradicional e Canny aperfeiçoado. .60 
Figura 29 - Implementação do comparativo entre método Canny tradicional e Canny aperfeiçoado. (a) Imagem original. (b) Resultado Canny tradicional (filtro Gaussiano). (c) Resultado Canny aperfeiçoado pelo filtro Mediana. (d) Resultado Canny aperfeiçoado pelo Filtro Bilateral. 60

Figura 30 - Região de interesse da impressão de Baumann. .................................62

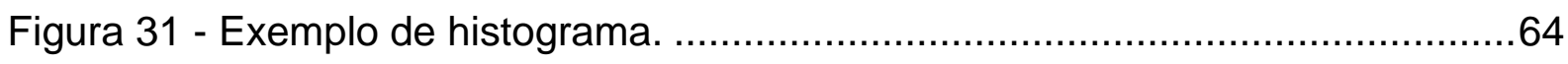

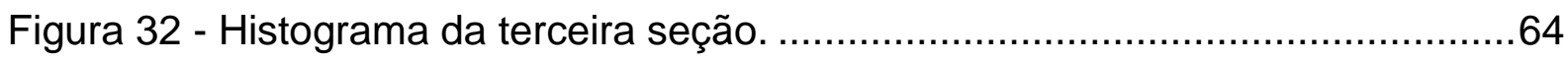

Figura 33 - Resultado da deteç̧ão de bordas. (a)antes. (b) Depois.........................66

Figura 34 - Histograma horizontal da quarta seção..............................................66

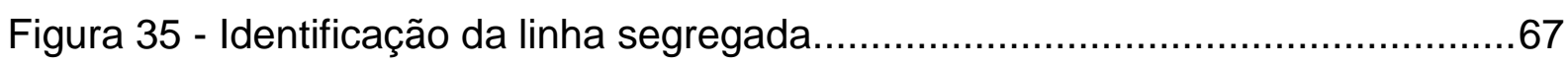

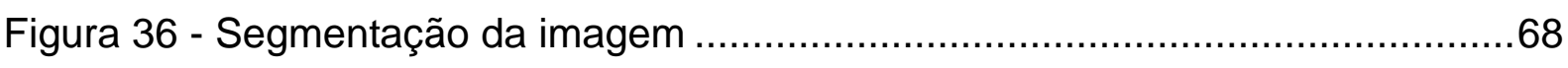

Figura 37 - Avaliação dos resultados da segmentação do algoritmo 2 por grau de severidade.

Figura 38 - Representação do ponto no espaço de Hough. (a) Espaço da Imagem.

(b) Espaço de Hough. .72

Figura 39 - Representação dois pontos no espaço de Hough. (a) Espaço da Imagem. (b) Espaço de Hough. .72

Figura 40 - Representação da reta no espaço de Hough. (a) Espaço da Imagem. (b) Espaço de Hough. .73

Figura 41 - Segmentação inicial da imagem. (a) Imagem original. (b) Imagem segmentada. .75

Figura 42 - Resultado do limiar adaptativo. .75

Figura 43 - Segmentação da linha segregada na 3ํㅗ seção. (a) Região selecionada.

(b) Imagem resultante. .78

Figura 44 - Aplicação do filtro da mediana na $3^{\text {a }}$ seção. (a) Antes. (b) Depois. .........78

Figura 45 - Identificação dos elementos da linha segregada ( $3^{a}$ seção)..................79

Figura 46 - Imagem resultante do algoritmo 3 ( $3^{\text {a }}$ seção)......................................79

Figura 47 - Avaliação dos resultados da segmentação do algoritmo 3 por grau de severidade. .80

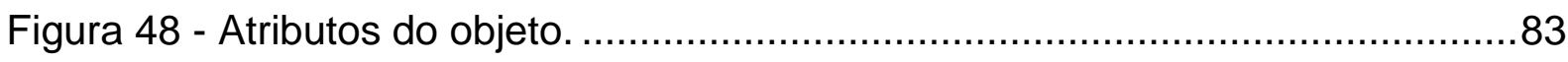

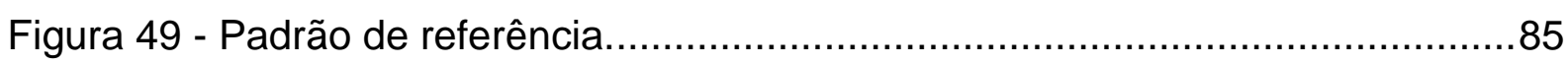

Figura 50 - Distribuição dos atributos dos objetos de maior comprimento e maior área. .86 
Figura 51 - Classe A: Distribuição dos atributos para o critério de intensidade..........89 Figura 52 - Classe B: Distribuição dos atributos para o critério de intensidade..........90 Figura 53 - Classe C: Distribuição dos atributos para o critério de intensidade. .......91 Figura 54 - Resultado do critério de continuidade..............................................94

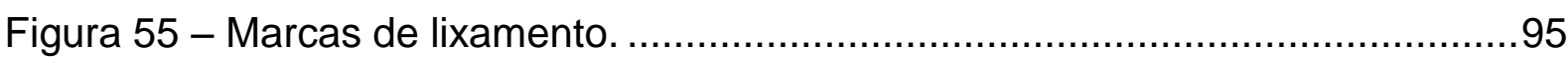

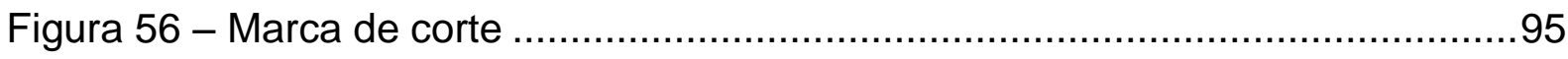

Figura 57 - Resultados do critério de continuidade e intensidade...........................96 


\section{LISTA DE TABELAS}

Tabela 1 - Classificação da continuidade da segregação central..........................18

Tabela 2 - Classificação da segregação central por intensidade. ...........................19

Tabela 3 - Pré-processamento da imagem..................................................62

Tabela 4 - Resultado da limiarização das seções. .................................................65

Tabela 5 - Imagens Resultantes da segmentação em seções. .............................76

Tabela 6 - Identificação da linha pela transformada de Hough para cada seção. .....77

Tabela 7 - Mapeamento dos atributos no critério de continuidade.........................88

Tabela 8- Classe A: Mapeamento dos atributos para o critério de intensidade.........90

Tabela 9- Classe B: Mapeamento dos atributos para o critério de intensidade.........91

Tabela 10- Classe C: Mapeamento dos atributos para o critério de intensidade. .....92 


\section{SUMÁRIO}

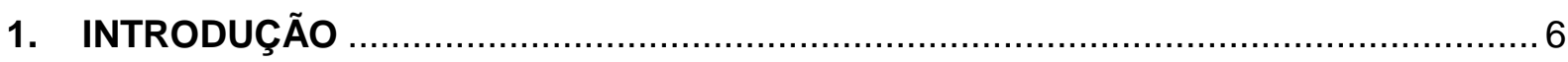

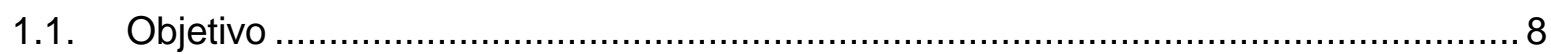

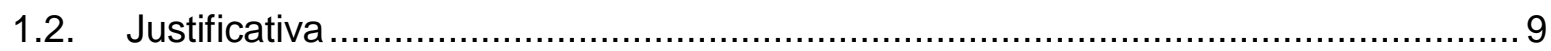

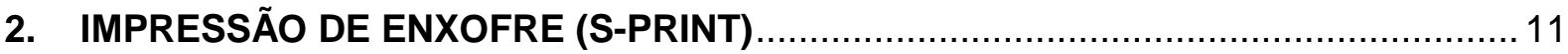



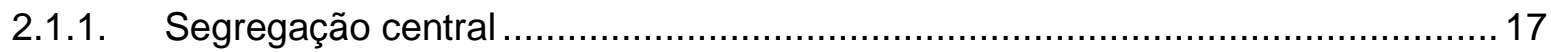

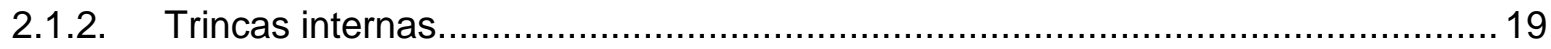

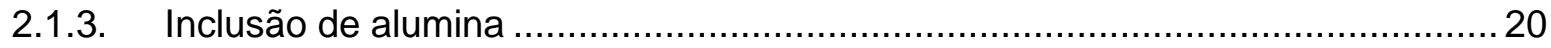

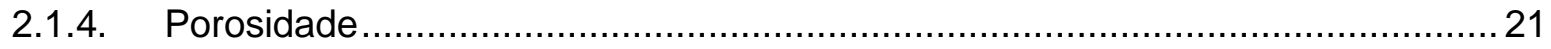

2.2. Análise dos resultados da Impressão de Enxofre ........................................... 22

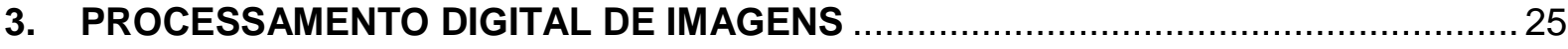

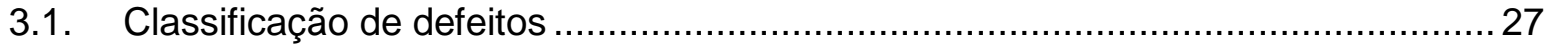

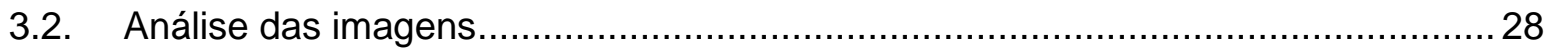

3.3. Algoritmo de Classificação ........................................................................... 33

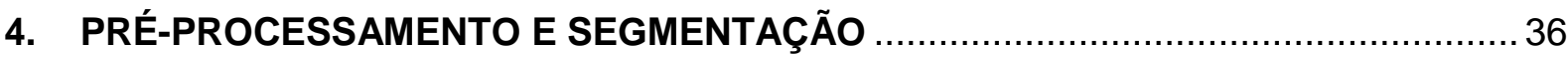

4.1. Algoritmo 1: Limiarização e Histograma........................................................... 37

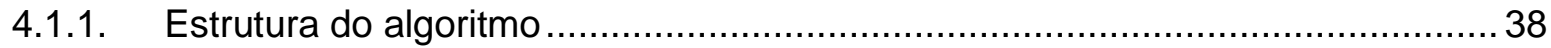



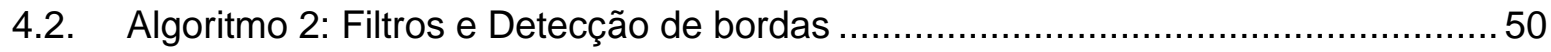

4.2.1. Comparativo entre as técnicas de detecção de bordas …................................56

4.2.2. Comparativo método Canny tradicional e aperfeiçoado ..................................... 59



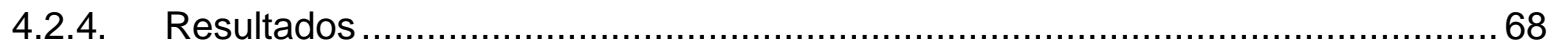

4.3. Algoritmo 3: Limiar adaptativo e transformada de Hough..................................... 71

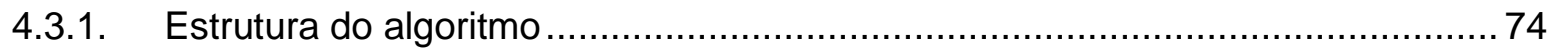

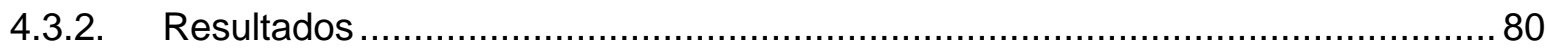

5. EXTRAÇÃO DE CARACTERÍSTICAS E CLASSIFICAÇÃO ................................... 82

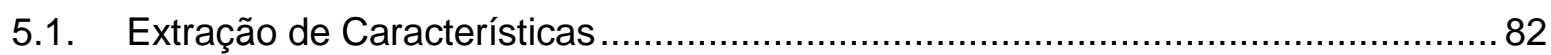

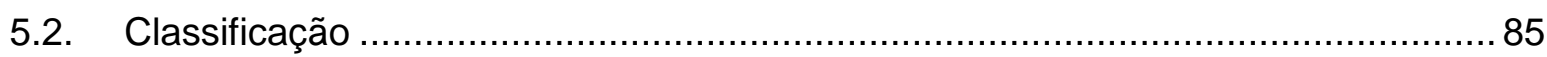

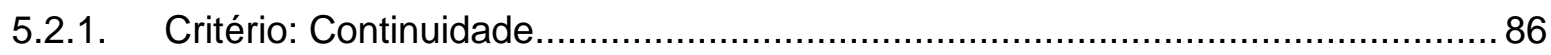

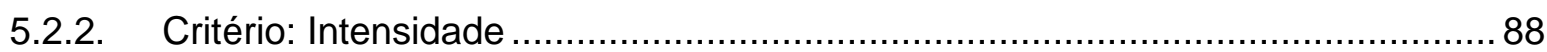

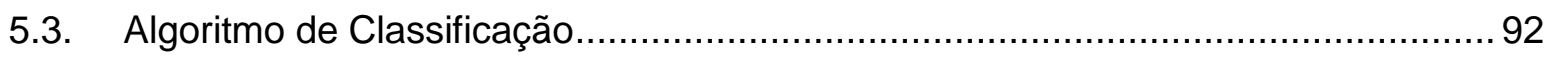

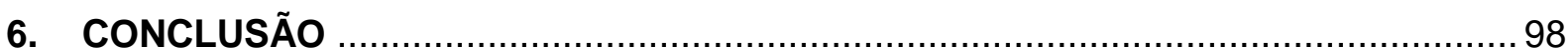

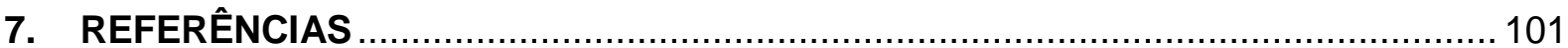




\section{INTRODUÇÃO}

Atualmente, vive-se num mundo globalizado, de forte concorrência e constantes mudanças onde, no ramo empresarial, destacam-se aqueles que são capazes de oferecer os melhores e mais atraentes produtos ou serviços para seus clientes. Desta forma, as empresas vêm ao longo dos anos intensificando os investimentos na utilização de novas tecnologias, visando garantir sua competitividade e posição no mercado através do aprimoramento de seus processos e da qualidade dos produtos/serviços prestados.

Este cenário não é diferente no setor siderúrgico, no qual ao longo do processo de fabricação do aço diversos fatores podem interferir e prejudicar a obtenção do produto final com características mecânicas e metalúrgicas uniformes. Desta forma, faz-se necessária à realização do controle de qualidade do material produzido ao longo de todo o processo de fabricação, visando garantir a aplicabilidade do material de acordo com as exigências dos clientes, o planejamento da produção e as normas internacionais de qualidade (NAKAGAWA, 2007).

Atingir esse objetivo por meio do controle do processo pode ser considerada uma tarefa árdua em função das características do processo siderúrgico, no qual ocorrem a manipulação e o controle do fluxo de substâncias químicas, como metal líquido e gases gerados ou utilizados no processo, além do controle dos equipamentos de grande porte utilizados na manipulação e/ou fabricação do aço.

Dentre os diversos processos que compõe uma usina siderúrgica integrada, destaca-se o processo de lingotamento do aço. Rizzo (2006) explica que nesta etapa, o aço é convertido do estado líquido para o sólido através da Máquina de Lingotamento Contínuo (MLC), dando origem a produtos semi-acabados como, perfis, placas, blocos ou tarugos.

O processo de solidificação do aço no lingotamento contínuo ocorre das bordas para o núcleo do veio em função do contato com as paredes refrigeradas do molde, aspersão de água em sprays e perda de calor por radiação para o ambiente 
(MA et al., 2004, p. 550). Essa troca de calor faz com que o aço se solidifique gradativamente, criando zonas onde o material pode ser encontrado em seus estados sólido e líquido. Voort (2007, p. 47) explica que durante o fenômeno de solidificação, o fósforo e o enxofre são rejeitados da zona sólida para a zona liquida porque a solubilidade do sólido de enxofre no ferro é muito baixa, fazendo com que todo o enxofre seja precipitado na forma de inclusões de sulfeto. Desta forma as últimas regiões solidificadas da placa possuem uma grande concentração destas impurezas, o que influencia diretamente na qualidade do material produzido.

Visto que o controle do processo de solidificação no lingotamento contínuo é relevante para a determinação da qualidade do aço produzido, faz-se necessária a utilização de métodos e ensaios capazes de avaliar as condições da MLC de maneira confiável e assertiva (CARVALHO, 1988, p. 319).

Neste cenário, é empregado o método Baumann, que consiste em um exame macrográfico que visa revelar a posição das áreas ricas em enxofre na amostra. Através deste exame é possível verificar a distribuição e o tamanho das inclusões de enxofre e consequentemente realizar correlações com o grau de uniformidade do processo de solidificação do aço (BS, 1982) ${ }^{1}$. O método Baumann, ou impressão de enxofre como também é conhecido, ressalta irregularidades químicas como, por exemplo, segregações e inclusões, e pode revelar irregularidades físicas como trincas (NAYAR, 2005, p. 129). Através da análise destas irregularidades é possível classificar os defeitos internos de acordo com critérios predefinidos para cada tipo de irregularidade.

A classificação desses defeitos é realizada visualmente por um especialista por meio da comparação do resultado da impressão de enxofre da amostra com o padrão de referência (SIRGO et al., 2006, p.516). Com os resultados obtidos neste ensaio, é possível tomar medidas corretivas de forma a garantir a qualidade do material (FACO, 2005, p. 147), evitando possíveis desvios, associados ao comprometimento da qualidade do mesmo.

\footnotetext{
${ }^{1}$ BRITISH STANDART. BS 6285: The macrographic examination of steel by sulphur print (Baumann method).
} 
A correta classificação do grau de severidade do defeito analisado na impressão de enxofre é importante para o controle do processo. Entretanto, dada a complexidade da classificação entre os diferentes níveis de severidade, esse processo torna-se totalmente dependente da experiência e conhecimento do especialista que realiza a análise. Em função da interferência humana nesta análise, divergências na classificação dos resultados são possíveis, já que a atividade é manual e, ocasionalmente, um especialista pode ser mais rigoroso do que outro durante o processo de classificação. Adicionalmente, fatores ambientais (frio ou calor excessivo), físicos e comportamentais (estresse, fadiga, fome, sono) podem influenciar a avaliação do especialista.

A avaliação deste cenário motivou a busca pelo desenvolvimento de recursos computacionais capazes de absorver esse conhecimento dos especialistas e auxiliar o processo de identificação e classificação dos defeitos analisados na impressão de enxofre.

\subsection{Objetivo}

O presente trabalho tem como objetivo apresentar uma proposta alternativa, ao processo de classificação manual dos defeitos internos presentes nas amostras da impressão de enxofre, utilizando para isso, as imagens digitais geradas durante 0 ensaio de Baumann.

Visando alcançar esse objetivo, propõe-se nesse trabalho um algoritmo, que agrega as técnicas de processamento digital de imagens e o conhecimento dos especialistas sobre o defeito da segregação central, para a classificação dos defeitos de referência.

O algoritmo inclui a identificação e a segmentação da linha segregada através da aplicação da transformada de Hough e limiar adaptativo. Adicionalmente, o algoritmo apresenta uma proposta para o mapeamento dos atributos da 
segregação central (extraídos da imagem digitalizada da amostra) nos diferentes graus de severidade do defeito visando sua classificação.

\subsection{Justificativa}

O ensaio de Baumann consiste na análise metalográfica realizada em uma secção transversal ou longitudinal da placa. Primeiramente, esta amostra passa pelo processo de corte, seguida pela preparação que consiste no desbaste, lixamento, polimento e ataque químico (SERVILHA, 1980, p.27). Somente após a conclusão da fase de preparação, é realizada a impressão de enxofre através da utilização de papel fotográfico apropriado (ISO, 1979) ${ }^{2}$.

A exposição do papel fotográfico a um determinado reagente químico, quando colocado em contato com a superfície da amostra, permite a revelação dos defeitos internos da placa de forma clara e nítida (ASTM, 2008) ${ }^{3}$. Outra alternativa existente, é a utilização de recursos digitais, empregados em detrimento da utilização do papel fotográfico, o que reduz os custos vinculados ao processo de guarda dos resultados das amostras (DIAS et al., 2006), mas mantém as características da análise manual em relação ao processo de classificação dos defeitos.

Usualmente a classificação dos defeitos na escala do padrão de referência é realizada manualmente baseada apenas no conhecimento e experiência dos especialistas. É importante destacar que a seleção entre os diversos padrões é considerada uma tarefa árdua em função das características das imagens, tornando passível a ocorrência de erros na classificação, uma vez que se baseia unicamente na experiência, observação e no grau de conhecimento de cada indivíduo (LOPEZ, 2011).

\footnotetext{
${ }^{2}$ INTERNATIONAL STANDARD ORGANIZATION. ISO 4968: Steel - Macrographic examination by sulphur print (Baumann method).

${ }^{3}$ AMERICAN SOCIETY FOR TESTING AND MATERIALS. ASTM E 1180-08: Standard Practice for Preparing Sulphur Prints for Macrostructural Evaluation
} 
A análise deste cenário motivou este trabalho que tem como objetivo à elaboração de um algoritmo capaz de classificar o defeito da segregação central através do reconhecimento das imagens digitais da amostra de Baumann. Esta proposta apresenta uma alternativa para reduzir a dependência existente na experiência individual dos especialistas, uma vez que o conhecimento relacionado ao processo de classificação do defeito da segregação central passa a estar contido no algoritmo, o que aumenta o grau de confiabilidade nos resultados das análises em função da uniformização do conhecimento, independente do individuo que esteja realizando a avaliação. 


\section{IMPRESSÃO DE ENXOFRE (S-PRINT)}

A impressão de enxofre (S-Print) foi desenvolvida por Baumann em 1906, ao longo do tempo o método também ficou conhecido como impressão de Baumann ou simplesmente método Baumann, e ainda hoje é um dos instrumentos utilizados para o controle da qualidade interna do material produzido no lingotamento contínuo (MORGENFELD et al., 1983, p.143). Além disso, o método Baumann destaca-se como uma importante ferramenta, adequada ao controle do processo, apoio à pesquisa, desenvolvimento de estudos, análise de falhas e para fins de aceitação de materiais (FACO, 2005, p. 146).

O método Baumann é amplamente difundido e utilizado por diversas usinas siderúrgicas ao redor do mundo, sendo objeto de padronização por diferentes órgãos normativos internacionalmente reconhecidos (LOPEZ, 2011, p.134). Dentre as normas que padronizam os procedimentos para a realização do ensaio de Baumann destacam-se:

- ISO 4968: Steel - Macrographic examination by sulphur print (Baumann method);

- BS 6285: The macrographic examination of steel by sulphur print (Baumann method);

- ASTM E1180 - 08: Standard practice for preparing sulphur prints for macrostructural evaluation.

Embora existam normas distintas para regulamentar as atividades que devem ser realizadas durante o ensaio, os procedimentos descritos nas normas acima citadas são similares.

O objetivo do exame macrográfico através da impressão de Baumann é revelar a posição das áreas ricas em enxofre na amostra. Por meio deste exame é possível verificar a distribuição e o tamanho das inclusões de enxofre e 
consequentemente realizar correlações com o grau de uniformidade no processo de solidificação do aço (BS, 1982). A impressão de enxofre ressalta irregularidades químicas como, por exemplo, segregações e inclusões, e pode revelar irregularidades físicas como trincas (NAYAR, 2005, p. 129). Através da análise destas irregularidades é possível classificar os defeitos internos do material analisado de acordo com critérios pré-definidos para cada tipo de irregularidade.

A impressão de enxofre complementa 0 método de macroataque proporcionando um procedimento capaz de avaliar a homogeneidade do aço produzido. A norma ASTM E340-00: Standard Test Method for Macroetching Metals and Alloys descreve os procedimentos para a realização do macroataque destacando os reagentes adequados para cada tipo de material. Apresenta-se a seguir uma breve revisão dos procedimentos executados desde a preparação da amostra, passando pela realização do macroataque até a impressão de enxofre.

O ensaio de Baumann tem início com a seleção e preparação da amostra. Usualmente a amostragem é realizada por veio, com uma frequência que pode variar de acordo com o rigor da aplicação do material (quanto maior o rigor, maior a frequência), estabilidade da MLC (máquinas mais modernas oferecem um grau de estabilidade maior podendo-se reduzir a frequência de amostragem), teor elevado de fósforo e enxofre na composição química do aço, entre outros fatores (CARVALHO, 1988, p. 319). O processo de preparação da amostra consiste basicamente nos seguintes estágios: corte, desbaste, lixamento, polimento e ataque (SERVILHA, 1980, p.27).

Servilha (1980, p. 27) destaca o corte como primeiro passo para a preparação da amostra, que pode ser considerado um estágio crítico, pois se mal executado pode causar danos irreparáveis para a realização dos próximos estágios invalidando completamente os dados que seriam obtidos a partir da amostra. Para a análise de Baumann as amostras podem ser seccionadas de duas formas distintas, transversal ou longitudinal como mostra a Figura 1. 
Figura 1 - Tipos de secção das amostras.

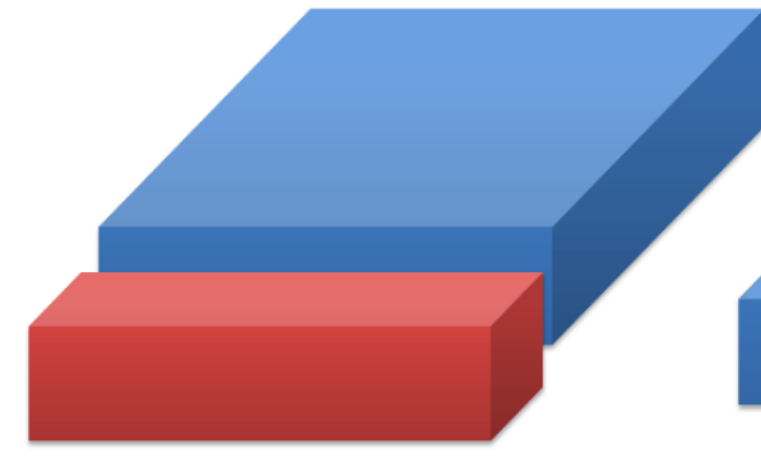

TRANSVERSAL

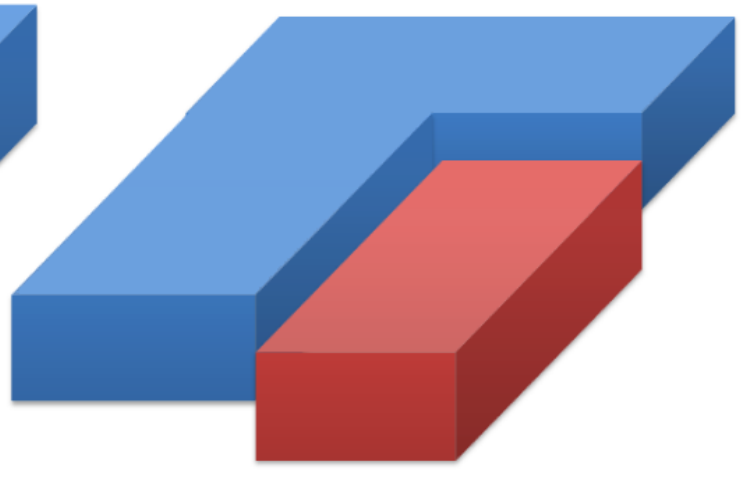

LONGITUDINAL

O desbaste, segundo estágio, tem basicamente a finalidade de eliminar as rebarbas e as deformações produzidas durante o corte (SERVILHA, 1980). O terceiro estágio, lixamento, tem como objetivo reduzir a camada de deformações oriundas do corte, através da utilização de lixas sob a superfície da face que será analisada (SERVILHA, 1980).

Servilha (1980) destaca o polimento como o último estágio responsável pela eliminação da camada de deformações da amostra, para obtenção de uma superfície plana e o mais lisa possível, removendo inclusive os riscos deixados na amostra durante a fase de lixamento.

A fase de preparação da amostra é encerrada com o ataque químico, que tem como objetivo colocar em relevo a macroestrutura do material analisado através da utilização de reagentes químicos. Voort $(2007$, p.48) explica que a ultima região solidificada do material é rica em inclusões de sulfeto, tal característica torna-se vantajosa para a realização do ataque químico, uma vez que a taxa de corrosão da última zona solidificada torna-se diferente da taxa de corrosão das demais regiões da amostra possibilitando a visualização da macroestrutura mais facilmente.

O ataque é realizado através da imersão do papel fotográfico comum, de brometo de prata, por aproximadamente cinco minutos em uma solução aquosa de ácido sulfúrico com composição volumétrica de 3 volumes de $\mathrm{H}_{2} \mathrm{SO}_{4}\left(\varrho_{20} 1,84 \mathrm{~g} / \mathrm{ml}\right)$ e 97 volumes de $\mathrm{H}_{2} \mathrm{O}$, em temperatura ambiente (ISO, 1979). Em seguida o papel 
fotográfico é colocado em contato com a superfície da amostra, que deve estar livre de qualquer tipo de graxa ou sujeira oriunda das fases anteriores de preparação (VOORT, 2007, p.48).

Os sulfetos existentes na superfície metálica reagem com o brometo de prata do papel fotográfico, formando o sulfeto de prata, que imprime manchas pardas ou negras no papel (ASTM, 2008). As reações químicas que ocorrem durante a impressão de enxofre podem ser descritas pelas eq.(1), (2), (3) e (4):

$$
\begin{aligned}
& \mathrm{H}_{2} \mathrm{SO}_{4}+\mathrm{MnS}=\mathrm{H}_{2} \mathrm{~S}+\mathrm{MnSO}_{4} \\
& \mathrm{H}_{2} \mathrm{SO}_{4}+\mathrm{FeS}=\mathrm{H}_{2} \mathrm{~S}+\mathrm{FeSO}_{4}
\end{aligned}
$$

Como podem existir sulfetos de ferro no aço

$$
\mathrm{H}_{2} \mathrm{~S}+2 \mathrm{AgCl}=\mathrm{Ag}_{2} \mathrm{~S}+2 \mathrm{HCl}
$$

$\mathrm{Ou}$

$$
\mathrm{H}_{2} \mathrm{~S}+2 \mathrm{AgBr}=\mathrm{Ag}_{2} \mathrm{Br}+2 \mathrm{HCl}
$$

ou ambos.

O tempo de exposição do papel fotográfico na superfície da placa pode variar de alguns segundos até minutos. A duração da exposição deve ser previamente avaliada levando em consideração as características do material analisado, como por exemplo, sua composição química (ASTM, 2008).

Após a remoção do papel fotográfico, o mesmo deve ser lavado em água corrente por aproximadamente dez minutos e em seguida mergulhado na solução fixadora por mais dez minutos. A solução fixadora tem como objetivo garantir a fixação no papel fotográfico das manchas geradas durante o processo de exposição do papel com a superfície do aço. O fixador é uma solução aquosa que contém de 15 a $20 \%$ de tiossulfato de sódio e 80 a $85 \%$ de água (BS, 1982). 
Na sequência, o papel fotográfico deve novamente ser lavado em água corrente por, aproximadamente, 30 minutos e secado. Após estes procedimentos 0 papel fotográfico estará pronto para ser analisado (ASTM, 2008).

As manchas impressas no papel fotográfico são utilizadas para identificação dos defeitos internos característicos da operação de lingotamento contínuo. A intensidade das manchas é influenciada pela concentração de enxofre no aço, composição química das inclusões de sulfetos, agressividade da solução aquosa utilizada como reagente e duração do contato do papel fotográfico com a superfície da amostra (ASTM, 2008).

Os aços que possuem uma concentração muito pequena de enxofre em sua composição química irão produzir manchas muito claras, o que prejudica a avaliação através deste método. Desta forma a impressão de Baumann é recomendada para a análise de aços que possuem concentração de enxofre entre 0,010 e 0,40\% (ASTM, 2008).

Após a obtenção da impressão de enxofre que revela os defeitos internos do material analisado em função das manchas presentes no papel fotográfico, é possível realizar a análise e classificação dos defeitos de acordo com seu aspecto, espessura e gravidade emitindo um relatório sobre a sanidade interna da placa (ASTM, 2008).

Rizzo (2006, p. 143) destaca que a principal finalidade da impressão de Baumann é atuar como uma ferramenta de apoio permitindo o controle do processo de lingotamento contínuo e da limpidez do aço, onde, para tal são analisados os seguintes parâmetros:

- Índice de macrossegregação central;

- Presença, tipo e intensidade de trincas internas;

- Presença e intensidade de inclusões e porosidade. 
A avaliação destes parâmetros, ou seja, classificação dos resultados conforme intensidade e criticidade é realizada visualmente por um especialista através da comparação da impressão de Baumann da amostra com critérios de classificação pré-estabelecidos. Após a interpretação dos resultados pelo especialista, Rizzo (2006, p. 143) destaca que os seguintes parâmetros podem ser corrigidos na máquina de lingotamento contínuo:

- Ponto de desencurvamento da placa;

- Desalinhamento dos rolos;

- Desgaste dos rolos;

- Anormalidades de espaçamento entre os rolos.

De acordo com Carvalho (1988, p. 320), a agilidade na realização do ensaio, é fundamental para a rapidez na tomada das ações corretivas na máquina de lingotamento, o que ocorre em função da característica contínua do processo. Logo, quanto mais rápido for realizado o ensaio, mais rapidamente pode-se parar ou ajustar a MLC e seus equipamentos auxiliares, evitando que o problema continue a ocorrer e mais placas sejam produzidas com o mesmo tipo de defeito identificado na análise de Baumann.

\subsection{Defeitos internos}

Os defeitos internos analisados na impressão de Baumann são classificados através da comparação dos resultados da amostra analisada com padrões de referência. Estes são conjuntos de fotografias que correspondem a cada tipo de defeito com diferentes níveis de gravidade. Estes padrões são elaborados por empresas do setor siderúrgico e dentre os mais conhecidos destacam-se NSC (Nippon Steel Corporation) e Mannesmann (FURTADO, 2007, p. 186).

Apresenta-se a seguir os defeitos internos analisados na impressão de Baumann, destacando como os mesmos são formados durante o processo 
solidificação do aço e os critérios adotados para sua classificação segundo o padrão de referência NSC e Mannesmann.

\subsubsection{Segregação central}

A presença da segregação central influencia negativamente o desempenho do produto laminado, pois altera as propriedades físicas e mecânicas da placa. Quanto mais acentuada a segregação central, maior seu impacto na qualidade do produto final (GHOSH, 2001, p. 5).

A segregação central é um defeito que ocorre na última região a solidificar da placa. Por ter esta característica, este defeito concentra-se na região central do produto (QUEIROZ, 2013, p. 183). De acordo com Voort (2007, p.47), as últimas regiões solidificadas da placa possuem uma grande concentração de impurezas nocivas à qualidade do aço, dentre as quais se destaca o enxofre.

Devido a este fenômeno de solidificação do aço, este defeito torna-se praticamente inerente ao processo de lingotamento contínuo. Desta forma, a segregação central dificilmente pode ser totalmente eliminada da placa. Entretanto, um grande acumulo destas impurezas podem comprometer a qualidade do material produzido, fazendo com que o acompanhamento sistemático do nível de segregação seja fundamental para o processo. A segregação central com nível elevado de severidade torna-se visível no laminado, principalmente após os ensaios de dobramento ou tração, em que pode ser observada a ocorrência de trincas no centro da espessura do material (CARVALHO, 1988, p. 327).

Outro aspecto que pode influenciar a formação da segregação central é o alinhamento e espaçamento dos rolos da MLC, principalmente na região próxima ao ponto final de solidificação. Caso os rolos estejam desalinhados ou excêntricos, a fração do aço ainda no seu estado líquido (que contém as impurezas) pode ser succionada para o centro da placa, formando a segregação central (GARCIA et al., 2006, p. 189). Com relação aos efeitos do espaçamento, caso os rolos estejam mais afastados do que o necessário, haverá um aumento do volume de líquido residual 
que contém os elementos segregados, aumentando o grau de severidade da segregação central. Isto pode inclusive nos casos mais graves resultar no sucateamento do material produzido (CARVALHO, 1988, p 327).

No padrão Mannesmann, a segregação central é classificada em quatro níveis de severidade. De acordo com a escala definida neste padrão, zero representa o menor nível de segregação, enquanto quatro é o maior nível na escala de severidade (FURTADO, 2007, p. 186).

O padrão NSC, por sua vez, adota critérios de classificação mais refinados por considerar a continuidade e a intensidade do defeito. A continuidade das linhas de segregação é classificada através das letras "A", "B" ou "C", sendo que "A" representa o maior grau de severidade e " $C$ " o menor. A Tabela 1 apresenta a definição de cada classificação de acordo com a continuidade da segregação central (FURTADO, 2007, p. 186).

Tabela 1 - Classificação da continuidade da segregação central.

\begin{tabular}{cl}
\hline Continuidade & Definição \\
\hline A & Linha pronunciada uniforme e contínua. \\
B & Linha pronunciada, porem não uniforme disposta na \\
C & forma de traços mais alongados. \\
\hline
\end{tabular}

Fonte: FURTADO (2007).

A intensidade por sua vez, é classificada de acordo com a dimensão da segregação central, medida em relação à espessura da linha segregada da placa com valores que variam de 0,0 a 3,0 em intervalos de 0,5. A Tabela 2 apresenta os valores adotados para a classificação da intensidade associada à continuidade da segregação (FURTADO, 2007, p. 186). 
Tabela 2 - Classificação da segregação central por intensidade.

\begin{tabular}{cl}
\hline Continuidade & Intensidade da faixa segregada \\
\hline A & $1,5-2,0-2,5-3,0$ \\
B & $1,5-2,0-2,5-3,0$ \\
C & $0,0-0,5-1,0-1,5-2,0-2,5-3,0$ \\
\hline
\end{tabular}

Fonte: FURTADO (2007).

É importante ressaltar que o grau de severidade em relação à intensidade varia de 3,0 (mais crítico) até 0,0 (menos crítico). Desta forma a classificação "C00" (que representa continuidade " $C$ " e intensidade " 0,0 ") indica a ausência de segregação.

\subsubsection{Trincas internas}

"Trincas internas ocorrem quando é aplicada à frente de solidificação uma tensão que resulta em deformação acima do seu limite de resistência. Essa tensão pode ser do tipo térmica ou mecânica." (CARVALHO, 1988, p. 322).

As tensões térmicas podem ser causadas, por exemplo, pelo resfriamento excessivo das faces largas das placas de aço. Isso resulta na contração da pele solidificada causando um desequilíbrio com a contração das camadas internas, resultando em uma trinca na interface de solidificação. $O$ abaulamento da face maior, esforços excessivos na região de desdobramento da placa, desalinhamento, desgaste e empeno dos rolos de sustentação são exemplos de fontes de tensões mecânicas (RIZZO, 2006, p. 147).

Com relação ao comportamento das trincas, elas se propagam da frente de solidificação para a pele solidificada. Estas trincas, inclusive, são preenchidas com o líquido residual, ricos em elementos segregados, o que torna possível a identificação do defeito através da impressão de Baumann (SHANKAR et al., 2003, p. 359).

As trincas normalmente ocorrem em duas regiões distintas: na região do encontro triplo colunar e fora dessa região. A região triplo colunar é caracterizada 
como a região do encontro das diferentes zonas de solidificação. As trincas que ocorrem na região triplo colunar são horizontais, e por isso, ganham o nome de trincas horizontais. As trincas de canto são localizadas próximas às quinas da amostra. As trincas perpendiculares, por sua vez, são chamadas de trincas verticais ou internas dependendo de sua posição. As trincas próximas à região triplo colunar são chamadas de trincas verticais. Já as trincas internas ocorrem perpendicularmente à linha segregação. A Figura 2 ilustra o perfil das trincas. (CARVALHO, 1988, p. 323).

Figura 2 - Trincas internas em placa.

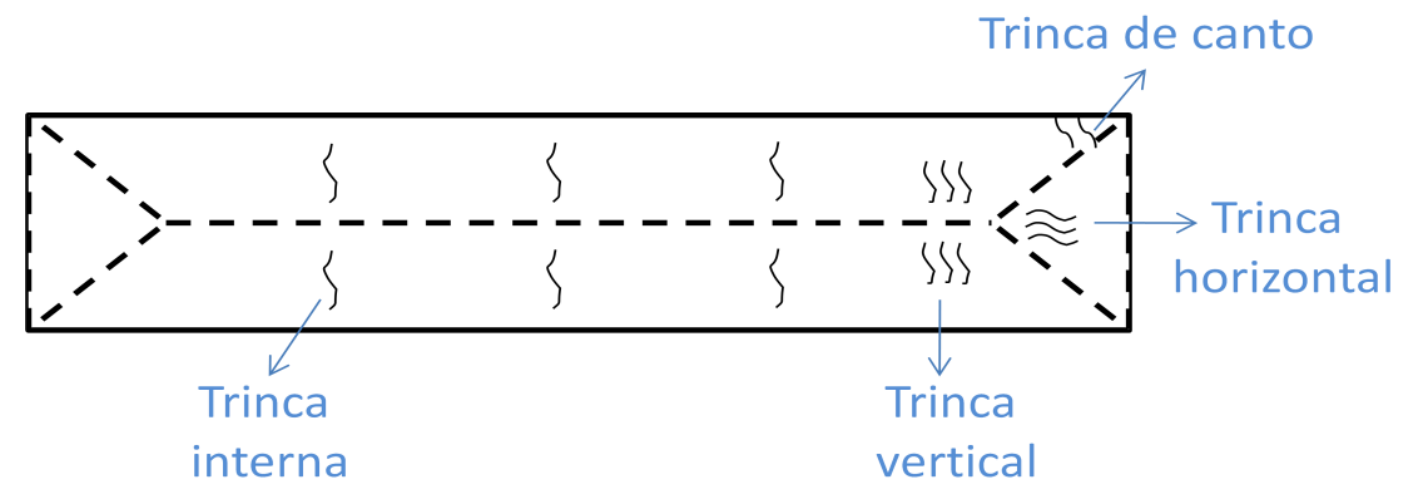

Fonte: adaptado de FURTADO (2007).

O padrão Mannesmann classifica estes defeitos numa escala que varia de 0,0 a 4,0 em intervalos de 1,0. Já o padrão NSC também utiliza uma escala de 0,0 a 4,0, porém considerando intervalos de 0,5 (FURTADO, 2007, p. 187).

\subsubsection{Inclusão de alumina}

As inclusões são partículas que podem ser originadas a partir das escórias, do desgaste do refratário e dos produtos adicionados para elaboração do aço. As inclusões de alumina $\left(\mathrm{Al}_{2} \mathrm{O}_{3}\right)$ são prejudiciais, pois alteram as propriedades mecânicas do material como, por exemplo, a resistência à fadiga e a ductibilidade no caso de chapas muito finas (RIZZO, 2006, p.149). A Figura 3 ilustra a ocorrência de inclusões de alumina na amostra. 
A inclusão de alumina é classificada segundo os mesmos critérios de avaliação adotados para as trincas, tanto no padrão Mannesmann, quanto NSC (FURTADO, 2007, p. 187).

Figura 3 - Inclusão de alumina e porosidade.

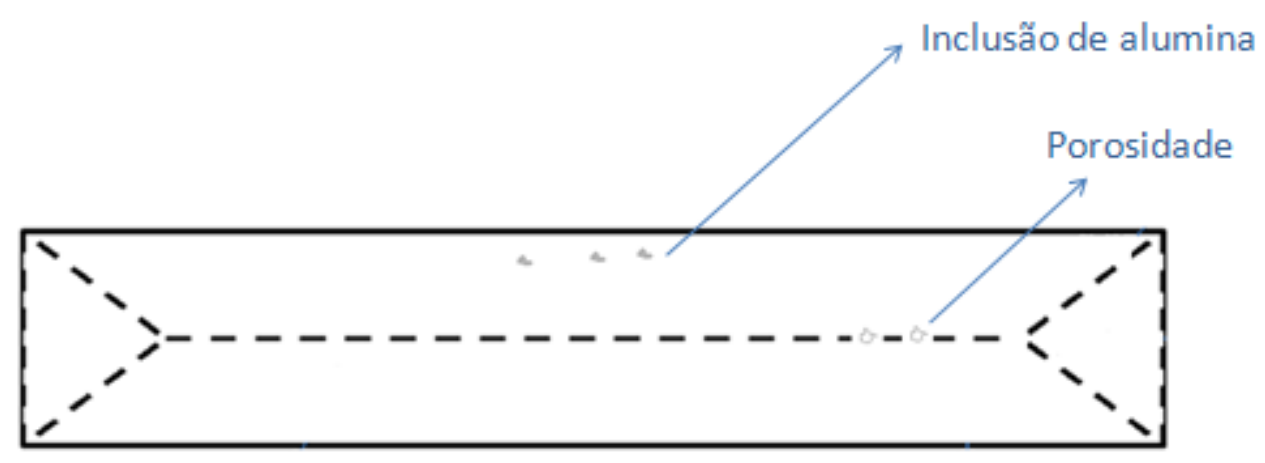

\subsubsection{Porosidade}

A porosidade é definida como vazios que acontecem na região final de solidificação e ocorrem devido a anormalidades no espaçamento da MLC. A Figura 3 ilustra a ocorrência de porosidade na amostra. A porosidade pode ser classificada como sendo de pequenos diâmetros ou grosseira (FURTADO, 2007, p. 193).

A porosidade de pequenos diâmetros é caracterizada por um diâmetro máximo de $2 \mathrm{~mm}$ e não apresenta problemas em relação à qualidade da placa que sofrerá elevada taxa de deformação (FURTADO, 2007, p. 193). Inclusive, segundo Carvalho (1988, p. 326), esse defeito ocorre com certa frequência.

Contudo, a porosidade classificada como grosseira pode acarretar no sucateamento do material (FURTADO, 2007, p. 193). Para ser considerada grosseira, a porosidade deve ter diâmetro de até $20 \mathrm{~mm}$ ou superior, e depende diretamente da espessura do material lingotado. O principal fator que contribui para a formação de porosidades grosseiras são anormalidades de espaçamento na MLC, próximas ao ponto final de solidificação (CARVALHO, 1988, p. 326). 


\subsection{Análise dos resultados da Impressão de enxofre}

A correta interpretação dos resultados da impressão de enxofre é fundamental para o controle das condições operacionais da máquina de lingotamento. Contudo, um processo de análise que requer a interferência humana apresenta como ponto negativo, a dependência da disponibilidade de um especialista, com grau de conhecimento adequado para classificar corretamente a amostra em questão.

Uma vez que ocorre a interferência humana nessa análise, é possível que ocorram divergências na classificação dos resultados, visto que a atividade é completamente manual e um especialista pode eventualmente ser mais rigoroso do que outro durante o processo de classificação. Adicionalmente, fatores ambientais (frio ou calor excessivo), físicos e comportamentais (estresse, fadiga, fome, sono) podem influenciar a avaliação do especialista.

Outro fator de destaque é a dificuldade para o armazenamento do papel fotográfico após a realização da impressão de Baumann. Por retratar aspectos qualitativos do material produzido, a impressão é muitas vezes utilizada para comprovar a sanidade interna do material, no caso de problemas durante o processo de laminação ou em casos específicos de reclamações dos clientes. Em função desta característica a impressão deve ser armazenada durante todo o período necessário para a eventual comprovação da qualidade do material em questão.

Este cenário abre oportunidades para o desenvolvimento de pesquisas que visem garantir o armazenamento e recuperação dos registros da qualidade interna do material, melhorar processo de análise da impressão de Baumann, reduzir o grau de dependência do especialista e a subjetividade nas avaliações.

Algumas iniciativas nesse sentido já podem ser observadas. A norma ASTM E1180 (2008), por exemplo, cita a utilização de computadores para auxiliar na identificação de defeitos. De acordo com a mesma, a intensidade das marcas da impressão de enxofre no papel fotográfico, depende da concentração de enxofre e 
da presença de sulfetos no aço, além da agressividade da solução aquosa utilizada como reagente associada ao tempo de exposição durante a aplicação da mesma.

Dessa forma, aços com baixo índice de enxofre produzirão impressões demasiadamente fracas para avaliações macroestruturais precisas. Para melhorar esses resultados, a impressão pode ser escaneada e sua imagem tratada no computador, no qual se realiza uma varredura na impressão de enxofre e com o auxílio de um editor de fotos, aumenta-se a saturação das cores. Assim é possível melhorar a visualização da estrutura do material auxiliando no processo de avaliação do mesmo.

Também já podem ser observadas algumas iniciativas no sentido de minimizar a dependência dos especialistas durante o processo de análise e classificação dos resultados (SANCHO et al. 2006). Os trabalhos desenvolvidos por Sirgo et al. (2006) e Dias et al. (2006), apresentam a implementação de um algoritmo capaz de classificar o nível de segregação central baseado na imagem escaneada da impressão de enxofre de uma amostra realizada com papel fotográfico.

Entretanto, tal método adiciona uma nova atividade aos procedimentos do ensaio para a realização da classificação da amostra, mas não reduz o tempo necessário para a análise, nem tão pouco os recursos empregados. Ou seja, o procedimento de preparação da amostra e ataque químico continua o mesmo, adicionando ao final do procedimento a realização do escaneamento do papel fotográfico e a aplicação do algoritmo para classificação.

Outra alternativa é a adoção do macroataque através da utilização do persulfato de amônia $\left(\mathrm{NH}_{4}\right) \mathrm{S}_{2} \mathrm{O}_{8}$, conforme descrito na norma ASTM E340 (2006) ${ }^{4}$. Neste método, todas as etapas de preparação da amostra são mantidas até a fase do ataque químico. Desta forma, ao invés de utilizar papel fotográfico imergido na solução aquosa de ácido sulfúrico, neste outro procedimento o ataque é realizado

\footnotetext{
${ }^{4}$ AMERICAN SOCIETY FOR TESTING AND MATERIALS. ASTM E 340-00 (2006): Standard Test Method for Macroetching Metals and Alloys.
} 
diretamente sob a superfície da placa, aplicando a solução de $10 \mathrm{~g}$ de persulfato de amônia para $100 \mathrm{ml}$ de $\mathrm{H}_{2} \mathrm{O}$.

O persulfato de amônia em contato com a superfície metálica do aço entra em reação química imprimindo manchas pardas ou negras na própria superfície do material agindo de forma similar ao método tradicional, mas dispensando a utilização do papel fotográfico. Desta forma, o tempo gasto com a lavagem do papel fotográfico e os custos referentes à utilização deste material assim como a solução fixadora são evitados, uma vez que a as manchas são impregnadas na própria amostra.

Entretanto, ainda se faz necessário o armazenamento da impressão para fins de conferência e garantia da sanidade do material. Neste caso a alternativa é realizar a fotografia digital da amostra utilizando câmeras com resolução capazes de possibilitar que a imagem seja recuperada de forma nítida sem que ocorra qualquer perda de informação.

Com esta alteração no procedimento traz-se uma significativa melhoria para o processo em relação ao tempo gasto para amostragem, em função da aplicação do papel fotográfico, escaneamento da imagem, entre outros. Consequentemente, o tempo para a atuação nas correções necessárias nos casos mais críticos também é reduzida.

Entretanto, a classificação dos defeitos internos em relação ao grau de severidade ainda permanece como uma atividade manual, que depende do grau de conhecimento e rigor do especialista. Baseado neste cenário, este trabalho tem como objetivo propor um algoritmo capaz de agregar as técnicas de processamento de imagem e os conhecimentos do especialista, visando à classificação das imagens geradas pelo método de aquisição direta através do ataque químico com persulfato de amônia. 


\section{PROCESSAMENTO DIGITAL DE IMAGENS}

O processamento digital de imagens consiste no conjunto de técnicas empregadas para captura, aprimoramento, representação e transformação de imagens com o auxílio do computador (PEDRINI; SCHWARTZ, 2008, p. 1).

Um sistema de processamento digital de imagens é tipicamente constituído por cinco etapas (JAIN et al., 2000), ilustradas na Figura 4, capazes de produzir um resultado a partir do domínio do problema. Neste trabalho, por exemplo, o domínio do problema consiste na identificação do defeito da segregação central na imagem digital da impressão de Baumann realizada em placas de aço, objetivando a classificação desse defeito de acordo com os critérios pré-estabelecidos. Desta forma, o resultado do processamento desejado é a classificação do defeito presente na amostra, de acordo com o padrão adotado como referência.

Figura 4 - Etapas de um sistema de processamento de imagens.

Domínio do problema

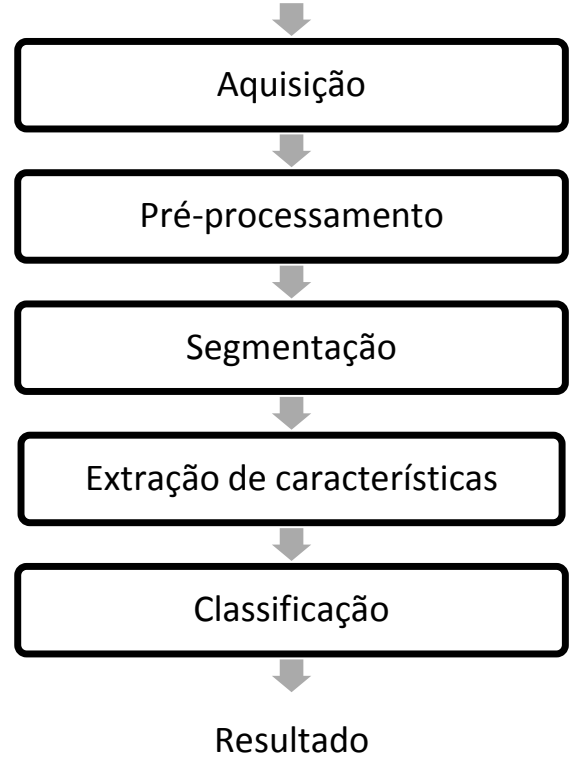

Fonte: Adaptado de PEDRINI; SCHWARTZ (2008).

A primeira etapa de "aquisição", captura a imagem por meio de um dispositivo ou sensor e converte-a em uma representação adequada para o 
processamento digital subsequente. Dentre os aspectos envolvidos nesta etapa estão à escolha do tipo de sensor, as condições de iluminação, a resolução e os níveis de cinza ou cores da imagem digitalizada. Esses aspectos podem variar de acordo com o tipo de aplicação ao qual o sistema de aquisição se destina (PEDRINI; SCHWARTZ, 2008, p. 3).

A etapa seguinte de pré-processamento, tem como principal objetivo o aprimoramento da qualidade da imagem, visando à melhoria na percepção das informações contidas na mesma (BHATTACHARYA et al., 2014). Esse aprimoramento é alcançado através da aplicação de técnicas para a atenuação de ruídos, correção de contraste ou brilho, e suavização de determinadas propriedades da imagem, sendo muito importante para o sucesso das etapas seguintes (JANANI; DINAKARAN, 2014).

Na etapa de segmentação por sua vez, é realizada a extração e identificação das áreas de interesse contidas na imagem. A segmentação é caracterizada pelo particionamento da imagem em diferentes regiões que possuem atributos similares, como textura, intensidade, escala de cinza, entre outras características. Essa etapa é geralmente baseada na detecção de descontinuidades (bordas) ou de similaridades (regiões) na imagem (BALI; SINGH, 2015).

O processo de extração de características ou propriedades visa à obtenção de atributos que possam ser utilizados na discriminação entre classes de objetos. Essas características são, em geral, descritas por atributos numéricos que formam vetores de características (SANDHAR; PHONSA, 2014). É importante observar que nesta etapa a entrada ainda é uma imagem, mas a saída é o conjunto de dados que correspondem à imagem (MARQUES; VIEIRA, 1999, p. 10).

A última etapa de classificação pode ser dividida em reconhecimento e interpretação dos componentes de uma imagem. O processo de atribuição de um rótulo a um objeto baseado em suas características ou atributos, traduzidas por seus descritores, denomina-se reconhecimento. A tarefa de interpretação, por outro lado, 
consiste em atribuir significado a um conjunto de objetos já reconhecidos (MARQUES; VIEIRA, 1999, p. 10).

\subsection{Classificação de defeitos}

O processo de classificação de defeitos consiste na detecção e atribuição de classes ou categorias pré-definidas aos defeitos. Na literatura, encontram-se aplicações nas quais as etapas típicas do processamento digital de imagens são utilizadas e associadas a diversas técnicas, para classificação de defeitos em vários tipos de materiais, tais como metais, madeiras, tecidos, entre outros.

Kauppinen et al. (1999) realizam as etapas típicas de um sistema de processamento de imagens para identificação de defeitos em madeiras. Kumar et al. (2002), Alves et al. (2006) e Kwak et al. (2000) utilizam esses passos em tecidos, enquanto Fraga et al. (2004), Jarvinen et al. (2002), Caleb et al. (2000); Garcia et al. (1994), Marino et al. (1999) e Yun et al. (2006) aplicam os passos típicos para classificação de defeitos em metais.

Dentre as iniciativas relacionadas à classificação de defeitos em derivados do aço, Martins et al. (2010) descrevem em seu trabalho o desenvolvimento de um sistema de inspeção visual para detecção de defeitos em aços laminados. Suvdaa et al. (2012) e Yang et al. (2007) apresentam em seus trabalhos outras abordagens para o reconhecimento de defeitos superficiais também em laminados. Yun et al. (2008) abordam em seu trabalho a detecção de defeitos superficiais em tarugos.

Embora existam muitas soluções já desenvolvidas para detecção e classificação de defeitos em superfícies de materiais como plástico, metal, madeira e têxtil. O problema continua atual, sendo inclusive um tema de pesquisa bastante explorado devido às peculiaridades de cada produto e de cada processo de classificação envolvido. As dificuldades encontradas em cada tipo de aplicação contribuem para o amadurecimento e evolução das técnicas relacionadas ao processamento de imagens. 
Apesar das diferenças existentes em cada tipo de aplicação, os diversos tipos de algoritmos para classificação de defeitos costumam enfrentar desafios semelhantes, como a redução ou eliminação de ruídos, correção de contraste ou brilho, detecção de bordas, extração de características e identificação de regiões de interesse.

Ao longo deste trabalho são apresentadas as particularidades envolvidas no processo de classificação das imagens oriundas do ensaio de Baumann e as dificuldades encontradas para o desenvolvimento deste algoritmo.

\subsection{Análise das imagens}

Para a realização deste trabalho foram analisadas as imagens digitais das amostras de Baumann de duas usinas siderúrgicas, intituladas neste trabalho de "Alfa" e "Beta". Nesta etapa foi avaliada a incidência e a distribuição das amostras coletadas entre os diferentes graus de severidade de acordo com a classificação adotada pelas usinas para cada tipo de defeito.

Nesta análise foi observado que as duas usinas adotam o padrão de referencia NSC, entretanto, alguns tipos específicos de defeitos possuem pequenas variações nos critérios de classificação em função da adequação do padrão as práticas operacionais e características dos equipamentos instalados. Esta fase teve como objetivo analisar e comparar os resultados de classificação obtidos a fim de compatibilizar essas pequenas adaptações operacionais ao padrão NSC.

Adicionalmente nesta fase foi avaliada a disponibilidade dos dados para a realização do trabalho, em função da variação dos resultados entre os diferentes graus de severidade de cada tipo de defeito. Inicialmente pretendia-se elaborar um algoritmo capaz de classificar todos os tipos de defeitos analisados na impressão de Baumann. Entretanto com esta análise verificou-se que a classificação de todos os tipos de defeitos pelo algoritmo seria inviável, em função dos dados disponíveis, 
fazendo com que os esforços para elaboração do algoritmo fossem concentrados apenas nos defeitos internos de maior relevância, em função de sua ocorrência e distribuição nos graus de severidade utilizados para a classificação das amostras.

Para esta avaliação foram analisadas 15.231 imagens da usina Alfa, coletadas no período de Janeiro de 2004 a Abril de 2009, e 4.617 imagens da usina Beta, coletadas no período de Março de 2008 a Junho de 2010, contabilizando um total de 19.848 amostras utilizadas nesta etapa do trabalho. Os resultados obtidos para cada defeito interno analisado são detalhados abaixo.

- Segregação central: As duas usinas analisadas adotam o mesmo critério de classificação para a segregação central. Este defeito é analisado em relação à continuidade e intensidade de acordo com o padrão NSC. Foram analisadas 15.231 amostras da usina Alfa e 4.617 amostras da usina Beta, das quais 4.538 apresentavam classificação de segregação central, enquanto 79 amostras não possuíam referência de classificação, sendo desconsideradas da análise. A Figura 5 ilustra as respectivas distribuições da segregação central em cada usina.

Figura 5 - Segregação central: Distribuição das amostras.



Alfa

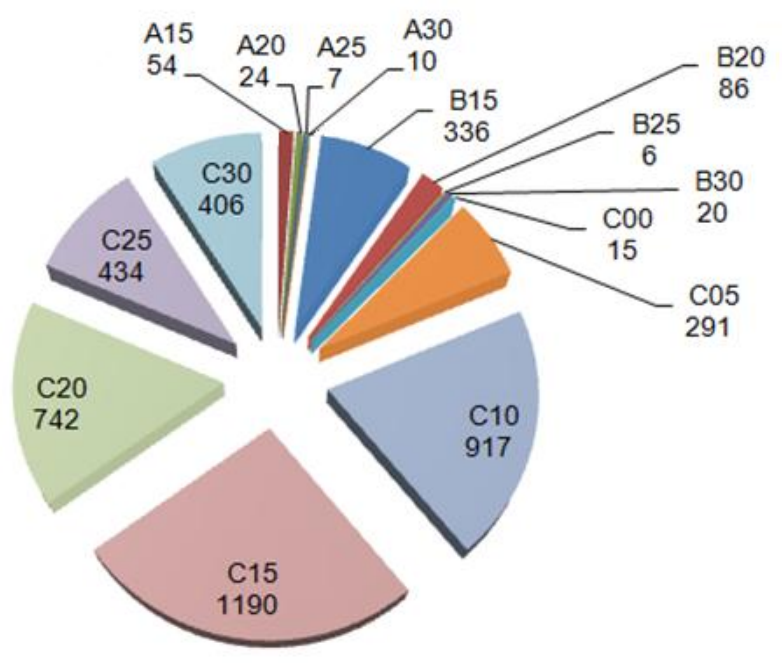

Beta 
- Trincas verticais e internas: As duas usinas utilizam o padrão NSC, entretanto as trincas verticais e internas são classificadas em conjunto. Foram analisadas 15.273 amostras da usina Alfa. A usina Beta por sua vez, teve 4.617 amostras analisadas, dentre as quais 400 amostras foram desconsideradas no estudo em função da ausência de classificação. A Figura 6 apresenta a distribuição destas amostras entre os diferentes graus de severidade analisados.

Figura 6 - Trincas verticais e internas: Distribuição das amostras.

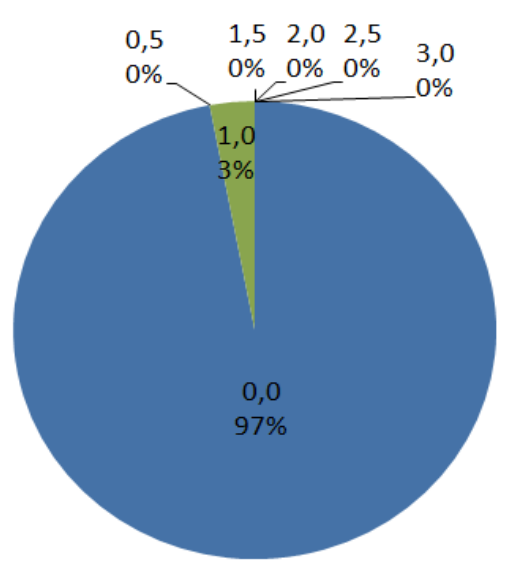

Alfa

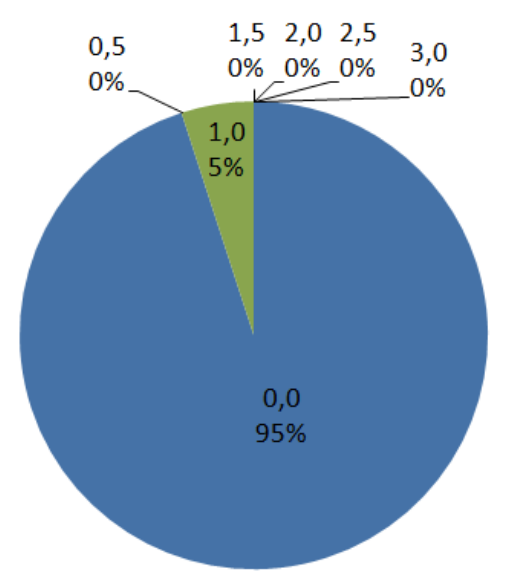

Beta

- Trincas horizontais: O padrão NSC é adotado para a classificação das trincas horizontais nas duas usinas. Foram analisadas 15.273 amostras da usina Alfa. A usina Beta por sua vez teve 4.617 amostras analisadas, nas quais 390 amostras foram desconsideradas do estudo em função da ausência de classificação. A Figura 7 apresenta a distribuição destas amostras entre os diferentes graus de severidade analisados. 
Figura 7 - Trincas horizontais: Distribuição das amostras.

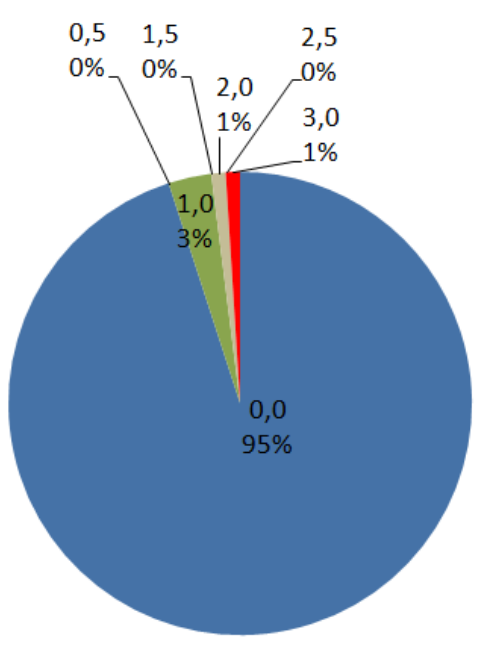

Alfa

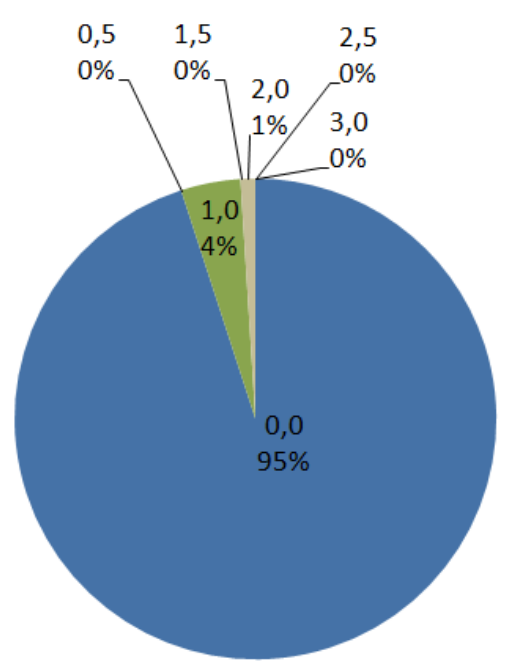

Beta

- Trincas de canto: Foram analisadas 4.617 amostras da usina Beta, dentre as quais 423 amostras foram desconsideradas do trabalho por não possuírem resultados. Observou-se 4.167 amostras com intensidade 0,0 , o que representa a ausência de trincas, enquanto apenas 27 amostras foram classificadas com grau de intensidade 1,0. Nenhuma amostra foi classificada nos demais níveis de intensidade. A usina Alfa adota a escala NSC para a classificação do defeito, entretanto, em função da baixa incidência de trincas de canto, as amostras que apresentam tal falha são tratadas isoladamente. Em função desta prática operacional não foi possível realizar a quantificação das amostras para esta usina.

- Inclusão de alumina: Devido à baixa incidência de inclusões de alumina, a usina Alfa não classifica o defeito tratando isoladamente os casos de intensidade mais severa. A usina Beta, por sua vez, teve 4617 amostras analisadas, dentre as quais 913 amostras foram desconsideradas do estudo em função da ausência de classificação. Dentre as 3704 amostras classificadas, 3007 amostras apresentaram intensidade 0,0 (ausência de inclusões), 3 amostras foram classificadas com intensidade 1,0 e 694 amostras apresentam grau de intensidade 3,0. 
- Porosidade: Devido à baixa incidência desse defeito as usinas Alfa e Beta não classificam os níveis de porosidade tratando isoladamente os casos mais graves do defeito.

Os defeitos internos que apresentam um baixo índice de variação de acordo com seu respectivo grau de severidade tornam inviável a elaboração do algoritmo devido à ausência de dados para realização do mesmo. Desta forma, foi analisado o índice de variação na classificação dos defeitos internos de acordo com sua respectiva escala de irregularidades.

Nesta análise foram excluídas todas as amostras classificadas com o menor grau de severidade, o que representa para os defeitos analisados, a ausência do mesmo. A Figura 8 ilustra o total de amostras obtidas nas demais classificações de acordo com o defeito interno.

Figura 8 - Variação das amostras



Conforme observado na análise das amostras das duas usinas, existe uma quantidade significativa de amostras classificadas entre os demais graus de severidade para a segregação central. O mesmo, entretanto, não ocorre para os demais defeitos internos.

As trincas de canto, horizontais, verticais e internas são analisadas nas duas usinas, mas apresentam baixa incidência de defeitos mais graves. A inclusão de alumina apresenta características recorrentes de baixa incidência de casos graves, 
sendo rotineiramente analisadas em apenas uma usina. A porosidade, por sua vez, é tratada isoladamente nas duas usinas devido à baixa incidência do defeito.

Baseado na análise dos dados apresentados, observou-se que apenas a segregação central apresenta uma variação significativa entre os padrões de classificação. Desta forma, optou-se neste trabalho pela concentração dos esforços na detecção deste defeito interno através do algoritmo.

\subsection{Algoritmo de Classificação}

O algoritmo de classificação foi direcionado para o defeito interno da segregação central baseado no padrão de referência NSC, apontado na análise realizada na etapa anterior como o defeito interno de maior relevância e incidência. Este algoritmo destina-se a classificação das imagens de amostras transversais oriundas do processo de lingotamento contínuo de placas de aço e abrange as etapas do pré-processamento até a classificação da imagem. Após esta análise, foram identificadas as restrições relacionadas ao sistema de aquisição que poderiam influenciar negativamente o processamento da imagem, uma vez que a etapa de aquisição não pertence ao escopo deste trabalho.

Inicialmente, foi identificado que em função do tamanho do corpo de prova (que varia de 800 a $2000 \mathrm{~mm}$ ) e para garantir a qualidade da imagem, a captura da imagem da amostra é realizada em seções. Após a captura da imagem de cada uma das seções da amostra, o aplicativo de aquisição concatena todas as imagens capturadas gerando uma imagem final do corpo de prova (imagem utilizada neste trabalho).

Entretanto, foi observado que em alguns casos por uma falha no sistema de aquisição, a concatenação das imagens não é realizada de forma precisa, gerando colunas na cor preta que representam o ponto de emenda entre as seções da imagem. Tal característica representa um ruído na imagem prejudicando o processo de classificação da mesma. Desta forma, optou-se em algumas etapas do algoritmo 
pela realização do processamento da imagem separadamente para cada seção, adotando tal característica como premissa. Cada seção possui dimensões fixas de 640 x 480 pixels, pré-definidas pelo aplicativo de aquisição das imagens utilizadas neste trabalho.

A avaliação do desempenho do algoritmo foi realizada em dois momentos específicos, de acordo com sua fase de implementação. Na primeira fase, o algoritmo foi avaliado através do método de contagem simples, no qual foi verificada a porcentagem de acerto da segmentação, ou seja, a porcentagem de amostras nas quais o algoritmo foi capaz de selecionar corretamente a região da segregação central.

Para a realização desta avaliação, foram analisadas 255 imagens oriundas do sistema de aquisição das usinas Alfa e Beta, distribuídas nos diferentes graus de severidade analisados pelo padrão NSC. Para possibilitar a análise visual da segmentação realizada pelo algoritmo, a região selecionada foi destacada na imagem. Em seguida, baseando-se nesta marcação, a imagem foi verificada manualmente e classificada. Caso a região da segregação central esteja completamente contida na região selecionada pelo algoritmo, a imagem será classificada como segmentada corretamente, caso contrário será classificada como não segmentada.

A segunda avaliação do algoritmo foi realizada após a implementação dos procedimentos para extração das características e das regras de mapeamento para classificação da amostra (segunda fase de implementação). O objetivo da avaliação realizada nesta etapa é verificar o grau de aderência do algoritmo ao padrão de classificação NSC. Para atender este objetivo, foram realizadas duas validações distintas.

A primeira validação do algoritmo nesta etapa foi realizada através do processamento das imagens do padrão de referência NSC. Nessa validação as imagens digitalizadas do padrão de referência foram submetidas ao algoritmo e os resultados avaliados. 
$\mathrm{Na}$ segunda validação, por sua vez, foram submetidas ao algoritmo as mesmas 255 imagens das amostras de Baumann utilizadas para validação do algoritmo na fase anterior de pré-processamento e segmentação. Nesta avaliação os critérios de classificação da segregação central (continuidade e intensidade) foram analisados separadamente.

Ambos critérios de classificação foram avaliados através do método de contagem simples, no qual foi verificada a porcentagem de acerto na classificação, ou seja, a porcentagem de amostras nas quais o algoritmo foi capaz de indicar corretamente o grau de severidade de cada critério de acordo com o padrão de referência. Por último foi avaliada a assertividade global do algoritmo considerando a porcentagem de acerto na classificação simultânea dois critérios. 


\section{PRÉ-PROCESSAMENTO E SEGMENTAÇÃo}

Neste capitulo é apresentada a primeira fase de implementação do algoritmo que contempla as etapas de pré-processamento e segmentação das imagens. $O$ pré-processamento das imagens tem como objetivo aprimorar a qualidade da imagem preparando-a para as etapas seguintes de processamento (RAJESHWARI; SHARMILA, 2013). A etapa de segmentação, por sua vez, tem como tarefa básica a divisão ou separação de uma imagem em suas unidades significativas, ou seja, nos objetos de interesse que a compõem (TANG,2010).

As técnicas de segmentação, de modo geral, utilizam duas abordagens distintas, a similaridade e a descontinuidade entre pixels (MUTHUKRISHNAN; RADHA, 2011). A limiarização é a técnica mais utilizada para abordagem baseada na similaridade dos pixels. Já a detecção de bordas, é por sua vez, a técnica baseada em descontinuidades mais utilizada (YANG; KANG, 2009).

Ao longo do processo evolutivo de desenvolvimento da primeira fase de implementação do algoritmo, foram analisadas três abordagens distintas de préprocessamento e segmentação das imagens. Dois algoritmos inspirados na abordagem baseada em técnicas de similaridades dos pixels e um algoritmo inspirado na abordagem baseada na análise de descontinuidades dos pixels. Esta evolução é detalhada nas seções seguintes, nas quais são apresentadas as metodologias e os resultados obtidos em cada um dos algoritmos analisados.

A Figura 9, de dimensões 3840 × 480 pixels, será utilizada ao longo deste capítulo como referência para a demonstração dos resultados obtidos em cada algoritmo.

Figura 9 - Imagem digitalizada da impressão de Baumann.

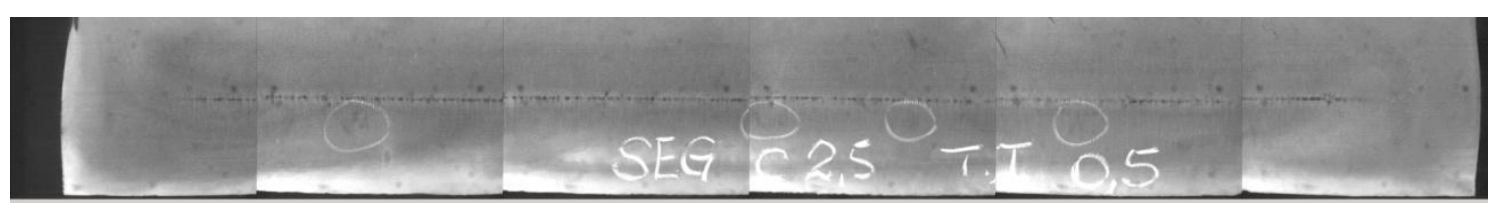




\subsection{Algoritmo 1: Limiarização e Histograma}

O primeiro algoritmo de pré-processamento e segmentação foi inspirado na abordagem baseada em técnicas de similaridades dos pixels. Dentre essas técnicas, foram adotadas neste algoritmo a limiarização e o histograma, consideradas as técnicas mais simples e usuais deste tipo de abordagem.

O histograma é uma técnica importante para o aprimoramento de imagens, pois fornece uma visão estatística sobre a distribuição dos pixels e também sobre os níveis de iluminação e contraste da imagem, sendo uma técnica muito utilizada devido sua simplicidade. Quanto maior a amplitude do histograma, maior é o contraste da imagem. Isto significa, por exemplo, que se o contraste da imagem for aumentado, a distribuição do histograma também é aumentada (SONAM, 2015). O histograma de uma imagem pode ser representado graficamente indicando 0 número de pixels na imagem para cada nível de cinza, a Figura 10 ilustra essa representação apresentando uma imagem e seu respectivo histograma.

Figura 10 - Histograma.

(a) Imagem. (b) Histograma da imagem.
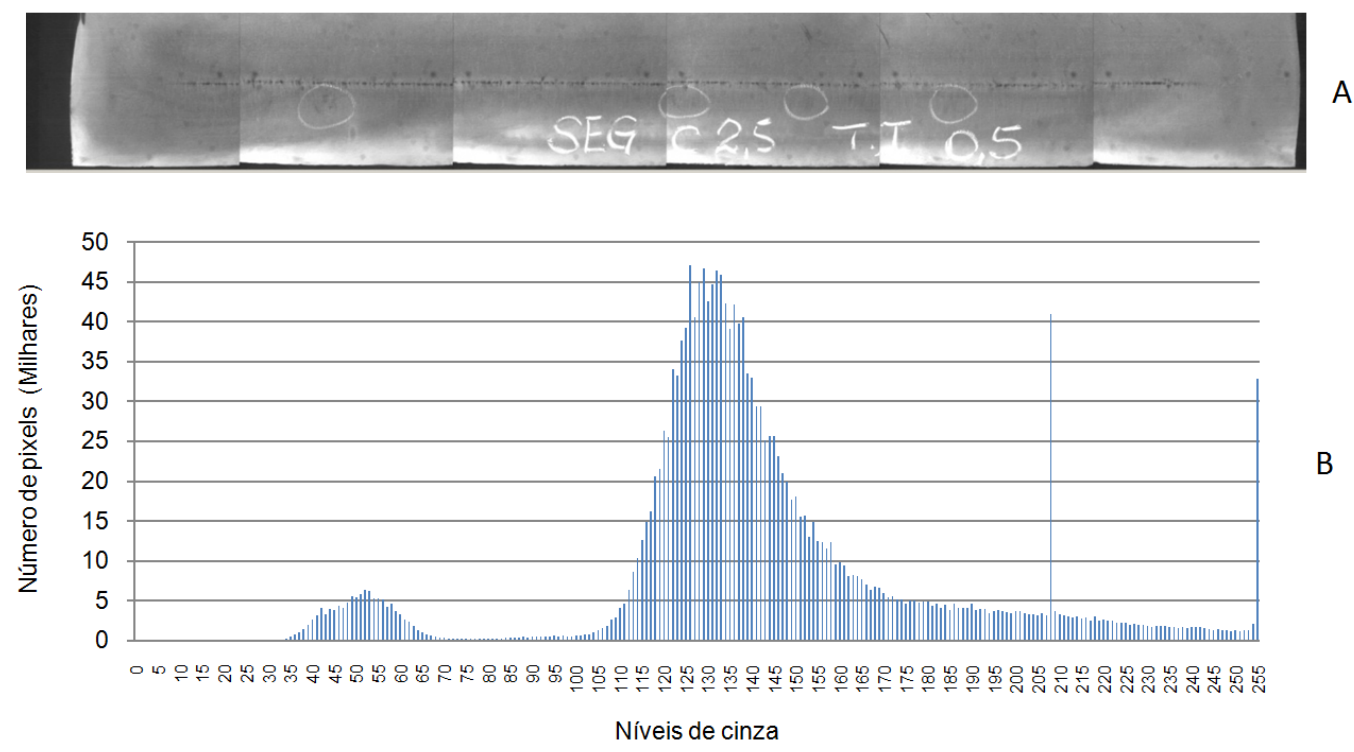

A limiarização consiste na separação da imagem em duas regiões, quando, por exemplo, esta apresenta duas classes (o fundo e o objeto). A forma mais simples de limiarização baseia-se na bipartição do histograma, convertendo os 
pixels cujo valor é maior ou igual a um valor limiar em brancos, e os demais em pretos (JANAKIRAMAN et al., 2013). A limiarização é uma das técnicas mais simples de segmentação e consiste na classificação dos pixels de uma imagem de acordo com a especificação de um ou mais limiares, também chamados de "thresholds" (BASAVAPRASAD; RAVI, 2014). Desta forma, a exatidão do valor do limiar é de extrema importância para que o processo de segmentação apresente bons resultados.

Especificamente em aplicações envolvendo aço, Nand et al (2014) utilizaram limiarização e histograma para separar o fundo da parte defeituosa em imagens da superfície de aços produzidos em um laminador de tiras a quente. Nesta aplicação, o objetivo é identificar três tipos de defeitos na superfície: gotas d'água, bolhas e arranhões. Solução semelhante é adotada por Wu et al. (2008) para, de acordo com as variações da escala de cinza, determinar os pixels que representam áreas defeituosas dos demais. O objetivo neste caso é identificar defeitos superficiais como arranhões, marcas, furos e fendas em tiras a quente.

\subsubsection{Estrutura do algoritmo}

O primeiro passo no pré-processamento e segmentação é a análise das propriedades da imagem a fim de identificar características que possam auxiliar no processo de segmentação da segregação central. Para isso foi realizado e analisado o histograma das imagens das amostras de Baumann, a fim de obter informações sobre a distribuição dos níveis de cinza das imagens que pudessem auxiliar nessas etapas.

A segregação central é identificada como a região onde ocorre uma grande concentração de manchas pardas ou negras situadas horizontalmente próximas ao centro da amostra. Sirgo et al.(2006), apresentam em seu trabalho a contagem dos níveis de cinza das linhas da imagem como método para localização da região da segregação central. Desta forma optou-se neste trabalho pela análise individual das linhas e colunas. A contagem do nível de cinza dos pixels realizada em relação às 
colunas da imagem será chamada de histograma vertical, enquanto a contagem realizada em relação às linhas da imagem será chamada de histograma horizontal.

Seja $f(x, y)$ uma imagem representada por uma matriz bidimensional, com dimensões $m \times n$ pixels, o histograma vertical é representado por um vetor $H_{v}$ com $n$ elementos. No histograma vertical cada coluna $j$ da imagem é analisada, através da soma de todos os pixels $p$ da coluna $j$ em relação à linha $i$, onde $m$ representa 0 número total de linhas da imagem. O cálculo do histograma vertical pode ser observado nas equações (5) e (6) Desta forma, cada posição do vetor $H_{v}$ corresponde à totalização dos níveis de cinza dos pixels de uma determinada coluna.

$$
\begin{array}{r}
h_{j}=\sum_{i=1}^{m} p_{i, j} \\
H_{v}=\left[\begin{array}{llll}
h_{0} & h_{1} & \ldots & h_{n}
\end{array}\right]
\end{array}
$$

A Figura 11 apresenta de forma gráfica o histograma vertical $H_{v}$ da imagem utilizada como referência.

Figura 11 - Histograma vertical

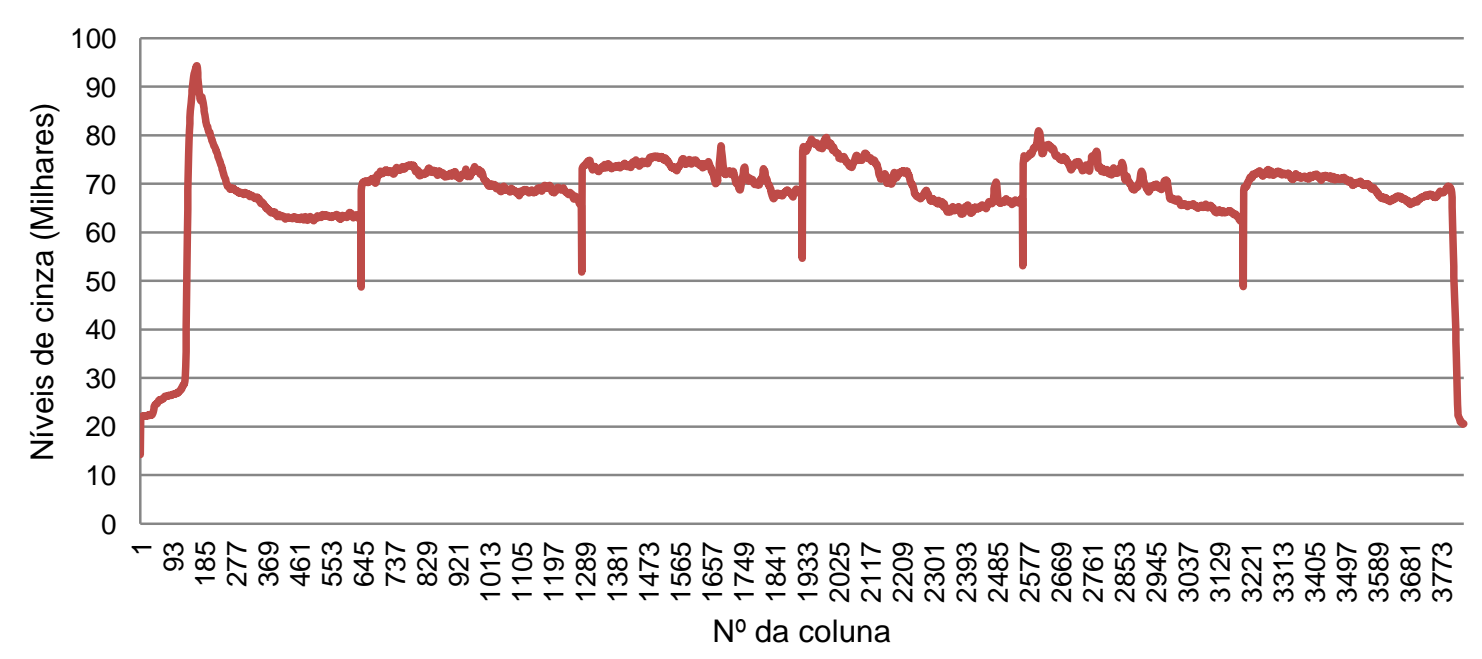

Pode ser nitidamente observado na figura acima que existem determinadas colunas que apresentam uma elevada concentração de pixels escuros (o que 
corresponde à concentração de níveis de cinza mais baixos). Tal característica seria um bom indicador para a localização da segregação central, que se destaca na imagem através de sua coloração parda ou negra, entretanto, observou-se que tal característica estava na verdade associada a uma falha no sistema de aquisição da imagem.

Em função do tamanho do corpo de prova e para garantir a qualidade da imagem, a captura da imagem da amostra é realizada em seções. Após a captura da imagem de cada uma das seções da amostra, o aplicativo de aquisição concatena todas as imagens capturadas gerando uma imagem final do corpo de prova (imagem utilizada neste trabalho).

Entretanto, foi observado que em alguns casos por uma falha no sistema de aquisição, a concatenação das imagens não era realizada de forma precisa, gerando colunas na cor preta que representam o ponto de emenda entre as seções da imagem. Tal característica representa um ruído na imagem o que poderia prejudicar o processo de segmentação e classificação da mesma. Desta forma, optou-se pela realização do tratamento da imagem visando à eliminação desta interferência.

Este tratamento consiste na exclusão das colunas com tais características, onde $h_{j}$ é menor que o limite de corte estipulado. O limite para exclusão da coluna baseia-se na média aritmética (medCol) da somatória dos níveis de cinza dos pixels da coluna como mostra a equação (7).

$$
\text { medCol }=\frac{\sum_{j=0}^{n} h_{j}}{n}
$$

O limite de corte da coluna (limCol) foi estipulado empiricamente pela equação (8). Após a exclusão das colunas uma nova imagem, com dimensões distintas foi gerada.

$$
\lim C o l=\frac{5 * \operatorname{medCol}}{6}
$$


A Figura 12 apresenta o histograma vertical da imagem após a realização do tratamento e a Figura 13 apresenta a imagem resultante após a exclusão das colunas.

Figura 12 - Histograma vertical após tratamento da imagem

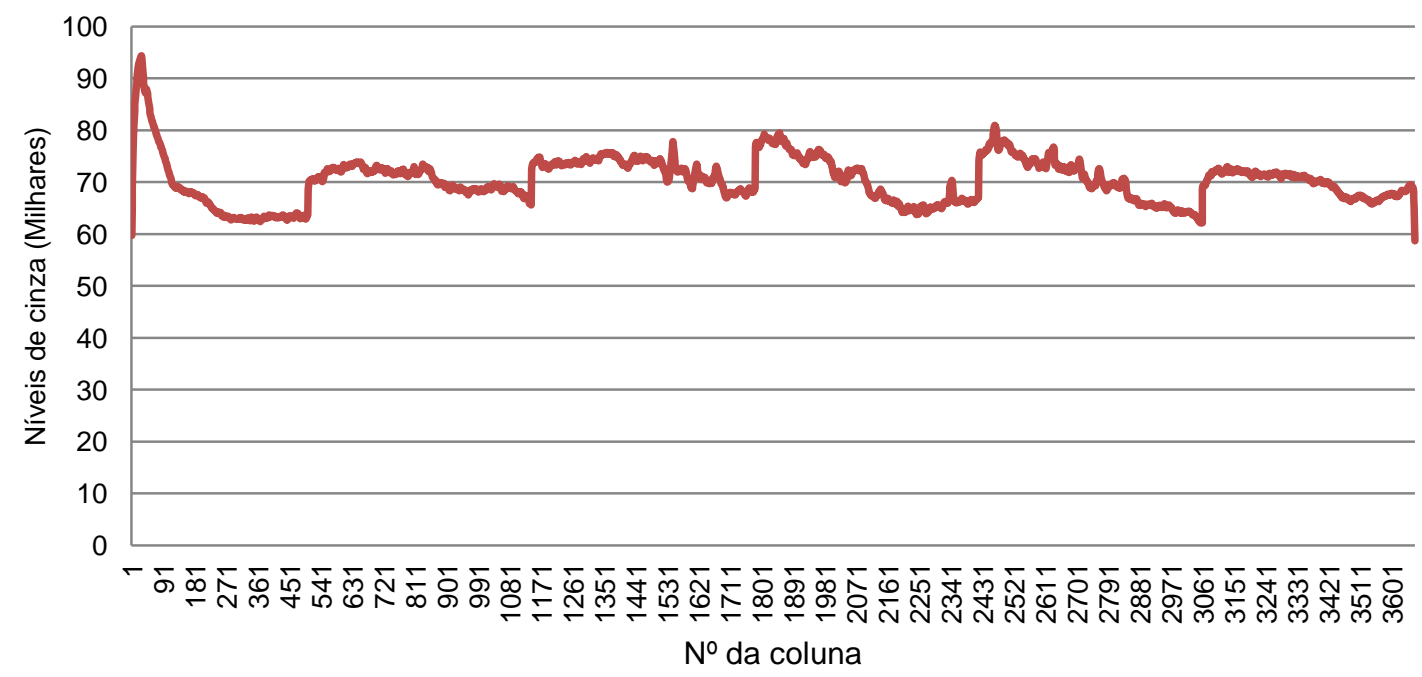

Figura 13 - Remoção das colunas.

(a) imagem antes da remoção. (b) imagem após remoção.
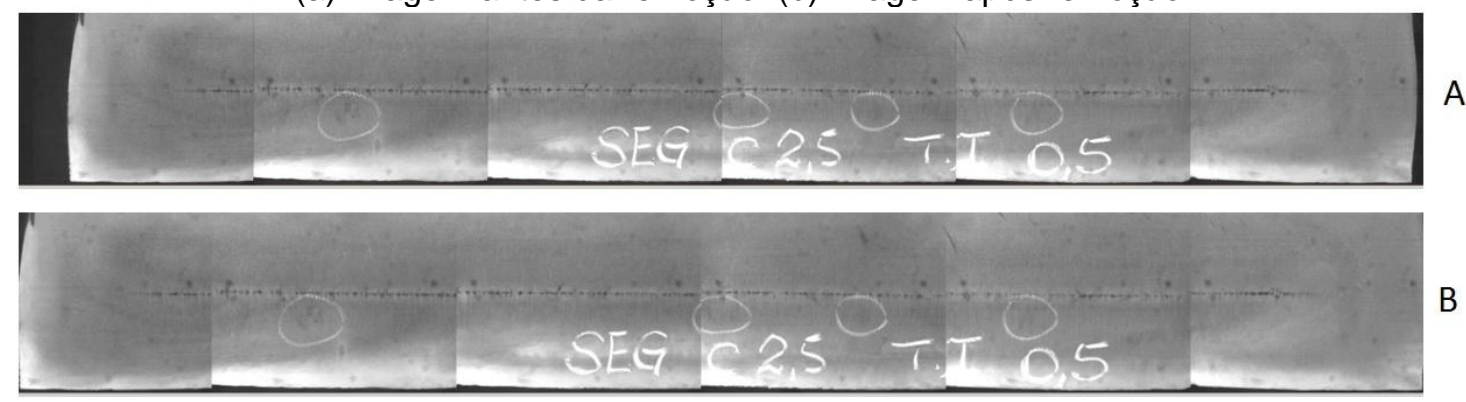

Em seguida foi analisado o histograma horizontal desta imagem resultante. Seja $f(x, y)$ a imagem representada por uma matriz bidimensional, com dimensões $m \times n$ pixels, o histograma horizontal é representado por um vetor $H_{h}$ com $m$ elementos. No histograma horizontal cada linha $i$ da imagem é analisada, através da soma dos níveis de cinza de todos os pixels $p$ da linha $i$ em relação à coluna $j$, onde $m$ representa o número total de linhas da imagem. O cálculo do histograma horizontal pode ser observado nas equações (9) e (10). 


$$
\begin{array}{r}
h_{i}=\sum_{j=1}^{n} p_{i, j} \\
H_{h}=\left[\begin{array}{llll}
h_{0} & h_{1} & \ldots & h_{m}
\end{array}\right]
\end{array}
$$

Desta forma, cada posição do vetor $H_{h}$ corresponde à totalização dos níveis de cinza dos pixels de uma determinada linha. A Figura 14 apresenta de forma gráfica o histograma horizontal $H_{h}$ da imagem analisada.

Figura 14 - Histograma horizontal.

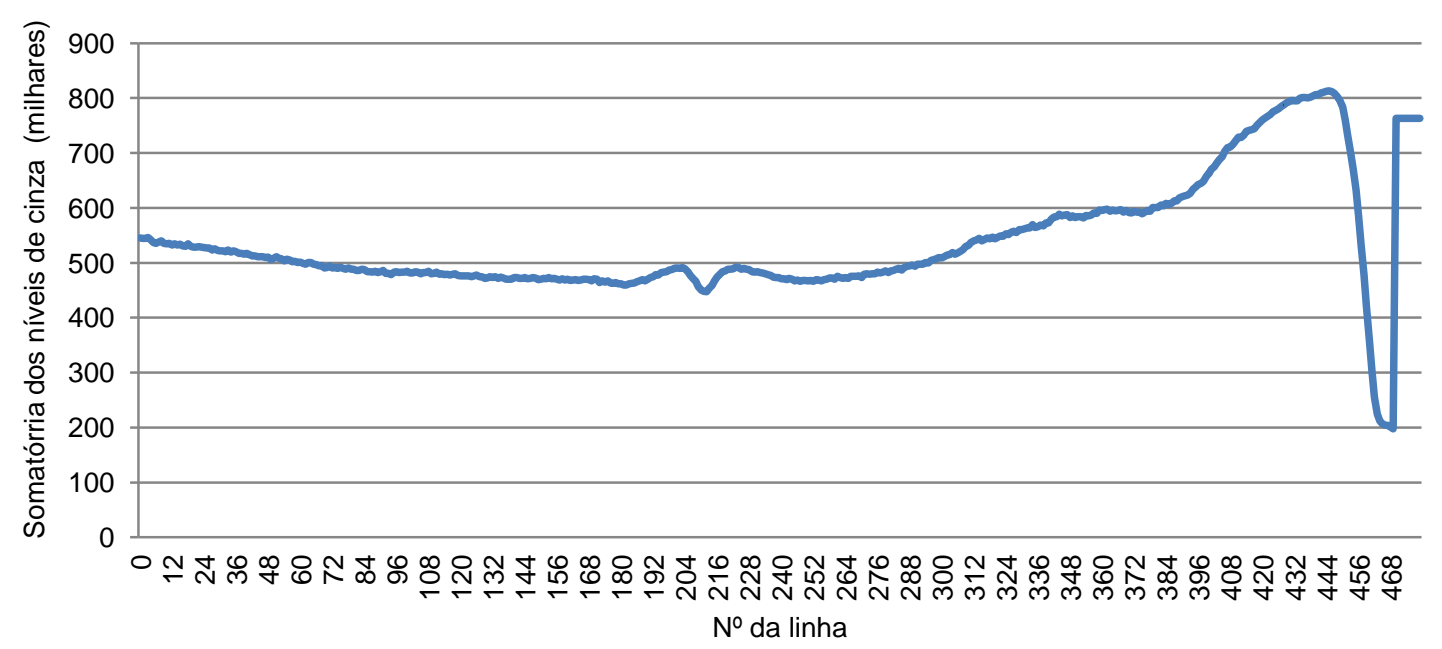

Entretanto, observou-se que as regiões que continham os menores níveis de cinza (regiões mais escuras) não correspondiam à área da segregação central visualizada na imagem, logo representavam ruídos. Nesta fase foi realizada a remoção das possíveis interferências para a identificação da posição da segregação central na imagem.

Pode ser nitidamente observado na imagem que existem determinadas linhas que apresentam uma elevada concentração de pixels na cor escura. De forma similar à análise realizada para o histograma vertical, tal característica seria um bom indicador para a localização da segregação central, entretanto observou-se que a maior concentração se localizava próxima a borda inferior e superior da imagem. 
Observou-se que em função do tamanho do corpo de prova em relação à área da imagem capturada pelo sistema de aquisição, a mesa onde a amostra é posicionada durante a aquisição, também é refletida na imagem. Para evitar que tal característica prejudique a segmentação da imagem, optou-se pela remoção destas linhas.

O tratamento utilizado para remoção das linhas é similar ao adotado para exclusão das colunas, onde $h_{i}$ é menor que o limite de corte estipulado. O limite para exclusão da linha baseia-se na média aritmética (medLin) da somatória dos pixels da linha como mostra a equação (11).

$$
\text { medLin }=\frac{\sum_{i=0}^{m} h_{i}}{m}
$$

O limite de corte da linha (limLin) foi estipulado empiricamente pela equação (12). Após a exclusão das linhas uma nova imagem, com dimensões distintas foi gerada.

$$
\operatorname{limLin}=\frac{5 * \text { medLin }}{6}
$$

A Figura 15 apresenta o histograma horizontal da imagem após a realização do tratamento e a Figura 16 apresenta a imagem resultante após a exclusão das linhas.

Figura 15 - Histograma horizontal após tratamento da imagem.




Figura 16 - Remoção das linhas.

(a) imagem antes da remoção. (b) imagem após remoção.

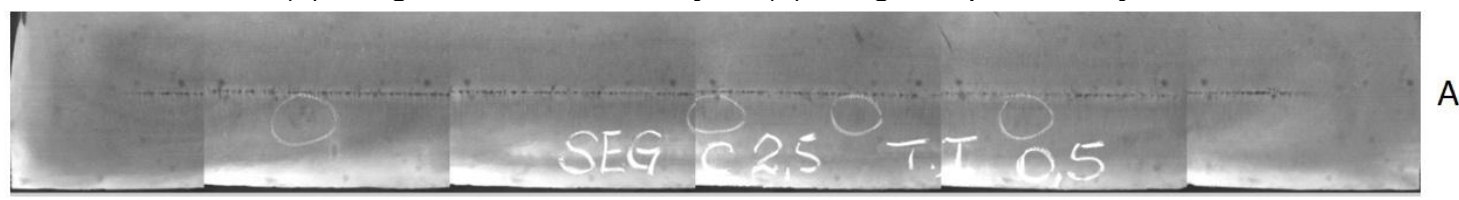

A

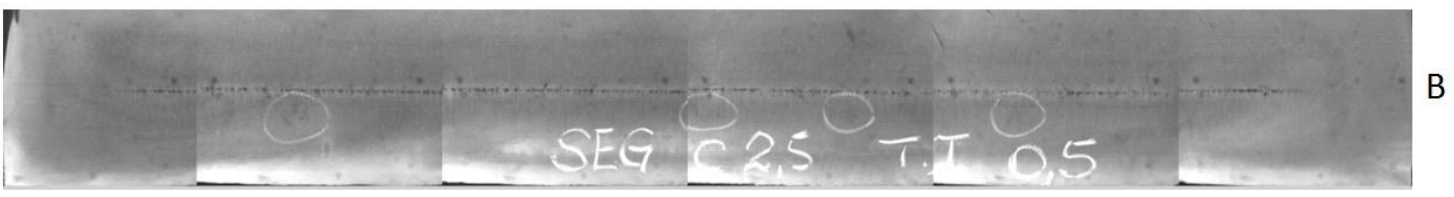

Em seguida foi analisado o histograma da nova imagem resultante, ilustrado na Figura 17 e calculada a mediana, que neste caso representa o tom de cinza da imagem, que corresponde a $50 \%$ da frequência relativa acumulada no histograma. O tom de cinza médio obtido será adotado como limiar. Para a imagem utilizada como demonstração neste trabalho, o limiar obtido foi 137.

Figura 17 - Histograma.

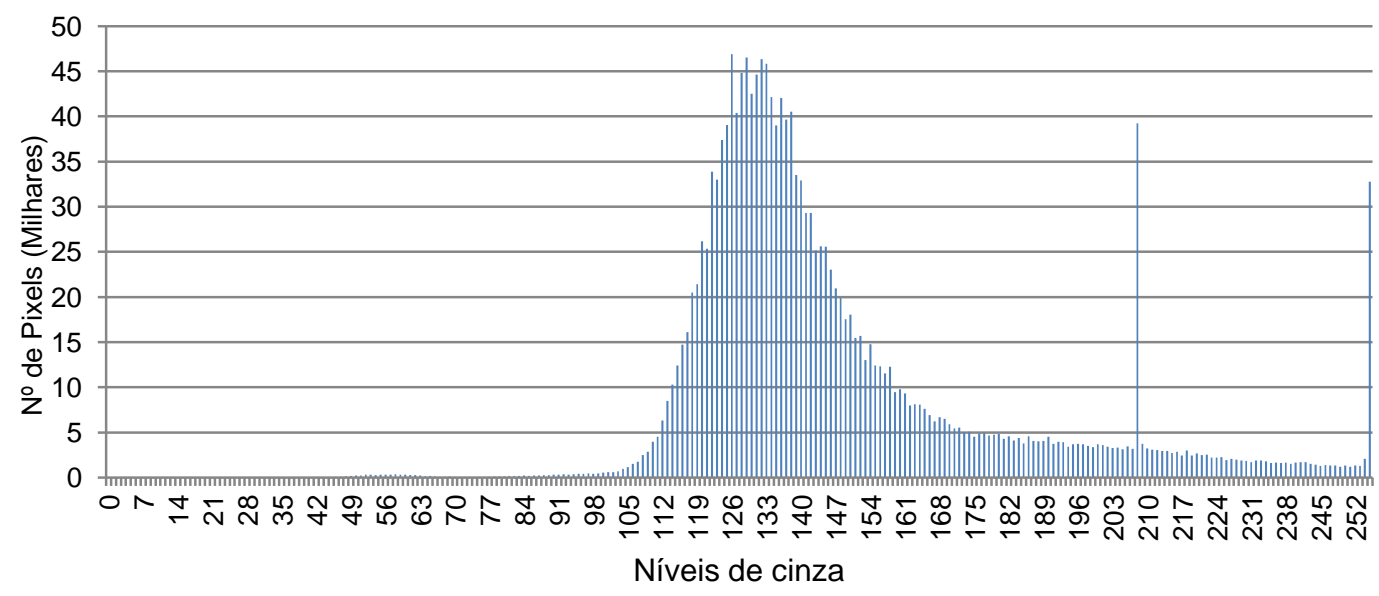

Sabe-se que a segregação central é representada por manchas escuras e pardas, logo as regiões claras da imagem podem ser desprezadas da análise. Para isso será realizada a limiarização da imagem, segundo a equação (13), onde $p_{i j}$, representa o pixel analisado na linha $i$ e coluna $j$, caso o tom de cinza de $p_{i j}$ seja inferior ao limiar estipulado, o mesmo será preservado. Caso contrário o valor de $p_{i j}$ é substituído pelo valor do limiar. 


$$
p_{i j}=\left\{\begin{array}{cl}
p_{i j}, & \text { se } p_{i j}<\text { limiar } \\
\text { limiar }, & \text { se } p_{i j} \geq \text { limiar }
\end{array}\right.
$$

Após o processo de limiarização, como pode ser observado na Figura 18, as interferências foram descartadas, enquanto a segregação central foi destacada na imagem. Após a eliminação desses ruídos foi possível identificar no histograma horizontal uma região onde existe uma concentração acentuada de níveis de cinza mais baixos. Essa depressão no histograma horizontal representa a segregação central na imagem e será utilizada como referência para segmentação da mesma.

Figura 18 - Resultado da limiarização.

Pela característica da formação do defeito da segregação central, sabe-se que a segregação esta normalmente situada horizontalmente próxima ao centro da amostra. Desta forma, a amostra foi dividida em quatro regiões $r$, aplicando a equação (14) e obtendo como resultado a separação apresentada na Figura 19, a primeira e a quarta região foram desprezadas na análise em função da característica de formação do defeito interno.

$$
r=m / 4
$$

Figura 19 - Segmentação em regiões.




Em seguida foi analisado o histograma horizontal apenas nas regiões 2 e 3 da imagem, ilustrado na Figura 20.

Figura 20 - Histograma horizontal da região 2 e 3.

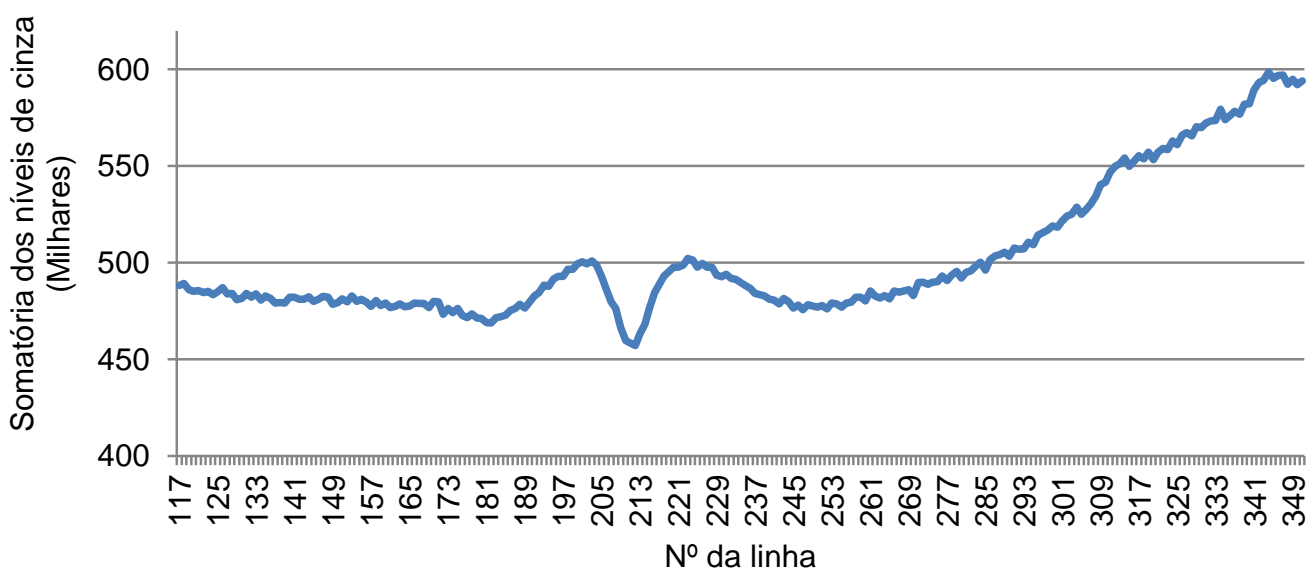

Para identificar a linha que representa o centro da segregação $c S e g$ foi calculado o vetor $D_{h}$ de dimensão $2 r$, que representa a diferença entre os elementos do vetor $H_{h}$ da região 2 e 3, que por sua vez, representa histograma horizontal da imagem. Os elementos do vetor $D_{h}$ são calculados de acordo com as equações (15) e (16), onde $h_{r}$ representa o primeiro elemento do vetor $H_{h}$ na região 2 da imagem.

$$
\begin{aligned}
& d_{i}=\left\{\begin{array}{cl}
0, & \text { se } i=0 \\
h_{r+i}-h_{r+i-1}, & \text { se } i>0
\end{array}\right. \\
& D_{h}=\left[\begin{array}{llll}
d_{0} & d_{1} & \ldots & d_{2 r}
\end{array}\right]
\end{aligned}
$$

Após o cálculo do vetor $D_{h}$ é possível determinar $c S e g$ pela equação (17), uma vez que a linha com maior variação nos níveis de cinza representa a borda da segregação, ou seja, o maior elemento do vetor $D_{h}$. Neste exemplo, a linha 215, como mostra a Figura 21.

$$
c \text { Seg }=i, \quad \text { onde } d_{i}=\max \left(D_{h}\right)
$$


Figura 21 - Identificação da linha.

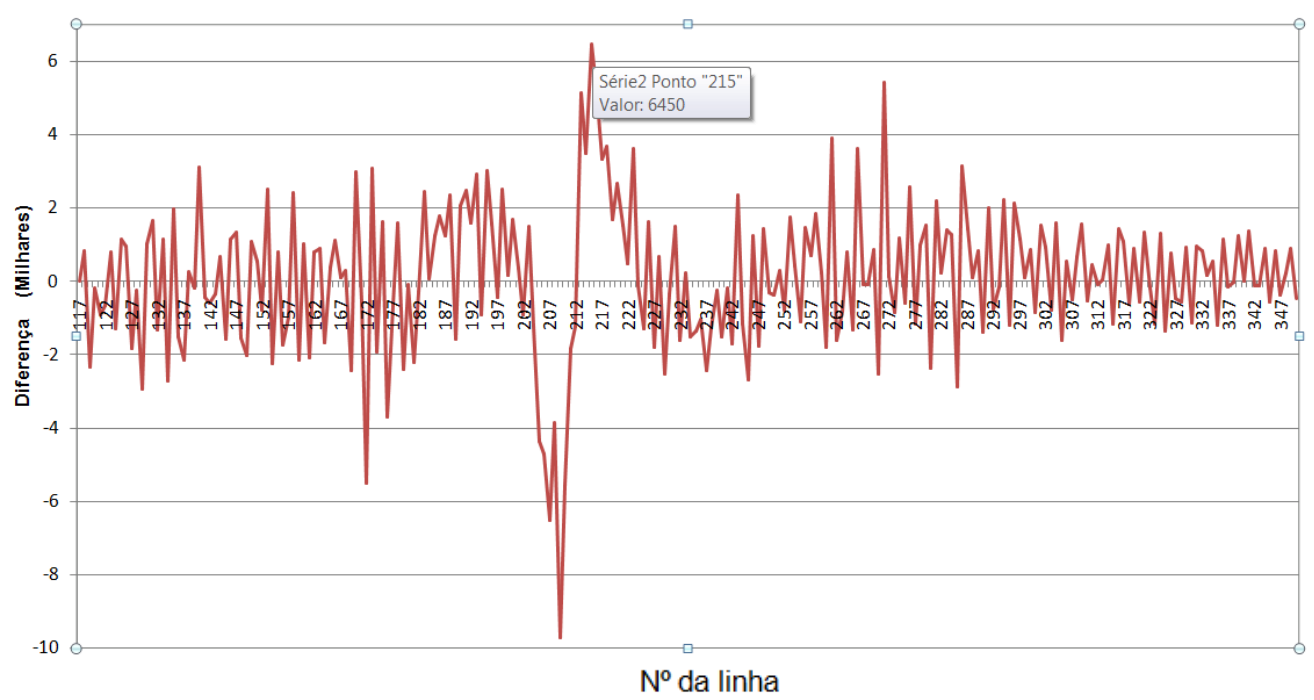

Por definição, a região selecionada para análise da segregação corresponde às linhas no intervalo [cSeg - 55, cSeg + 55]. Desta forma pode ser segmentada a região de interesse da imagem na qual a segregação central esta situada, destacada na cor vermelha da Figura 22 que representa o histograma. Adicionalmente, a Figura 23 apresenta a imagem resultante do processamento com o segmento selecionado.

Figura 22 - Intervalo selecionado no histograma horizontal da região 2 e 3.

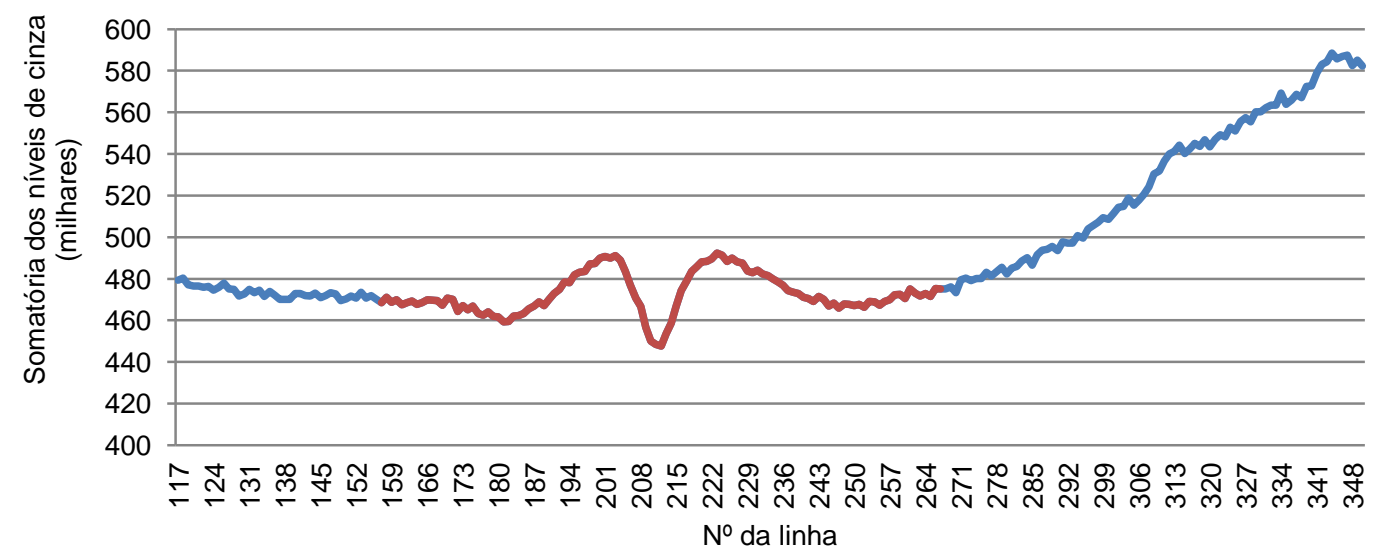

Figura 23 - Segmentação da imagem. 


\subsubsection{Resultados}

Para avaliar a aplicabilidade dos critérios adotados nas etapas de préprocessamento e segmentação, foram submetidas ao algoritmo 255 imagens de amostras oriundas das usinas Alfa e Beta, distribuídas nos diferentes graus de severidade. É importante ressaltar que esta avaliação tem como objetivo analisar o desempenho do algoritmo em relação à segmentação da linha segregada nas imagens. Desta forma, para a avaliação realizada nesta fase foram excluídas do conjunto de dados 20 amostras classificadas com o padrão "C00", uma vez que o mesmo representa a ausência de regiões segregadas na amostra.

As 235 imagens avaliadas foram processadas individualmente e o algoritmo produziu como resultado uma nova imagem, destacando a região selecionada no processo de segmentação. A avaliação da segmentação realizada pelo algoritmo foi executada manualmente através da verificação visual da existência de segregação central na região da imagem selecionada pelo algoritmo.

As amostras foram classificadas como "segmentada" e "não segmentada", de acordo com os seguintes critérios:

- Segmentada: a segregação central está completamente contida na região da imagem selecionada pelo algoritmo;

- Não segmentada: a segregação central está parcialmente contida na região da imagem selecionada pelo algoritmo ou a segregação central não está contida na região selecionada.

No algoritmo foi obtida a correta segmentação da região da segregação central em $78 \%$ das imagens analisadas. O algoritmo, por sua vez, segmentou parcialmente ou não segmentou corretamente $22 \%$ das imagens analisadas. A Figura 24 apresenta os percentuais obtidos na classificação das amostras, em função de cada grau de severidade analisado. 
Figura 24 - Resultados da segmentação do algoritmo 1 por grau de severidade.

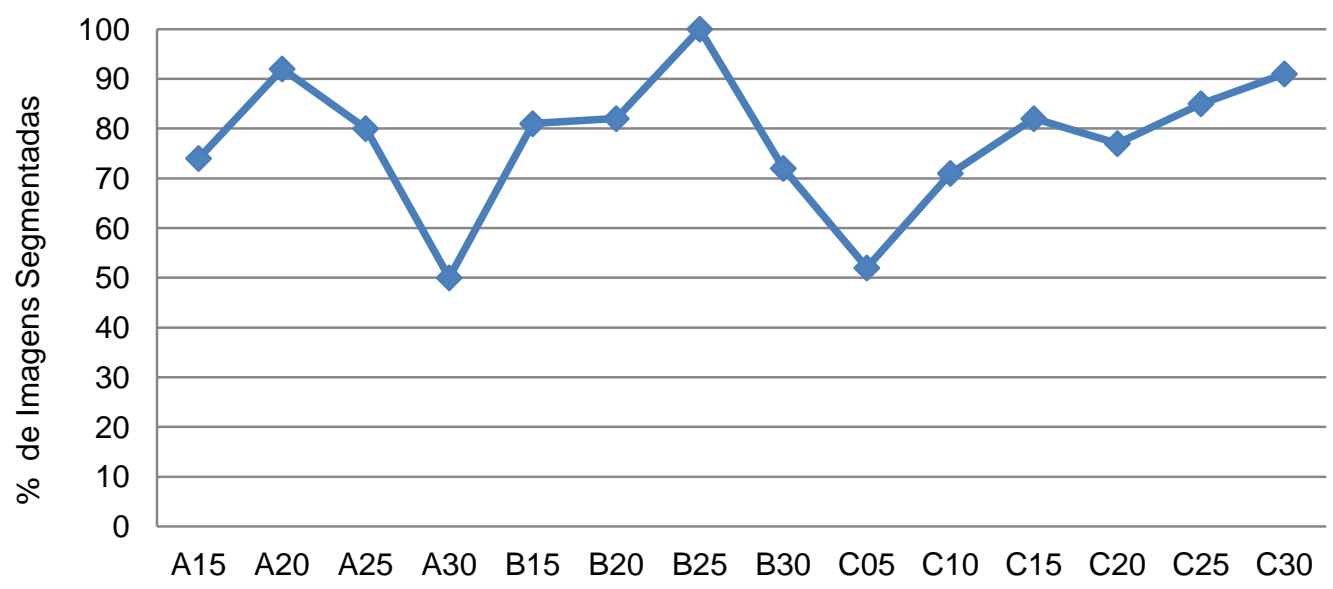

Ao longo da implementação do algoritmo, observou-se que alguns aspectos associados aos procedimentos de preparação e manipulação das amostras podem interferir no processamento das imagens. Dentre estes aspectos destacam-se as marcas de corte. Tais marcas se apresentam como falhas, que podem ocorrer em qualquer região do corpo de prova, e são caracterizadas por manchas escuras, oriundas do processo de preparação da amostra.

Essas marcas interferem no processamento da imagem, caso estejam situadas próximas à região da segregação central. As marcas de corte são usualmente evitadas no processo de preparação da amostra, uma vez que podem comprometer completamente a análise da mesma. Entretanto, sua ocorrência nem sempre pode ser completamente evitada, fazendo com que eventualmente algumas regiões ou pequenos segmentos do corpo de prova possam ser comprometidos. Observou-se que a ocorrência dessas marcas influencia negativamente o desempenho do algoritmo, segmentando incorretamente a região segregada da amostra, uma vez que o algoritmo analisa as regiões de maior concentração de pixels escuros no histograma.

As marcas de giz destacam-se como outro aspecto de interferência no processamento das imagens. Tais marcas são oriundas de identificações realizadas como procedimentos operacionais, para destacar ou enfatizar a região de um defeito específico, assim como a classificação atribuída ao mesmo. Os impactos dessa 
interferência foram minimizados através da limiarização, uma vez que os tons de cinza superiores aos valores médios encontrados na imagem foram desprezados.

Embora o algoritmo desenvolvido tenha sido capaz de segmentar corretamente uma quantidade significativa de amostras, foi observado que a quantidade de ruídos existentes na região segmentada ainda era elevada, o que consequentemente comprometeria o desempenho da fase seguinte de extração de características e classificação. Mesmo o algoritmo minimizando ruídos como as marcas de giz e considerando a eliminação de interferências como a falha na concatenação das imagens durante o processo de aquisição, observou-se que a qualidade da região segmentada na imagem precisava ser melhorada e não estava adequada para a realização da próxima fase do algoritmo.

\subsection{Algoritmo 2: Filtros e Detecção de bordas}

Em função dos resultados obtidos no primeiro algoritmo de segmentação, buscou-se no segundo algoritmo uma nova abordagem que fosse capaz de reduzir os ruídos, preservando os resultados já obtidos no algoritmo anterior. A melhoria na qualidade da imagem faz-se necessária para a correta identificação dos elementos de interesse que serão analisados ao longo do processo de extração de características da próxima fase.

Ao contrário da abordagem adotada no algoritmo anterior, o segundo algoritmo foi inspirado na análise das descontinuidades da imagem, visando a futura identificação e dimensionamento dos elementos estruturantes através de suas bordas. É importante ressaltar que a correta identificação dos elementos é fundamental para a fase de classificação, logo os ruídos precisam ser reduzidos ou eliminados na etapa de pré-processamento e segmentação, a fim de minimizar as possíveis interferências nas próximas etapas.

A técnica de filtragem tem como objetivo tornar a imagem adequada a uma aplicação específica e são comumente aplicadas quando a imagem sofre algum tipo 
de degradação ou perda de qualidade provocada pela presença de ruídos, borrões, entre outros (KHARE et al., 2011). Neelamani et al. (2004) explicam que imagens reais, frequentemente sofrem degradações durante seu processo de aquisição, transmissão ou processamento, tornando a utilização de filtros um passo importante para correção ou redução de imperfeições.

A aplicação do filtro tem como objetivo a eliminação ou redução de ruídos, melhoria no contraste enfatizando a separação de regiões contínuas e o destaque de objetos ou estruturas com orientações espaciais similares (VERNON, p. 53, 1991). Dentre os principais filtros destacam-se o filtro da Mediana, filtro Gaussiano e o filtro Bilateral.

- Filtro Mediana: consiste na substituição do valor do pixel central à janela usada no processo de filtragem pelo valor da mediana dos pixels vizinhos localizados dentro de tal janela (EKSTROM, p. 25, 1984). O objetivo deste filtro é reduzir o ruído, sendo muito aplicado na remoção de ruídos impulsivos do tipo "sal e pimenta" (CHANG et al., 2008). Este filtro tem a propriedade de reduzir o ruído enquanto preserva as bordas, sendo considerado um dos filtros não lineares mais importantes (PEDRINI; SCHWARTZ, p. 123, 2008). Embleton et al. (2003) aplicam este filtro para suavizar o perímetro de regiões de interesse. Gajendran e Rodriguez (2004) usam o filtro da mediana para remover ruído do tipo "sal e pimenta" e também pequenos buracos no interior dos objetos (cromossomos). Flores et al. (2008) aplicam o filtro de mediana cinco vezes a fim de melhorar o contraste das bordas dos objetos (larvas). Su et al. (2008) combinam um filtro de mediana com redes neurais pulsadas (pulse-coupled) a fim de remover ruído de imagens contendo células sanguíneas.

- Filtro Gaussiano: é a média ponderada das intensidades dos pixels vizinhos, no qual os pesos são definidos pela função Gaussiana (PARIS et al., 2008). Nesse filtro o valor do pixel central da janela é alterado em função do valor do desvio padrão da gaussiana usada como semente em relação aos vizinhos localizados no interior da janela, ou seja, quanto menor é o desvio padrão, 
maior é o peso atribuído ao pixel central, resultando num menor grau de suavização (PEDRINI e SCHWARTZ, p.126, 2008). Basu et al. (2002) descreve que o filtro Gaussiano é o filtro mais utilizado para suavização, sendo amplamente adotado na área de processamento de imagens e visão computacional, em função de sua capacidade de suavização e redução de ruídos nas imagens. Kumagai et al. (2008) e Zhou et al. (2010) aplicam este filtro em seus trabalhos objetivando a redução do ruído de alta frequência.

- Filtro Bilateral: Segundo Paris et al. (2008), de forma similar ao filtro Gaussiano, o filtro bilateral também pode ser definido como a média ponderada dos pixels na janela. A diferença entre o filtro Gaussiano é que o filtro Bilateral considera a variação das intensidades visando à preservação de bordas (ELAD, 2002). Para o filtro Bilateral, dois pixels são relacionados entre si, se ocupam posições espaciais próximas e se possuem similaridades em relação à escala fotométrica (PARIS et al., 2008). O filtro bilateral pode ser resumido como uma técnica de suavização de imagens que visa à preservação de bordas. A primeira referência ao filtro é associada ao trabalho de Aurich e Weule (1995) sobre filtros Gaussianos não lineares. Posteriormente o filtro foi redescoberto por Smith e Brady (1997) como parte do SUSAN framework, mas foram Tomasi e Manduchi (1998) que atribuíram o nome pelo qual o filtro é conhecido atualmente. Desde então, o filtro bilateral foi utilizado em diversos tipos de aplicações, dentre as quais se destacam a aplicação para redução ou eliminação de ruídos (BENNETT e MCMILLAN, 2005; ALEKSIC et al., 2006; SABLE e JOHDHALE, 2010), realce e edição de texturas (OH et al., 2001) e gerenciamento de tons (DURAND e DORSEY, 2002; PETSCHNIGG et al., 2004; EISEMANN e DURAND, 2004; ELAD, 2005; BAE et al., 2006).

Enquanto a filtragem é dedicada a remoção ou redução de interferências indesejadas nas imagens, Cung (1990) destaca que o objetivo das técnicas de detecção de bordas é reduzir a quantidade de dados a serem processados, e descartar informações consideradas irrelevantes da imagem, preservando as características estruturais das regiões de interesse que serão utilizadas nas etapas 
posteriores do processamento da imagem. Gonzalez e Woods (2007) definem a borda como o limite ou fronteira entre duas regiões com propriedades relativamente distintas de níveis de cinza. Essas características são utilizadas, por exemplo, para distinguir um objeto de interesse, do fundo de uma imagem.

Hocenski et al. (2006) afirmam que a detecção de bordas é, essencialmente, a operação de identificação de mudanças locais significativas nos níveis de cinza da imagem e essas mudanças podem ser descritas através do conceito de derivada. De acordo com Shrivakshan e Chandrasekar (2012), existem diversas técnicas de detecção de bordas, entretanto, elas podem ser agrupadas basicamente em duas categorias: gradiente e Laplaciano.

No método do gradiente as bordas são detectadas através do máximo e do mínimo da derivada de primeira ordem da imagem. No método Laplaciano, por sua vez, as bordas são detectadas através do cruzamento em zero da derivada de segunda ordem. Tanto a abordagem do gradiente quanto do Laplaciano, podem ser aproximadas por máscaras de convolução (SHRIVAKSHAN e CHANDRASEKAR, 2012). Dentre os principais detectores de bordas destacam-se:

- Sobel: O operador Sobel para detecção de bordas utiliza como máscara duas matrizes de tamanho $3 \times 3$, para calcular uma aproximação do gradiente da função de intensidade da imagem. A primeira matriz, $G_{x}$ estima o gradiente na direção do eixo $x$, enquanto a segunda $G_{y}$, estima 0 gradiente na direção do eixo y (MA et al., 2010). Cada máscara é convolucionada com a imagem I, como mostra a Figura 25, para calcular as derivadas aproximadas das alterações de intensidade horizontais e verticais $\left(G_{x}\right.$ e $\left.G_{y}\right)$.

Figura 25 - Máscaras do operador Sobel.

$$
G_{x}=\begin{array}{|l|l|l|}
\hline-1 & 0 & 1 \\
\hline-2 & 0 & 2 \\
\hline-1 & 0 & 1 \\
\hline
\end{array} * I
$$$$
G_{y}=\begin{array}{|c|c|c|}
\hline 1 & 2 & 1 \\
\hline 0 & 0 & 0 \\
\hline-1 & -2 & -1 \\
\hline
\end{array} * I
$$ 
Em seguida, para cada ponto da imagem, é calculada a magnitude do gradiente, conforme equação (18), através da combinação dos resultados parciais do gradiente horizontal e vertical, obtidos nos cálculos anteriores (DENG et al., 2011).

$$
|G|=\sqrt{G_{x}^{2}+G_{y}^{2}}
$$

O operador de Sobel é relativamente barato em termos computacionais, uma vez que ele realiza a convolução da imagem com um pequeno filtro de valores inteiros. As principais desvantagens deste tipo de detector são a aproximação inadequada para variações de alta frequência e a alta sensibilidade a ruído (SHARIFI et al., 2002).

Xin-sheng et al. (2009) apresentam em seu trabalho a aplicação do operador Sobel na localização e reconhecimento do código de barras em imagens digitais. Feng et al. (2007) aborda outra aplicação deste operador, relacionada à tecnologia de navegação em veículos inteligentes, objetivando a identificação das faixas de rolagem de uma via pública. Xiang et al. (2011) apresentam a aplicação do método Sobel no processamento de imagens oriundas de um microscópio binocular.

- Laplaciano do Gaussiano: O operador Laplaciano do Gaussiano (LOG) ou como também é conhecido operador Marr-Hildreth foi proposto pela primeira vez por Marr-Hildreth em 1980, baseado em suas investigações sobre o sistema visual humano (Zhao e deSilva, 1998). Neste método, o filtro Gaussiano é combinado ao filtro Laplaciano, a fim de evitar resultados distorcidos, uma vez que por ser derivativo, o filtro Laplaciano é muito sensível a ruídos.

Desta forma, primeiramente, o filtro Gaussiano é aplicado à imagem visando à minimização dos ruídos, o que aumenta a sensibilidade do Laplaciano e intensifica o processo de detecção de bordas. O 
Laplaciano, por sua vez, destaca as regiões onde ocorre uma alteração brusca de intensidade, utilizada na identificação da borda. (SHRIVAKSHAN e CHANDRASEKAR, 2012).

De acordo com Loukas et al. (2003) o Laplaciano do Gaussiano foi adotado em seu trabalho porque a operação de suavização realizada pelo filtro gaussiano é desejável sob as condições altamente ruidosas encontradas em material histológico. De forma similar, este método também é usado por Cosio et al. (2003) para contagem de células imunocitoquimicamente marcadas e, Nasution e Suryaningtyas (2008) para contagem de hemácias. Em outra abordagem, o filtro Laplaciano do Gaussiano é aplicado por Pritha et al. (2010) para o reconhecimento facial.

- Canny: John F. Canny (1986) descreveu uma abordagem computacional para detecção de bordas, posteriormente chamada de Operador Canny. Em seu método, Canny estabeleceu que um detector de bordas deve essencialmente satisfazer três critérios básicos de desempenho: boa detecção, boa localização e boa resposta.

Cheng et al. (2008) descreveram, em outras palavras, que o operador Canny visa reduzir a taxa de erro, minimizando o número de falsos positivos (pixels detectados que não representam bordas) e falsos negativos (pixels que representam bordas, mas que não são detectados); minimizar a distância entre a borda detectada e a borda real da imagem processada e; minimizar a probabilidade de múltiplas respostas para uma mesma borda.

O algoritmo de Canny pode ser dividido em quatro etapas (SHRIVAKSHAN e CHANDRASEKAR, 2012):

I. Suavização da imagem de entrada através da aplicação do filtro Gaussiano, visando à remoção de detalhes irrelevantes como elementos de textura e ruídos; 
II. Determinação da magnitude e direção do gradiente para cada pixel da imagem suavizada;

III. Aplicação da técnica de supressão não máxima para a magnitude do gradiente. Essa etapa visa remover os pixels, cujos valores não são máximos locais, na direção perpendicular à borda, proporcionando o afinamento e a melhor localização da borda;

IV. Aplicação da técnica de limiarização, através de dois limiares (inferior e superior), visando à remoção de bordas fracas.

O método Canny pode ser adotado em diferentes tipos de aplicações. Toh et al. (2009) apresentam em seu trabalho a aplicação do método para a contagem de peixes em tanques monitorados por vídeo. Outro exemplo é descrito por Mall et al.(2013), no qual o operador Canny é aplicado para a verificação de autenticidade de imagens digitais. Além disso, podem ser encontradas iniciativas relacionadas às áreas de geoprocessamento (LI et al., 2010) e odontologia (ALI e CLAUSI, 2001).

\subsubsection{Comparativo entre as técnicas de detecção de bordas}

Três técnicas de detecção de bordas foram selecionadas para realização do comparativo de identificação das imagens da segregação central do ensaio de Baumann (Sobel, Laplaciano do Gaussiano e Canny). O objetivo desta análise comparativa é identificar qual das técnicas analisadas apresenta o melhor resultado, visando sua posterior aplicação no algoritmo de segmentação.

A abordagem utilizada no comparativo é apresentada na Figura 26 e consiste inicialmente, na leitura da imagem da amostra de Baumann que será processada. Em seguida, a imagem é convertida para escala de tons de cinza, e por último, as técnicas de detecção de bordas são aplicadas, dando origem à imagem final que apresenta as bordas e limites detectados. 
Figura 26 - Estrutura do algoritmo no comparativo de detecção de bordas.

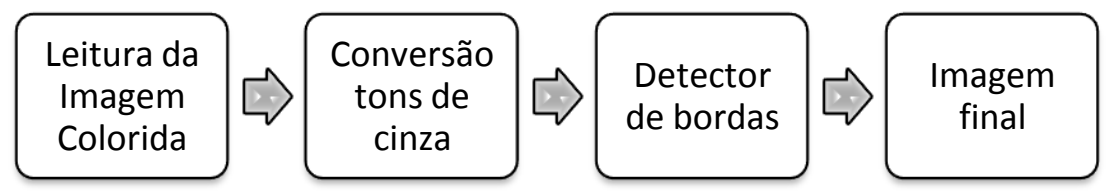

As técnicas de detecção de bordas foram aplicadas em um segmento da imagem da amostra de Baumann previamente selecionado e os resultados podem ser visualizados na Figura 27. No método Sobel, o resultado obtido apresenta bordas espessas e distorcidas, o que contribui para a perda de informações sobre a estrutura da segregação central, podendo comprometer as etapas posteriores de processamento da imagem. Outro aspecto importante é a ocorrência excessiva de falsos positivos, ou seja, ruídos que foram identificados como bordas na imagem.

Figura 27 - Implementação dos algoritmos de detecção de bordas.

(a) Imagem original. (b) Resultado Sobel. (c) Resultado Laplaciano do Gaussiano.

(d) Resultado Canny.

(a)

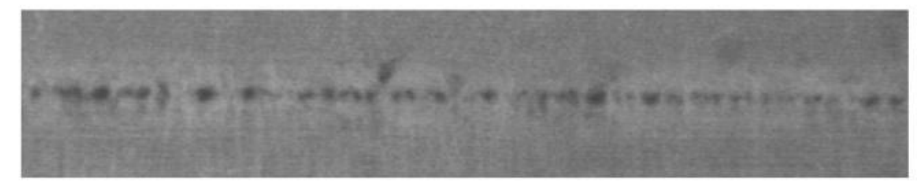

(b)

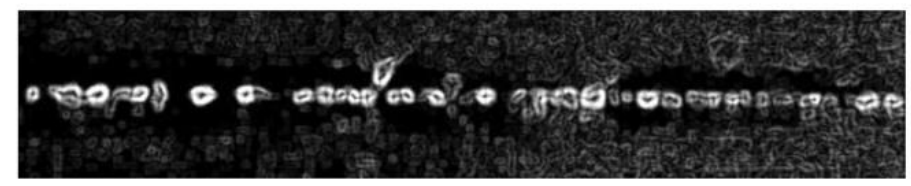

(c)

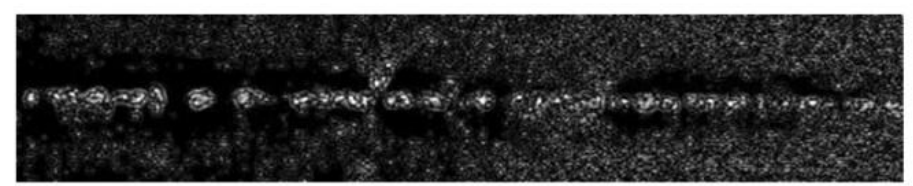

(d)

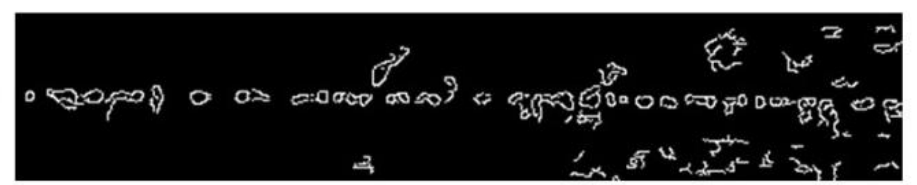

$\mathrm{Na}$ aplicação do método Laplaciano do Gaussiano, o resultado do teste apresenta a perda de dados importantes para identificação da estrutura da segregação central e as bordas não foram identificadas corretamente, dificultando a identificação das regiões de interesse da imagem. 
Para o detector de bordas Canny, foi adotado o liminar inferior de $17 \mathrm{e}$ superior de 37. Adotando estes valores, as bordas foram identificadas e os ruídos na imagem foram praticamente eliminados, enquanto as características estruturais da segregação central foram preservadas. Mesmo com a ocorrência de falsos positivos na imagem (detecção de bordas onde não existem efetivamente), no método Canny, uma quantidade menor de pixels que correspondem a ruídos, foram identificados como "borda" se comparado ao método Sobel.

É importante ressaltar que no método Canny o correto ajuste dos limiares é fundamental para a obtenção de resultados satisfatórios. A adoção de um limiar muito grande pode causar a perda de informações importantes. Em contrapartida, a adoção de um limiar muito pequeno, pode acarretar na identificação excessiva de informações desnecessárias (ruídos) como bordas. O desafio na utilização desse método é justamente encontrar um limiar (nem muito pequeno, nem muito grande) que apresente resultados satisfatórios com diferentes imagens.

O comparativo entre os métodos analisados apresentou resultados positivos na aplicação dessas técnicas no problema de identificação da segregação central. Adicionalmente, foi observado que para os limiares adotados, o método Canny apresentou resultados melhores na detecção das bordas da segregação central, se comparado ao método Sobel e Laplaciano do Gaussiano.

Embora o método Canny tenha apresentado o melhor resultado dentre as demais técnicas analisadas, a quantidade de bordas desconexas e ruídos na imagem ocasionou a ocorrência de falsos positivos, que podem comprometer as etapas posteriores de processamento. Wong et al. (2008) apresentam em seus trabalhos a utilização do método Canny aperfeiçoado através da integração ao algoritmo de otimização da colônia de formigas ( $\mathrm{ACO}$, do inglês ant colony optimization algorithm) para solução do problema de bordas desconexas produzidas pelo método Canny tradicional.

Em outra abordagem, Agaian et. al.(2009) apresentam em seu trabalho a alteração do núcleo do filtro Gaussiano tradicional, aplicado na etapa de suavização, para obtenção de resultados melhores com o método Canny. De forma similar, 
Wang e Fan (2009), e Xu et al. (2006) propõe respectivamente em seus trabalhos a adoção de um filtro adaptativo e filtro mediana, ao invés do filtro Gaussiano na etapa de suavização. Nessas aplicações, o método Canny tradicional foi modificado e adaptado para a solução de um problema específico, melhorando assim os resultados observados em comparação ao método tradicional.

Em função dos resultados obtidos pela aplicação do método Canny tradicional para detecção da segregação central e inspirado nos resultados demonstrados nos trabalhos de Agaian et. al. (2009), Xu et. al. (2006), Wang e Fan (2009), optou-se pela realização do comparativo entre o método Canny tradicional em relação aos métodos aperfeiçoados propostos.

No primeiro passo do método Canny tradicional, é realizada a suavização da imagem através da aplicação do filtro gaussiano. Esta etapa do algoritmo visa reduzir os ruídos na imagem que podem interferir nos próximos passos do método. Com base nessa característica do algoritmo, propõe-se a adaptação do método Canny através da aplicação de outros filtros na etapa de suavização.

Apresentam-se a seguir o comparativo realizado entre o método Canny tradicional, que utiliza o filtro gaussiano na etapa de suavização e dois métodos aperfeiçoados, que aplicam respectivamente o filtro da Mediana e filtro Bilateral na mesma etapa do algoritmo, aplicados na identificação da segregação central.

\subsubsection{Comparativo método Canny tradicional e aperfeiçoado}

A abordagem proposta neste comparativo, ilustrada na Figura 28, é similar ao algoritmo utilizado no comparativo realizado entre as técnicas de detecção de bordas. Inicialmente, será realizada a leitura da imagem da amostra de Baumann que será processada. Em seguida, a imagem é convertida para escala de tons de cinza. Na etapa de suavização é aplicado o filtro proposto e, na sequência, são 
realizadas as demais etapas do método Canny, dando origem à imagem final que apresenta as bordas e limites detectados.

Figura 28 - Estrutura do algoritmo no comparativo entre método Canny tradicional e Canny aperfeiçoado.

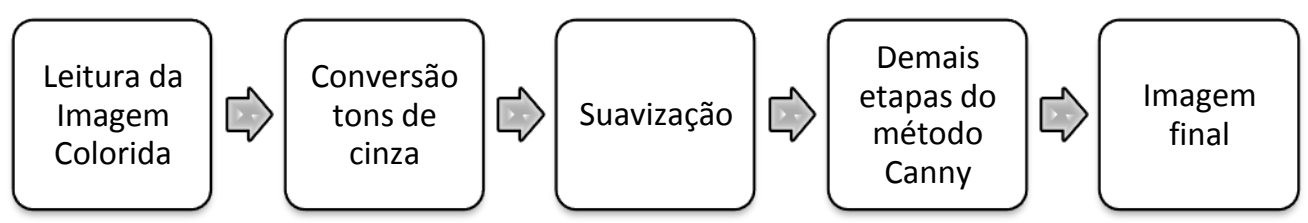

O método Canny aperfeiçoado foi aplicado no mesmo segmento da imagem da amostra de Baumann utilizado no comparativo anterior, e os resultados podem ser visualizados na Figura 29.

Figura 29 - Implementação do comparativo entre método Canny tradicional e Canny aperfeiçoado. (a) Imagem original. (b) Resultado Canny tradicional (filtro Gaussiano). (c) Resultado Canny aperfeiçoado pelo filtro Mediana. (d) Resultado Canny aperfeiçoado pelo Filtro Bilateral.

(a)

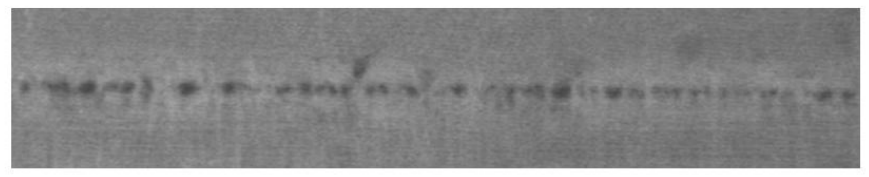

(b)

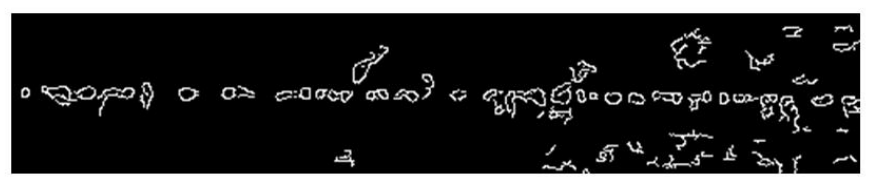

(c)

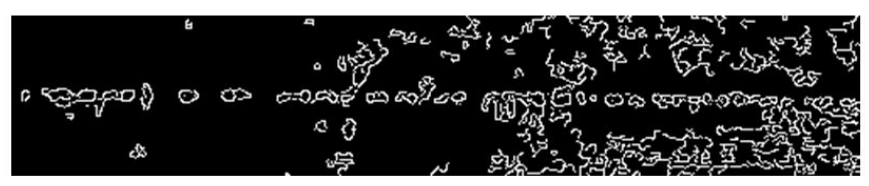

(d)

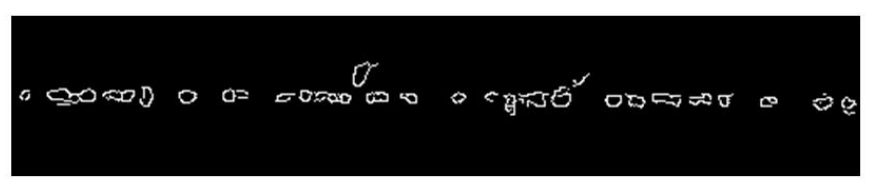

No método Canny aperfeiçoado pelo filtro da mediana, o resultado obtido apresenta uma quantidade excessiva de falsos positivos. Esse método apresentou um resultado inferior ao resultado obtido pelo método tradicional, como pode ser observado na Figura 29. Em contrapartida, na imagem analisada, o método Canny aperfeiçoado pelo filtro bilateral eliminou quase que em sua plenitude a ocorrência de falsos positivos, apresentando um resultado superior ao método Canny tradicional. 
A eliminação dos ruídos na imagem, sem comprometer as informações relevantes, representa um fator importante para o desempenho das etapas seguintes de extração de características e reconhecimento da imagem. Em função dos resultados obtidos neste comparativo, optou-se para elaboração do algoritmo 2 pela utilização do método Canny aperfeiçoado através da utilização do filtro bilateral na etapa de suavização para a identificação da segregação central.

\subsubsection{Estrutura do algoritmo}

No primeiro algoritmo elaborado foi identificado que as interferências causadas pelo sistema de aquisição comprometem o desempenho do algoritmo na etapa de pré-processamento e segmentação da imagem. Entretanto, as características do sistema de aquisição e a forma como é realizada a concatenação das imagens já são conhecidas. Adicionalmente, sabe-se que a segregação central está situada horizontalmente próxima ao centro da amostra. Desta forma, tal característica descarta o aparecimento deste defeito próximo às bordas da amostra.

Neste algoritmo essas características foram adotadas como premissas, iniciando a etapa de pré-processamento da imagem pela segmentação da imagem em seções de 640 x 480 pixels (de acordo com as características do sistema de aquisição já mencionadas), nas quais foi selecionado o intervalo [-100; 100] pixels em relação ao centro da imagem, restringindo a região analisada e descartando as bordas da imagem, conforme exemplo apresentado na Figura 30. A seleção de 200 pixels como região de interesse da imagem, não compromete as informações do defeito da segregação central, uma vez que como já foi observado no primeiro algoritmo, o defeito não é comprometido com a seleção da segunda e da terceira região da imagem com tamanho total de 240 pixels ( 480 pixels $/ 4$ regiões $=120$ pixels por região). 
Figura 30 - Região de interesse da impressão de Baumann.

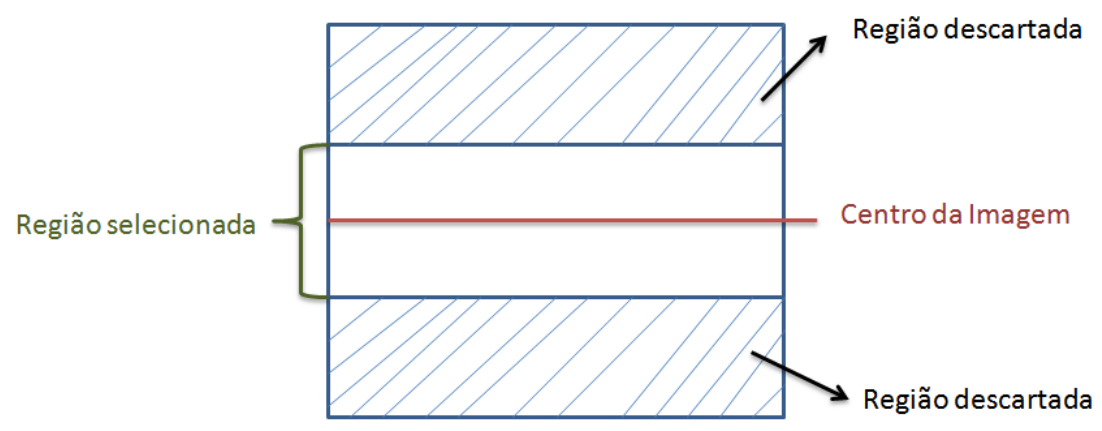

Observou-se que com essa abordagem as etapas realizadas no algoritmo anterior de separação da imagem em quatro regiões iguais e a eliminação das linhas que representavam ruídos através da análise do histograma horizontal correspondentes a mesa, na qual o corpo de prova é posicionado para a realização da imagem, poderiam ser facilmente eliminadas sem comprometer a região central de interesse da imagem. A Tabela 3 apresenta as imagens resultantes de cada seção, após a realização da seleção do intervalo de interesse de [-100;100] em relação ao centro da seção.

Tabela 3 - Pré-processamento da imagem.

\begin{tabular}{|c|c|c|c|}
\hline Seção & $\begin{array}{c}\text { Imagem original } \\
(640 \times 480)\end{array}$ & $\begin{array}{l}\text { Seleção região de } \\
\text { interesse }\end{array}$ & Imagem resultante \\
\hline $1^{a}$ & & & \\
\hline $2^{\mathrm{a}}$ & & & \\
\hline & & & \\
\hline
\end{tabular}




\begin{tabular}{|c|c|c|c|}
\hline Seção & $\begin{array}{c}\text { Imagem original } \\
(640 \times 480)\end{array}$ & $\begin{array}{c}\text { Seleção região de } \\
\text { interesse }\end{array}$ & Imagem resultante \\
\hline $3^{\mathrm{a}}$ & & SEG & \\
\hline $4^{a}$ & $1025 T$ & 1225 & \\
\hline $5^{a}$ & $T .05$ & $\pi 05$ & \\
\hline $6^{a}$ & & 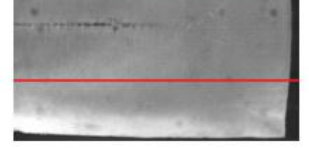 & \\
\hline
\end{tabular}

Kotas et al.(2012), apresentam em seu trabalho a análise típica da distribuição dos níveis de cinza de uma imagem da segregação central, através do histograma como mostra a Figura 31, para a obtenção de características que possam contribuir no processamento da imagem. Na análise clássica do histograma, os níveis de cinza compreendidos na região entre as setas vermelhas apresentadas na Figura 31 seriam selecionados, enquanto as extremidades seriam descartadas. Entretanto (KOTAS et al.,2010), para o problema da segregação central, os tons mais escuros de cinza são mais relevantes do que os demais, tornando o conhecimento sobre as características do defeito fundamental para correta seleção da região relevante do histograma, neste caso, a região mais a esquerda do histograma. 
Figura 31 - Exemplo de histograma.

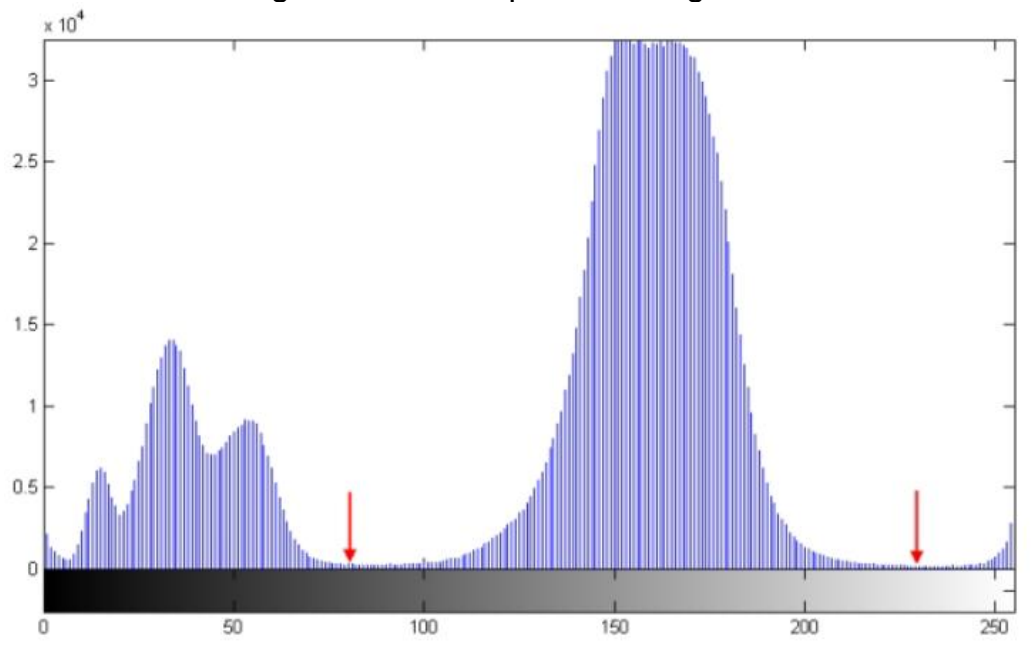

Fonte: KOTAS et al. (2012).

Com base na análise desse cenário, foi realizado o histograma da região de interesse de cada seção da imagem, selecionada na etapa anterior, e realizado o cálculo da mediana, que neste caso representa o tom de cinza da seção, que corresponde a $50 \%$ da frequência relativa acumulada no histograma. $O$ tom de cinza médio obtido será utilizado como limiar no próximo passo do algoritmo. A Figura 32, apresenta, como exemplo, o histograma da terceira seção, em que o limiar obtido para esta imagem foi 129.

Figura 32 - Histograma da terceira seção.

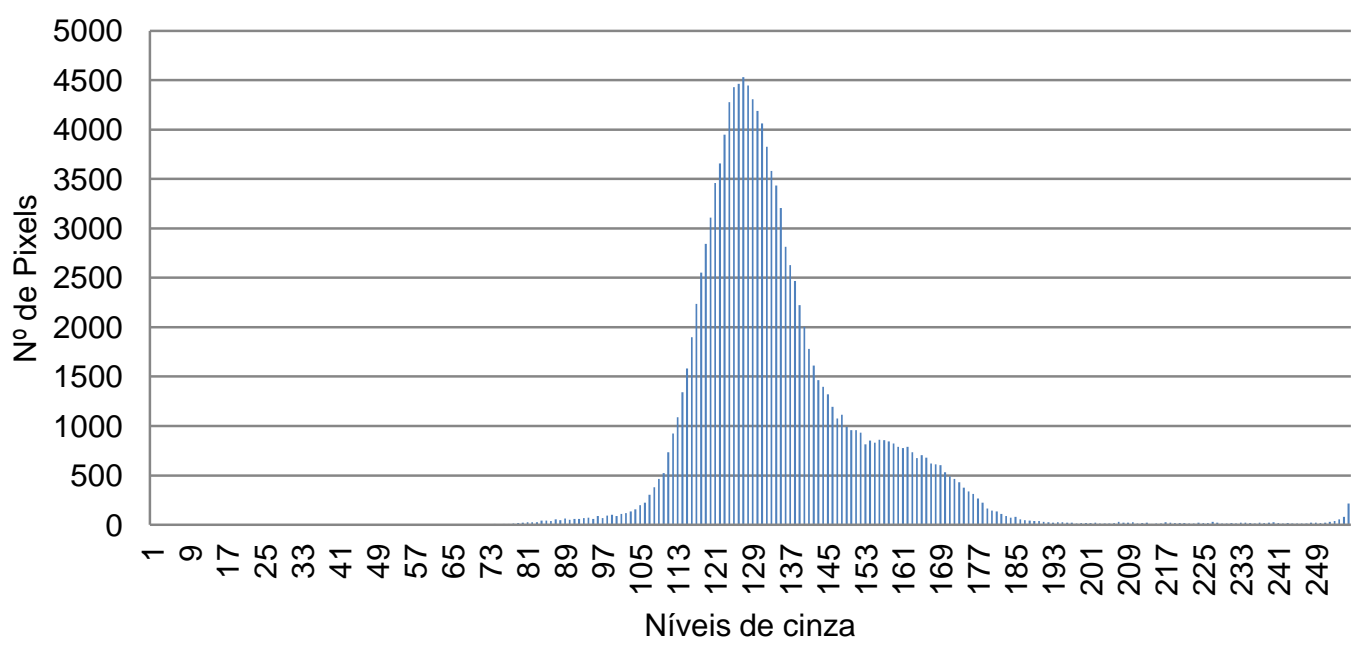


Na sequência foi realizada a limiarização de cada seção da imagem, segundo a Equação (19), onde $p_{i j}$, representa o pixel analisado na linha $i$ e coluna $j$, caso o tom de cinza de $p_{i j}$ seja inferior ao limiar estipulado, o mesmo será preservado. Caso contrário o valor de $p_{i j}$ é substituído pelo valor do limiar.

$$
p_{i j}=\left\{\begin{array}{cl}
p_{i j}, & \text { se } p_{i j}<\text { limiar } \\
\text { limiar }, & \text { se } p_{i j} \geq \text { limiar }
\end{array}\right.
$$

Após o processo de limiarização, como pode ser observada na Tabela 4, a segregação central é destacada na imagem, enquanto as interferências foram reduzidas.

Tabela 4 - Resultado da limiarização das seções.

\begin{tabular}{|c|c|c|}
\hline Seção & Antes da limiarização & Após limiarização \\
\hline $1^{\text {a }}$ & & \\
$2^{\text {a }}$ & & \\
$3^{\text {a }}$ & & \\
$4^{\text {a }}$ & & \\
$5^{\text {a }}$ & & \\
\hline
\end{tabular}

Nesta etapa foi realizada a segmentação da imagem, conforme os resultados obtidos no comparativo realizado entre as técnicas de detecção de bordas aplicadas à identificação da segregação central, onde a aplicação do filtro 
bilateral seguido do operador Canny apresentaram os melhores resultados. A Figura 33 apresenta os resultados da quarta seção, após a aplicação dessas técnicas.

Figura 33 - Resultado da detecção de bordas. (a)Antes. (b) Depois.

(a)

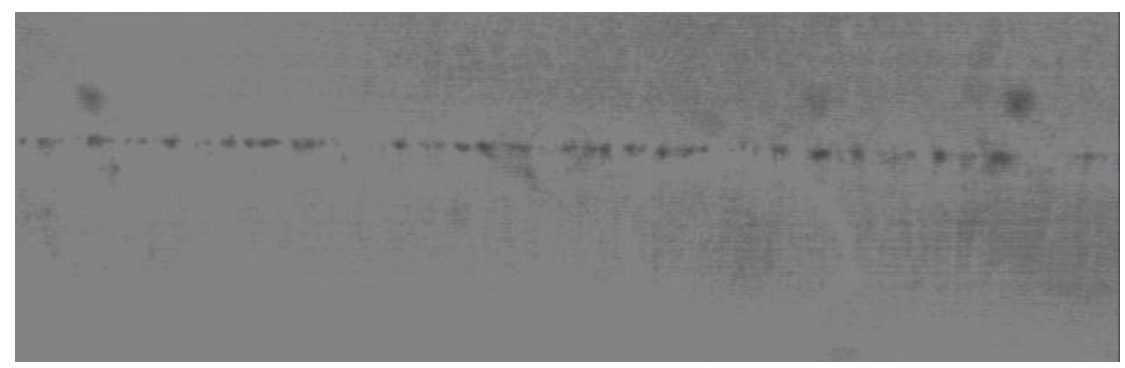

(b)

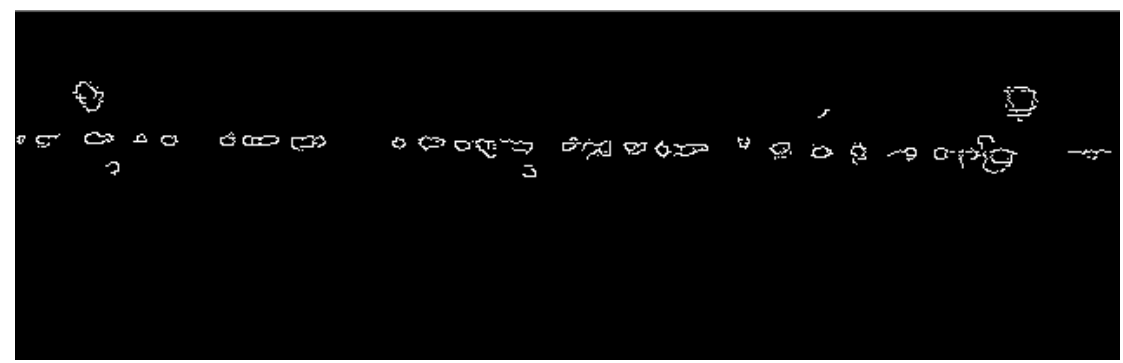

Após a eliminação das interferências e a aplicação do detector de bordas na imagem foi possível identificar no histograma horizontal, uma região onde existe uma concentração acentuada de pixels brancos, caracterizada pelas bordas identificadas na etapa anterior. Essa elevação no histograma horizontal representa as bordas da segregação central na imagem e será utilizada como referência para restringir a região de interesse da imagem e identificar a linha da segregação central. A Figura 34, apresenta o histograma horizontal da quarta seção.

Figura 34 - Histograma horizontal da quarta seção.

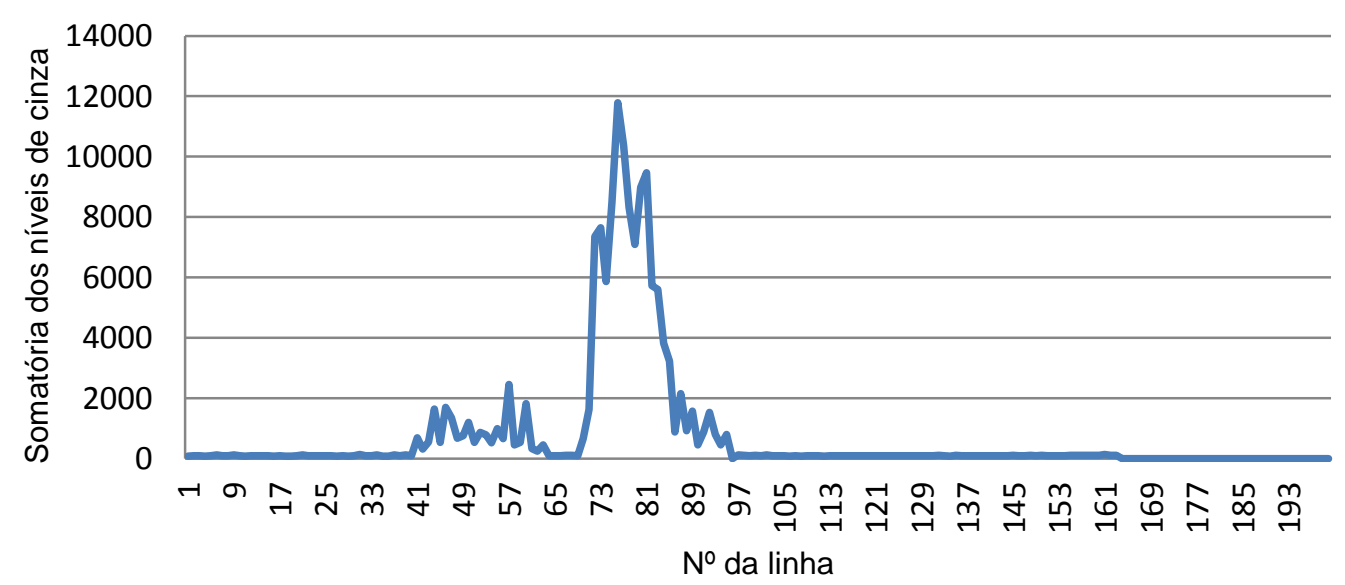


Para identificar a região da segregação na imagem, foi calculado o vetor $D_{h}$ de dimensão igual região selecionada (200 pixels), que representa a diferença entre os elementos do vetor $H_{h}$, que por sua vez, representa o histograma horizontal da imagem. Os elementos do vetor $D_{h}$ são calculados de acordo com as equações (20) e (21), onde $h_{r}$ representa o primeiro elemento do vetor $H_{h}$ da imagem.

$$
\begin{array}{r}
d_{i}=\left\{\begin{array}{cc}
0, & \text { se } i=0 \\
h_{r+i}-h_{r+i-1}, & \text { se } i>0
\end{array}\right. \\
D_{h}=\left[\begin{array}{llll}
d_{0} & d_{1} & \ldots & d_{200}
\end{array}\right]
\end{array}
$$

Após o cálculo do vetor $D_{h}$ é possível determinar a faixa da segregação central na seção analisada, selecionando o menor e o maior valor do vetor $D_{h}$, uma vez que as linhas com maior variação correspondem às bordas da segregação. Uma vez determinado o valor mínimo e o máximo para a linha da segregação central de cada uma das seções, foram identificados os valores de mínimo e máximo global da imagem, e realizada uma nova segmentação preservando apenas as linhas contidas entre os valores de mínimo e máximo global. Neste exemplo, as linhas 71 e 81 , como mostra a Figura 35.

Figura 35 - Identificação da linha segregada.

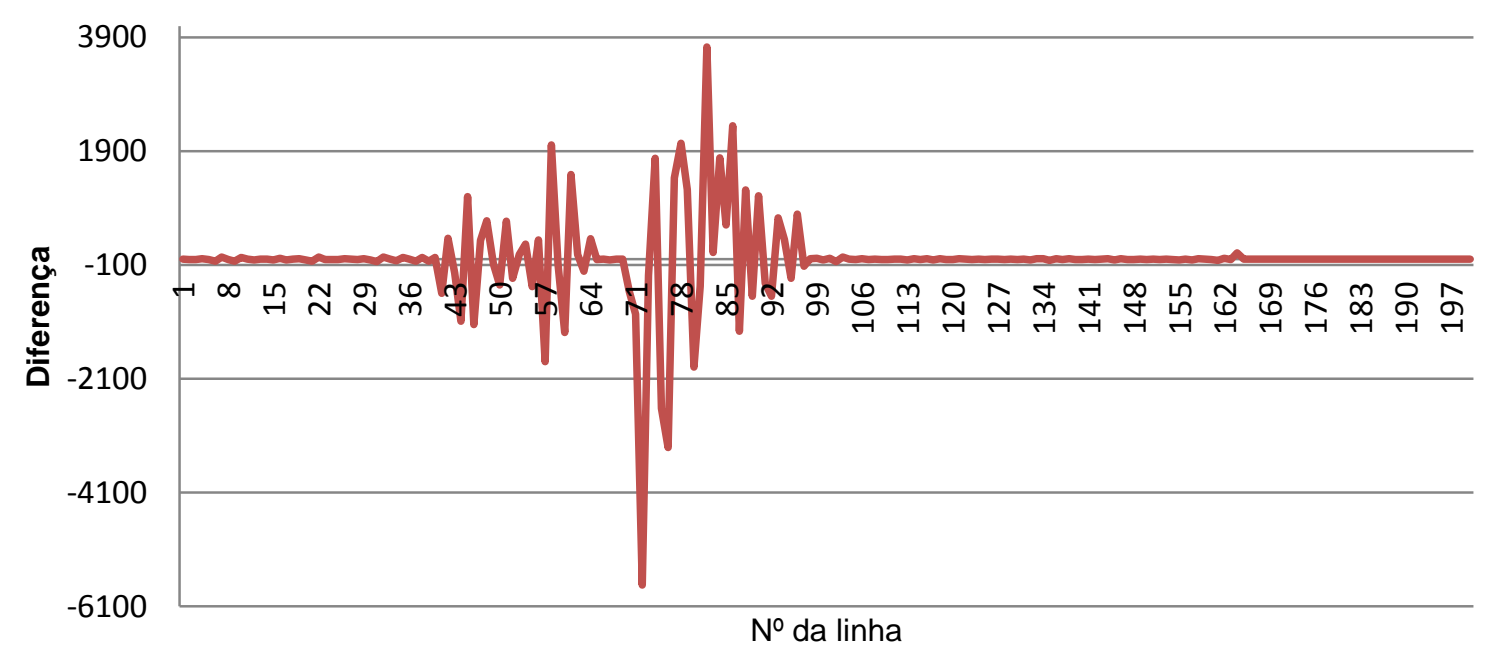


Uma vez definido o valor mínimo e máximo da faixa da segregação para cada seção, então, é calculado o valor global da faixa da segregação para a imagem original (antes da separação nas seções), selecionando o menor e o maior valor dentre todas as seções. Desta forma se obtém o segmento da imagem onde a segregação central está situada. A Figura 36 apresenta o segmento selecionado.

Figura 36 - Segmentação da imagem

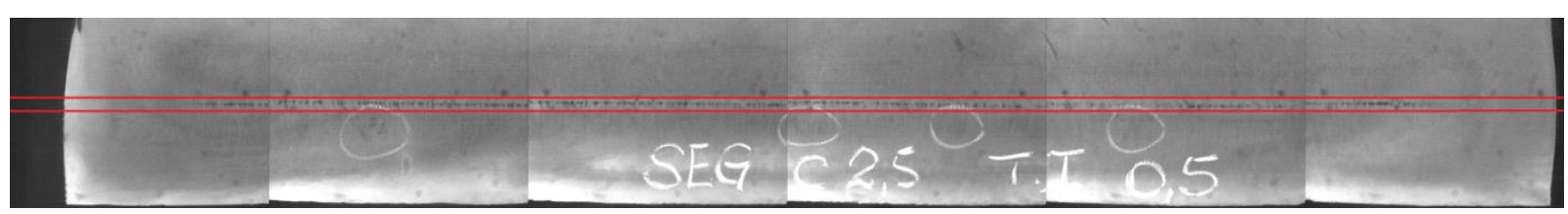

\subsubsection{Resultados}

Para avaliar a aplicabilidade dos critérios, o segundo algoritmo foi implementado, contemplando as regras descritas anteriormente. Nesta avaliação foram analisadas as mesmas 255 imagens processadas no primeiro algoritmo, distribuídas nos diferentes graus de severidade. É importante destacar que nesta avaliação as 20 imagens correspondentes ao padrão "C00" (que representa a ausência de defeito) também foram excluídas da análise.

Todas as imagens foram submetidas e processadas individualmente pelo algoritmo que produziu como resultado uma nova imagem, destacando a região selecionada no processo de segmentação. A avaliação da segmentação realizada pelo algoritmo foi executada através da verificação visual da existência de segregação central na imagem selecionada, utilizando os mesmos critérios adotados na avaliação do primeiro algoritmo.

No algoritmo foi obtida a correta segmentação da região da segregação central em $89 \%$ das imagens analisadas. O algoritmo, por sua vez, segmentou parcialmente ou não segmentou corretamente $11 \%$ das imagens analisadas. $O$ 
segundo algoritmo aumentou em $11 \%$ a segmentação correta das imagens em relação ao primeiro algoritmo.

A Figura 37 detalha os resultados obtidos pelo segundo algoritmo em relação ao primeiro para cada grau de severidade. Como pode ser observado nesta figura, somente os graus de severidade "B25" e "C25" apresentaram para o segundo algoritmo resultados piores do que os resultados obtidos anteriormente no primeiro algoritmo.

Figura 37 - Avaliação dos resultados da segmentação do algoritmo 2 por grau de severidade.

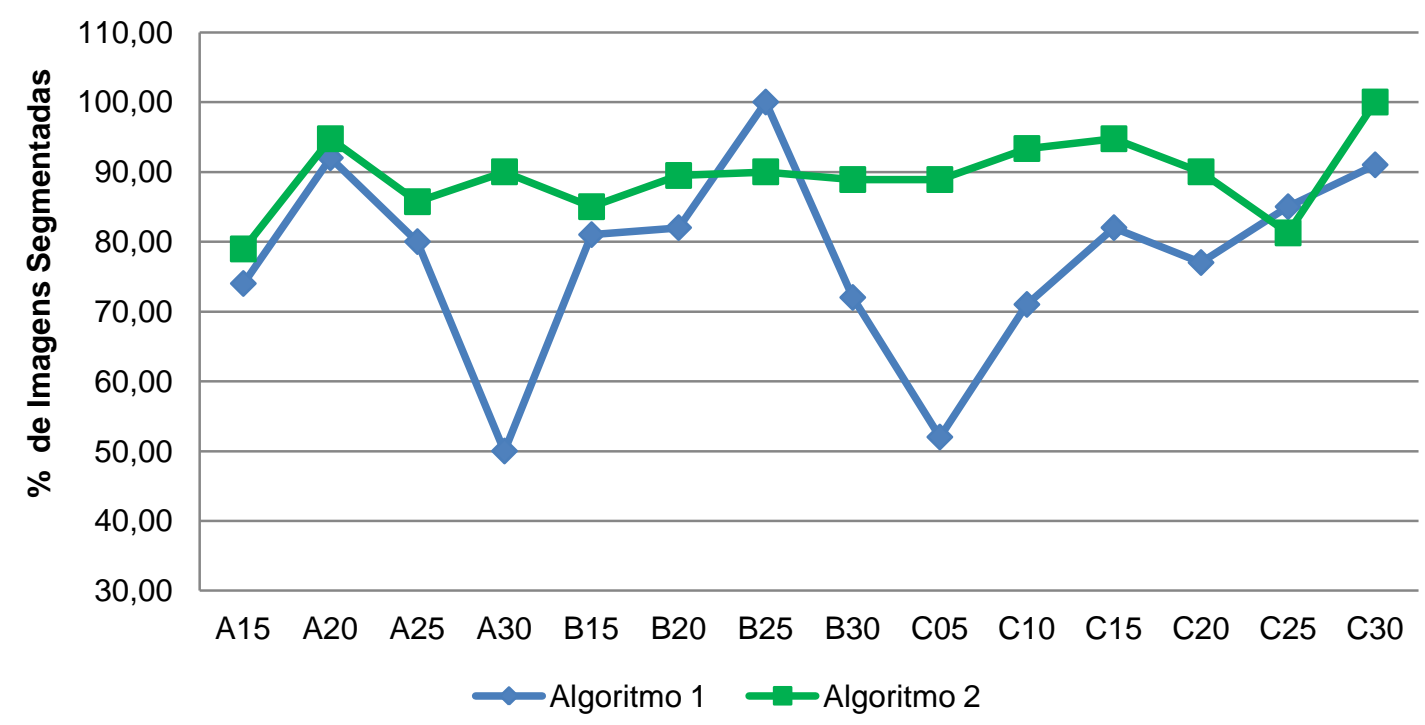

Embora o desempenho do algoritmo tenha sido pior para determinados graus de severidade, observou-se que houve uma melhoria expressiva na segmentação correta na maioria das faixas de classificação.

Ao analisar as imagens que não foram segmentadas corretamente, observou-se que em parte dessas imagens, a linha da segregação central está situada horizontalmente próxima ao centro da imagem (em conformidade com a característica do defeito), porém a linha segregada apresenta-se com um elevado grau de inclinação.

A inclinação observada nas imagens está relacionada a dois aspectos distintos. O primeiro refere-se ao posicionamento irregular do sistema de captura da 
imagem em relação ao corpo de prova, fazendo com que a inclinação do sistema de captura seja refletida na imagem. O segundo aspecto, por sua vez, é inerente ao defeito da segregação central, mesmo em casos excepcionais nos quais é possível observar um grau muito acentuado de inclinação. Tal característica indica a necessidade de refinamento no algoritmo para que estes casos também sejam contemplados.

Em relação à identificação dos objetos de interesse que serão analisados na próxima fase do algoritmo, foi observada uma quantidade significativa de falsos positivos, ou seja, ruídos identificados como bordas dos elementos. Foi possível identificar que parte desses ruídos estavam associados às marcas da lixadeira utilizada na preparação da amostra. Os riscos impressos no corpo de prova apresentam-se como descontinuidades nos tons de cinza durante o processamento das imagens, sendo confundidos pelo algoritmo com as bordas da linha segregada.

Outro aspecto observado foi à iluminação irregular da amostra durante a aquisição da imagem. A falta de homogeneidade entre os tons de cinza causada pela iluminação irregular ocasiona o surgimento de discrepâncias significativas entre os tons de cinza, identificadas pelo algoritmo como descontinuidades e consequentemente bordas de elementos inexistentes.

Embora o algoritmo desenvolvido tenha sido capaz de aumentar expressivamente a quantidade de imagens segmentadas corretamente, foi identificada a necessidade de refinamento do algoritmo para que as linhas segregadas que apresentam um grau acentuado de inclinação também sejam contempladas e segmentadas corretamente. Apesar da melhoria observada na identificação dos elementos de interesse, os ruídos oriundos da etapa de lixamento e a iluminação irregular durante o processo de aquisição da amostra, comprometem a correta identificação e dimensionamento dos elementos de interesse. Tais características podem influenciar negativamente o desempenho da fase seguinte de extração de características e classificação. Desta forma conclui-se que o algoritmo precisa ser melhorado e não está adequado para a realização da próxima fase. 


\subsection{Algoritmo 3: Limiar adaptativo e transformada de Hough}

Em função das necessidades de refinamento identificadas no segundo algoritmo, buscou-se no terceiro algoritmo uma nova abordagem que fosse capaz de reduzir a influência dos ruídos oriundos da etapa de preparação da amostra (lixamento) e aquisição da imagem (iluminação), preservando a melhoria nos resultados obtidos do segundo algoritmo em relação ao primeiro. Adicionalmente, o terceiro algoritmo tem como objetivo a correta segmentação das linhas segregadas que apresentam elevado grau de inclinação e não foram identificadas corretamente nos algoritmos anteriores.

A Transformada de Hough foi desenvolvida em 1962 por Paul Hough, sendo originalmente elaborada para a detecção de características analiticamente representáveis em imagens binarizadas, como linhas, círculos e elipses (HOUGH, 1962). Como vantagem deste método pode-se citar que não é muito sensível a ruídos ou dados imperfeitos (SONKA et al., 2014). Tais características destacam a transformada de Hough como um método com potencial para identificação das linhas segregadas que possuem algum grau de inclinação.

O conceito principal da Transformada de Hough está em definir um mapeamento entre o espaço da imagem e o espaço de parâmetros (BOTELHO, 2013). Uma linha reta é descrita como $y=m x+b$. As características desta reta são a inclinação $m$ e a intersecção $b$. Assim, uma reta $y=m x+b$ pode ser representada como um ponto $(b, m)$ no espaço de parâmetros.

Porém, ambos os parâmetros são ilimitados, isto é, à medida que a reta torna-se vertical, as magnitudes de $b$ e $m$ tendem ao infinito. Assim, para efeitos computacionais, as retas são parametrizadas através dos parâmetros $(\theta, \rho)$ das coordenadas polares, conforme equação (22).

$$
x \cos \theta+y \operatorname{sen} \theta=\rho
$$


Isto associa cada reta da imagem a um único ponto $(\theta, \rho)$ no plano dos parâmetros (ou espaço de Hough). Todas as retas que passam por esse ponto $(\theta, \rho)$ formam uma senóide no plano de Hough, como mostra a Figura 38.

Figura 38 - Representação do ponto no espaço de Hough. (a) Espaço da Imagem. (b) Espaço de Hough.

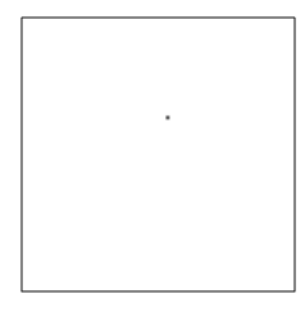

(a)

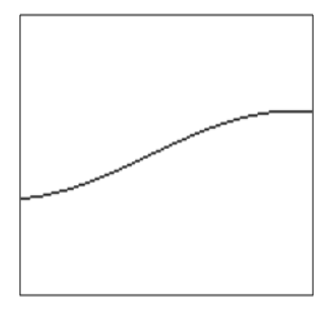

(b)

Dois pontos $p$ e $q$ no plano da imagem que definem a reta $p q$ correspondem a duas senóides no plano de Hough. A intersecção das senóides representa a reta pq que passa pelos dois pontos $p$ e $q$ no plano da imagem, conforme Figura 39.

Figura 39 - Representação dois pontos no espaço de Hough. (a) Espaço da Imagem. (b) Espaço de Hough.

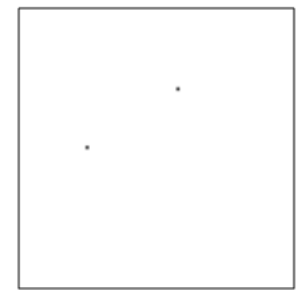

(a)

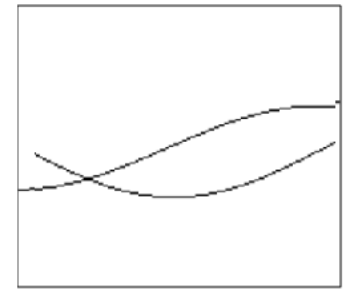

(b)

Uma reta no plano da imagem corresponde a infinitas senóides no plano de Hough que intersectam num único ponto, como ilustra a Figura 40. Este ponto do plano de Hough representa à reta. Desta forma, a transformada de Hough é capaz de detectar grupos de pixels que pertencem a uma linha reta. 
Figura 40 - Representação da reta no espaço de Hough. (a) Espaço da Imagem. (b) Espaço de Hough.

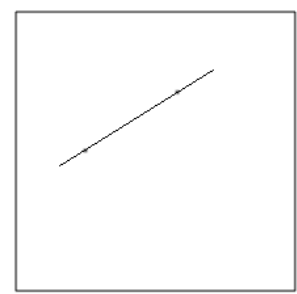

(a)

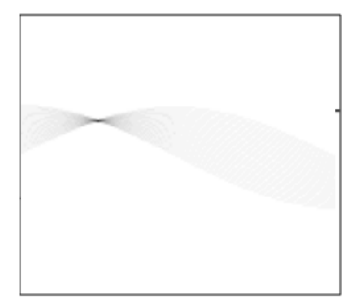

(b)

As aplicações da transformada de Hough são diversas. Macedo (2013) propõe um método computacional de rastreamento e extração de atributos em redes vasculares a partir de imagens de angiografia 3D sintéticas, utilizando a transformada de Hough para identificar o diâmetro do vaso em cortes transversais em pontos ao longo de um vaso e a análise da curvatura do contorno para classificar o ponto de bifurcação. Tambur (2007) desenvolveu um sistema de inspeção visual automática para analisar carga de vagões ferroviários utilizando técnicas de processamento de imagens, como a Transformada de Hough e outros métodos baseados em cor e textura, para identificação de regiões com possíveis objetos sobrepostos. Hardzeyeu et al. (2008) apresentam uma aplicação da Transformada de Hough voltada para detecção de faixas de rolagem em pistas e localização de sinais de trânsito, compondo um sistema inteligente para auxílio à direção veicular.

Especificamente em aplicações envolvendo metais, Ying et al. (2010) desenvolveram um método que analisa as extremidades das barras de aço utilizando imagens, a fim de resolver o problema de contagem dessas barras nas fábricas. Martins et al. (2010) apresentam um sistema de inspeção visual para detectar e classificar defeitos em aços laminados, neste trabalho a transformada de Hough é utilizada especificamente para classificar três defeitos com forma geométrica bem definida: solda laminada, grampo e furo de identificação.

$\mathrm{Na}$ técnica de limiarização adaptativa local pelo valor médio, o limiar é calculado em função do valor médio dos níveis de cinza presentes na vizinhança de cada pixel. Em cada janela (máscaras de vizinhança) é calculado um valor de limiar local, aplicado ao pixel analisado. Desta forma, são obtidos limiares distintos em 
cada região da imagem. A principal vantagem do uso desta técnica, em relação ao limiar fixo, é a compensação de variações nas condições de iluminação da cena na qual a imagem foi gerada. Além disso, em alguns casos é possível compensar variações nas condições de iluminação como sombras ou reflexos locais.

Em termos de aplicações, Yazdchi et al. (2009) aplicam a técnica para separar o fundo e o defeito de uma imagem, convertendo-a posteriormente em uma imagem binária através da limiarização. O objetivo é identificar defeitos em superfícies de aço como furos, ferrugem, sujeira na superfície e falhas por recozimento. Em outro tipo de aplicação, Cao et al. (2003) utilizam a técnica do limiar adaptativo para identificação de placas de veículos automotores.

\subsubsection{Estrutura do algoritmo}

No segundo algoritmo elaborado foi identificado que a iluminação ambiente durante a aquisição das imagens interfere no desempenho do algoritmo na etapa de pré-processamento e segmentação. Como a iluminação afeta o corpo de prova como um todo, optou-se neste algoritmo pela realização da adequação dos tons de cinza das imagens a fim de reduzir a interferência causada pela iluminação irregular, antes de sua segmentação nas dimensões pré-definidas no sistema de aquisição (como havia sido praticado no algoritmo anterior).

Desta forma, foi mantida apenas a primeira parte segmentação da imagem que visa reduzir a área analisada da imagem, considerando a característica do defeito da segregação central que ocorre horizontalmente próximo a região central da amostra. O intervalo $[-100 ; 100]$ pixels em relação ao centro da imagem foi selecionado, restringindo assim a região analisada (sem comprometer as informações do defeito da segregação central) e descartando as bordas da imagem, conforme exemplo apresentado na Figura 41. 
Figura 41 - Segmentação inicial da imagem. (a) Imagem original. (b) Imagem segmentada.

(a)

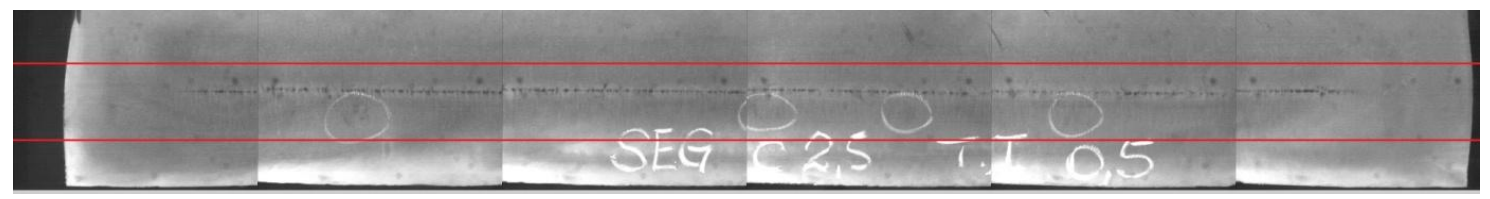

(b)

Em seguida foi realizado o limiar adaptativo local pelo valor médio, utilizando a máscara de vizinhança de $15 \times 15$. A Figura 42 apresenta o resultado da imagem após a limiarização adaptativa.

Figura 42 - Resultado do limiar adaptativo.

Após a realização da limiarização, foi realizada a segmentação da imagem em seções de $640 \times 200$ pixels. A referência de 640 pixels é a mesma referência adotada pelo sistema de aquisição ( 640 × 480 pixels para cada seção) e foi adotada como premissa para realização das segmentações. $O$ valor de 200 pixels, por sua vez corresponde ao intervalo de $[-100 ; 100]$ selecionado no passo anterior do algoritmo.

Conforme observado nos algoritmos anteriores, esta segmentação garante a eliminação das interferências causadas pelo sistema de aquisição durante o processo de concatenação das imagens. A Tabela 5 apresenta as imagens resultantes de cada seção, após a realização desta segmentação. 
Tabela 5 - Imagens Resultantes da segmentação em seções.

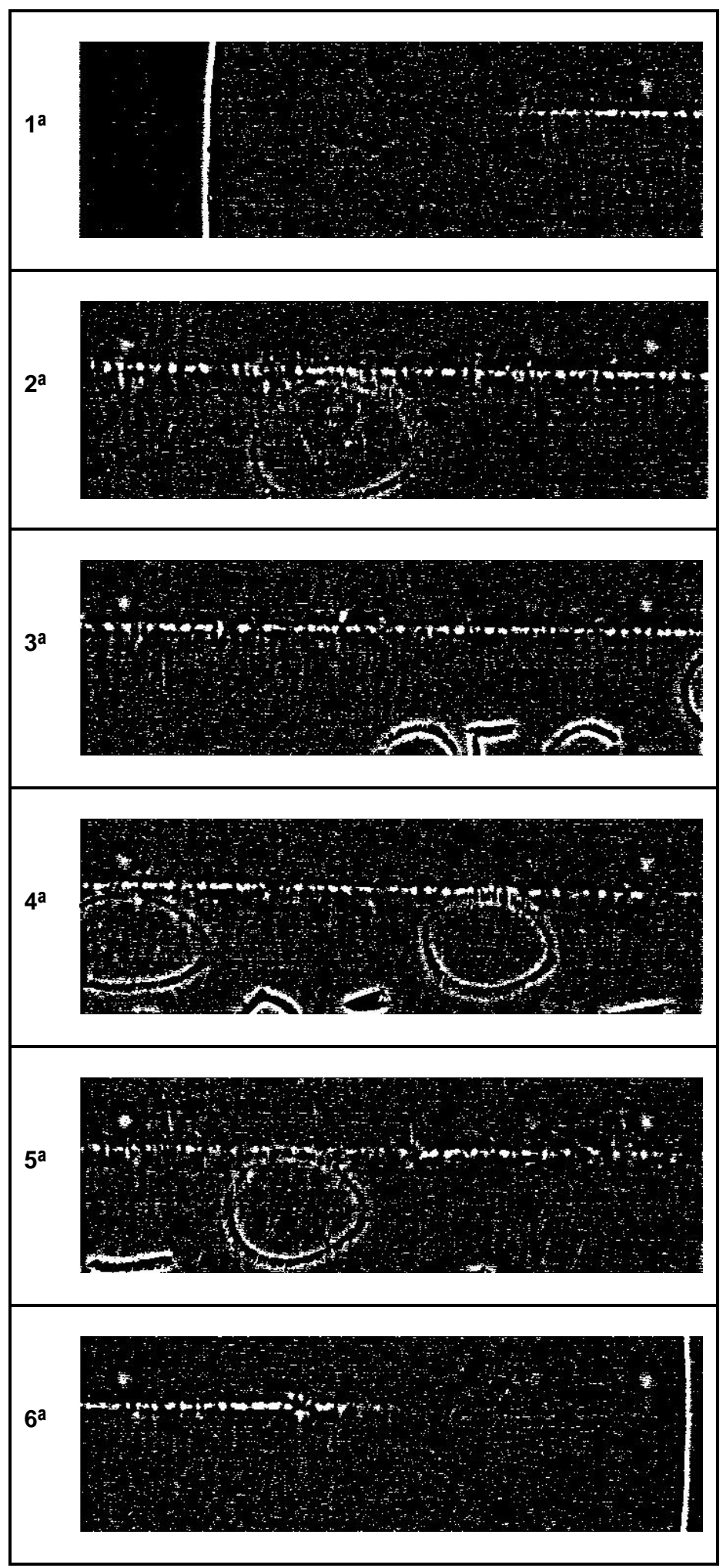

Com base na análise desse cenário, foi aplicada a transformada de Hough em cada seção da imagem, selecionada na etapa anterior. Foram identificadas como retas no espaço da imagem, os pontos no espaço de Hough que são interceptados 
por mais de 100 senóides. As linhas que apresentam ângulo fora do intervalo [160 ; 200] graus foram descartadas, ou seja, somente a linha horizontalmente orientada foi preservada. A Tabela 6 apresenta cada uma das seções destacando em verde a linha identificada pela transformada de Hough.

Tabela 6 - Identificação da linha pela transformada de Hough para cada seção.

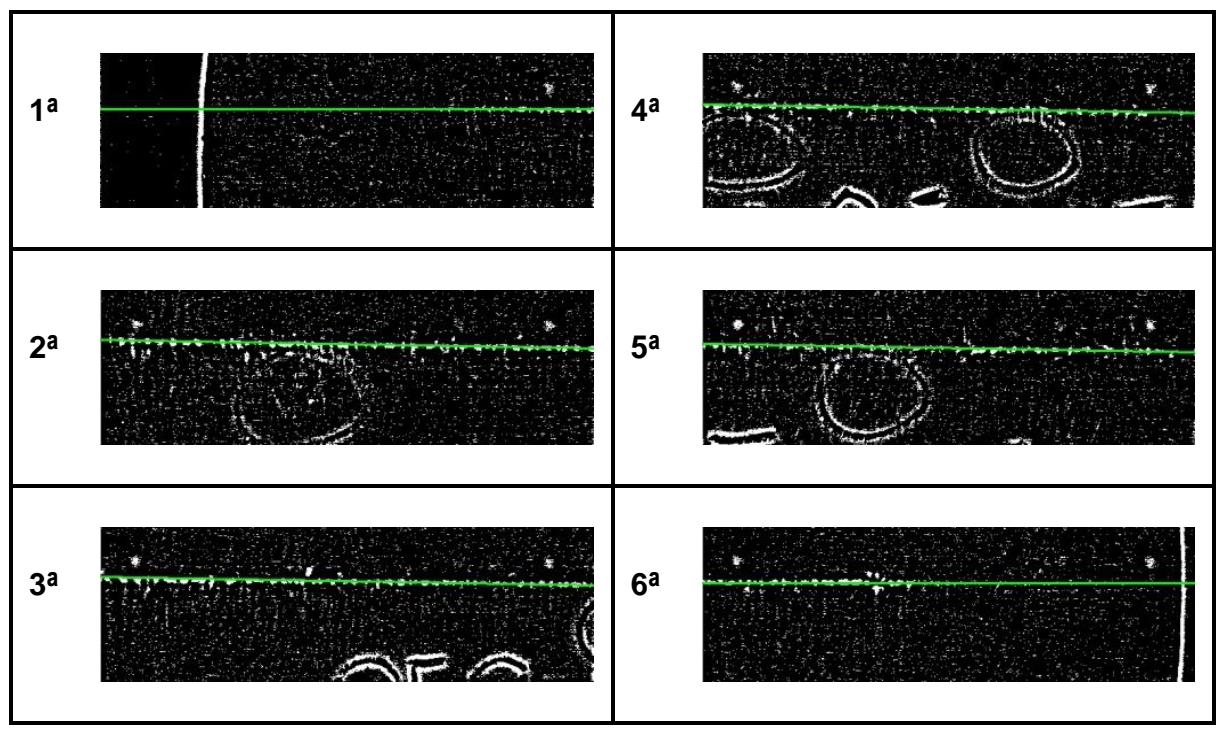

Analisando as seções de forma conjunta, é possível perceber que a inclinação da linha segregada não é continua ao longo do corpo de prova, apresentando um grau de inclinação distinto em cada uma das seções. Esta variação é oriunda do posicionamento do equipamento responsável pela aquisição da imagem em relação à amostra.

Para que tal interferência não comprometa a segmentação da região de interesse da amostra, para cada seção da imagem foi calculada a média do valor do eixo $y$ dos pontos contidos na linha de referência identificada pela transformada de Hough no passo anterior. Baseado neste valor médio encontrado para cada seção foi calculada a média global da imagem. O valor resultante deste calculo foi adotado como referência para a segmentação da imagem considerando o intervalo de [-45; 45]. A Figura 43, apresenta o intervalo selecionado para a terceira seção e a imagem resultante. 
Figura 43 - Segmentação da linha segregada na 3ํㅗㄹ seção. (a) Região selecionada. (b) Imagem resultante.

(a)

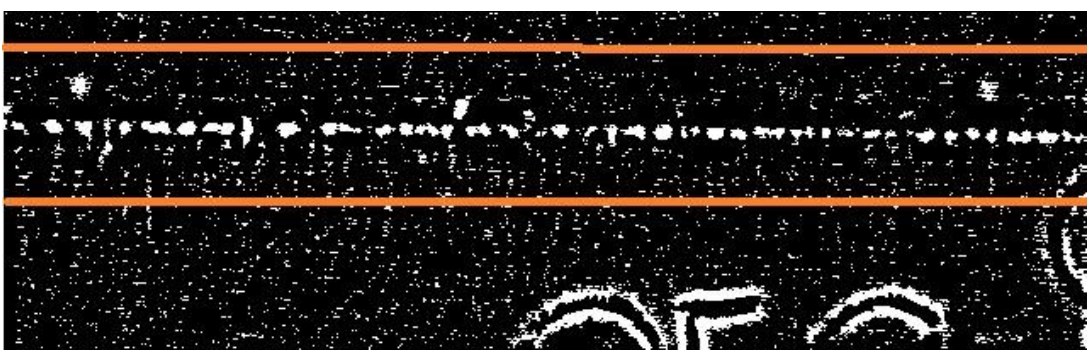

(b)

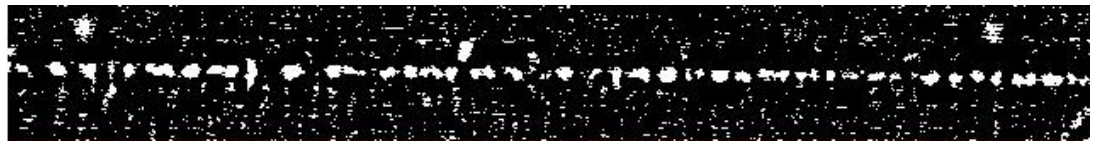

Nesta etapa foi concluída a segmentação da linha segregada proposta por este algoritmo, entretanto, como pode ser observado na Figura 43, existe uma quantidade elevada de ruídos que certamente irão comprometer a identificação e o dimensionamento dos elementos de interesse na próxima etapa do algoritmo. Estes ruídos apresentam-se como pequenos pontos ou manchas dispersas ao longo de toda a imagem. Visando a eliminação destes ruídos, foi realizada a aplicação do filtro da mediana com elemento estruturante de dimensão 3x3 em cada uma das seções. A Figura 44 apresenta a terceira seção antes e depois da aplicação do filtro da mediana.

Figura 44 - Aplicação do filtro da mediana na 3로 seção. (a) Antes. (b) Depois.

(a)

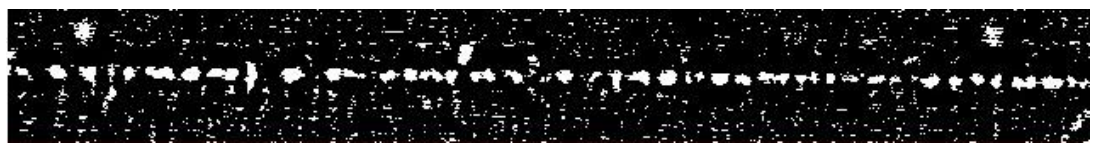

(b)

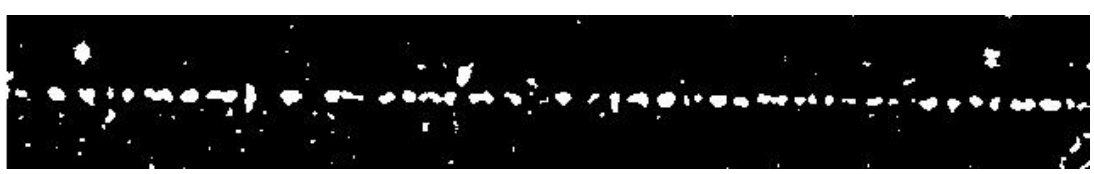

Em seguida, todos os pixels contidos na linha de referência identificada pela transformada de Hough que possuem a cor branca, na imagem resultante do passo anterior, são utilizados como "sementes" para a separação dos elementos de interesse da imagem em relação aos ruídos. Esses pontos são inicialmente identificados na imagem na cor azul e à medida que os componentes conexos (na 
cor branca) destes pontos são identificados, também são convertidos para a cor azul. A Figura 45 apresenta a imagem resultante deste processamento para a terceira seção da imagem.

Figura 45 - Identificação dos elementos da linha segregada (3ª seção).

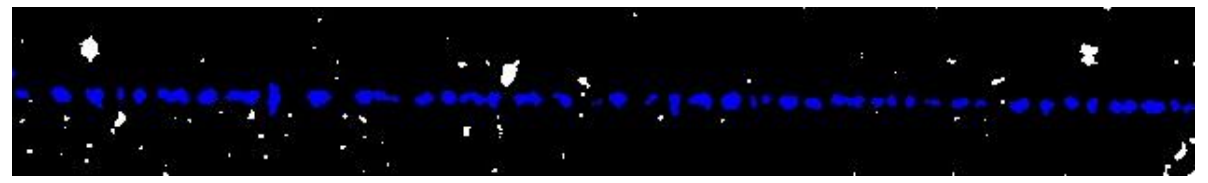

Por último, foi realizada a limiarização de cada seção da imagem, segundo a equação (23), onde $p_{i j}$, representa o pixel analisado na linha $i$ e coluna $j$, caso a cor do pixel de $p_{i j}$ seja igual a azul ( $\left.R G B=0,0,255\right)$, o mesmo será convertido em branco $(R G B=255,255,255)$. Caso contrário o valor de $p_{i j}$ é substituído pelo valor correspondente a cor preta $(R G B=0,0,0)$.

$$
p_{i j}=\left\{\begin{array}{c}
R G B(255,255,255) \text { branco, se } p_{i j}=R G B(0,0,255) \text { azul } \\
R G B(0,0,0) \text { preto, se } p_{i j} \neq R G B(0,0,255) \text { azul }
\end{array}\right.
$$

A Figura 46 apresenta a imagem final obtida para a terceira seção. Como podem ser observados nesta imagem, os ruídos foram eliminados e os elementos de interesse preservados sem comprometer as características de suas respectivas estruturas.

Figura 46 - Imagem resultante do algoritmo 3 (3로 seção).

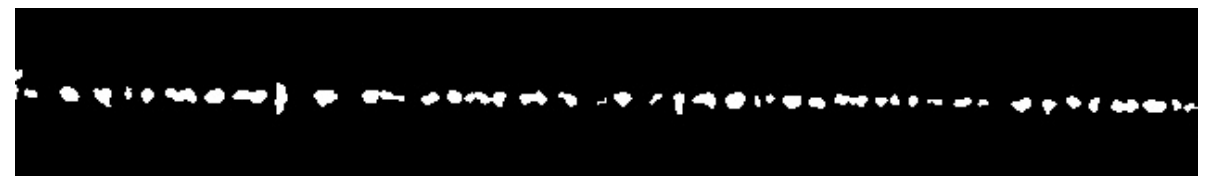

Por último as imagens resultantes de cada seção são concatenadas gerando uma única imagem resultante da etapa de pré-processamento e segmentação do algoritmo. 


\subsubsection{Resultados}

Para avaliar a aplicabilidade dos critérios, o terceiro algoritmo foi implementado contemplando as regras descritas anteriormente e, utilizando para avaliação do desempenho os mesmos critérios de segmentação, assim como o mesmo conjunto de imagens (235) utilizadas nos demais algoritmos. Todas as imagens foram submetidas e processadas individualmente pelo algoritmo que produziu como resultado uma nova imagem, destacando a região selecionada no processo de segmentação.

O algoritmo segmentou corretamente a região da segregação central em 93\% das imagens analisadas, enquanto segmentou parcialmente ou não segmentou corretamente $7 \%$ das imagens. O terceiro algoritmo aumentou em $15 \%$ a segmentação correta em relação ao primeiro algoritmo e em $4 \%$ em relação ao segundo algoritmo.

Figura 47 - Avaliação dos resultados da segmentação do algoritmo 3 por grau de severidade.

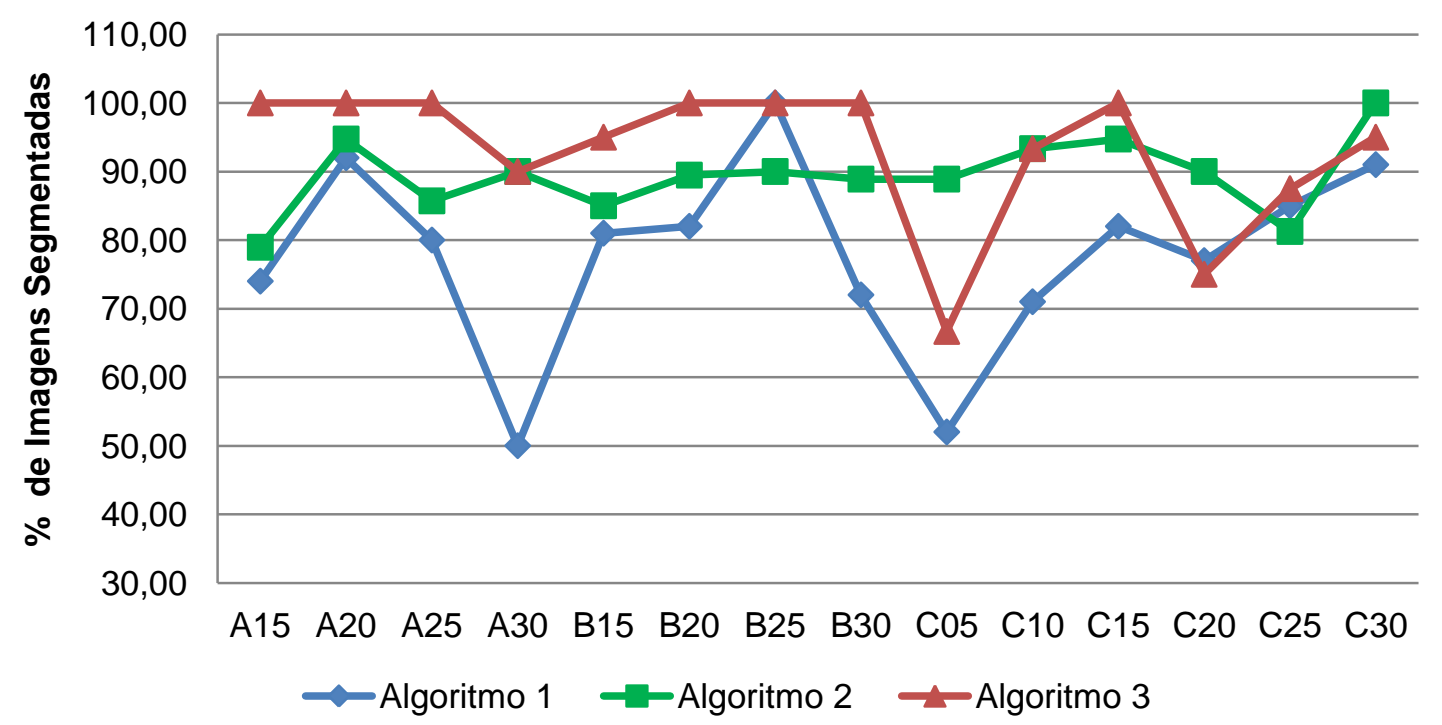

A Figura 47 detalha a diferença entre os resultados obtidos pelo terceiro algoritmo em relação ao primeiro, para cada grau de severidade. Como pode ser observado nesta figura, somente o grau de severidade "C20" apresentou para o terceiro algoritmo um resultado $2 \%$ inferior aos resultados obtidos anteriormente no 
primeiro algoritmo. Em todos os demais graus de severidade houve melhoria nos resultados do terceiro algoritmo em relação ao primeiro.

Adicionalmente, na Figura 47 é possível verificar o desempenho do terceiro algoritmo em relação ao segundo. O terceiro algoritmo apresentou resultados superiores ou iguais ao segundo algoritmo em 11 dos 14 graus de severidade analisados. Desta forma, foi identificada uma melhoria ainda mais expressiva na segmentação correta das imagens pelo terceiro algoritmo.

Ao analisar as imagens que não foram segmentadas corretamente, não foi possível identificar características em comum que pudessem ser diretamente correlacionadas aos ruídos observados. Em relação à identificação dos objetos de interesse que serão analisados na próxima fase do algoritmo, foi observado que a estrutura dos elementos foi preservada, e uma quantidade pequena de ruídos foram observadas.

O terceiro algoritmo desenvolvido foi capaz de aumentar expressivamente a quantidade de imagens segmentadas corretamente, além de reduzir significativamente a quantidade de ruídos/interferências que poderiam influenciar negativamente o desempenho da fase seguinte de extração de características e classificação. Desta forma conclui-se que o terceiro algoritmo está adequado para a realização da próxima fase. 


\section{EXTRAÇÃO DE CARACTERÍSTICAS E CLASSIFICAÇÃO}

Neste capítulo é apresentada a segunda fase de implementação do algoritmo que contempla as etapas de extração de características e classificação das imagens. A etapa de extração de características ou propriedades visa à obtenção de atributos que possam ser utilizados na discriminação entre classes de objetos. Essas características são, em geral, descritas por atributos numéricos que formam vetores de características (SANDHAR; PHONSA, 2014). É importante observar que nesta etapa a entrada ainda é uma imagem, mas a saída é o conjunto de dados que correspondem à imagem (MARQUES; VIEIRA, 1999, p. 10).

A etapa de classificação, por sua vez, pode ser dividida em reconhecimento e interpretação dos componentes de uma imagem. O processo de atribuição de um rótulo a um objeto baseado em suas características ou atributos, traduzidas por seus descritores, denomina-se reconhecimento. A tarefa de interpretação, por outro lado, consiste em atribuir significado a um conjunto de objetos já reconhecidos (MARQUES; VIEIRA, 1999, p. 10).

\subsection{Extração de Características}

Após a etapa de segmentação da imagem em regiões ou objetos de interesse, os segmentos obtidos são representados e descritos em um formato adequado para a etapa de processamento seguinte. A descrição destes objetos depende da representação adotada e deve permitir sua identificação sem ambiguidades, utilizando um número reduzido de características ou medidas extraídas do mesmo (NUNES; CONCI, 2007).

Gomes (2001) explica que existem basicamente duas classes de medidas para descrição dos objetos da imagem. A primeira quantifica os atributos da imagem como um todo, por exemplo, número de objetos, área total de objetos, entre outros. A segunda, por sua vez, esta associada aos atributos da região de interesse que se 
referem aos objetos independentemente, por exemplo, área, perímetro, forma e entre outros. Os atributos de região podem ser muito sofisticados, permitindo uma nova separação dos objetos em classes de similaridades, em função dos parâmetros medidos.

Baseada na imagem resultante da primeira fase do algoritmo (préprocessamento e segmentação) foram extraídos os seguintes atributos da imagem:

- Atributos da região (objeto): Para cada elemento/objeto identificado na imagem foram calculadas as características abaixo, ilustradas na Figura 48:

Figura 48 - Atributos do objeto.
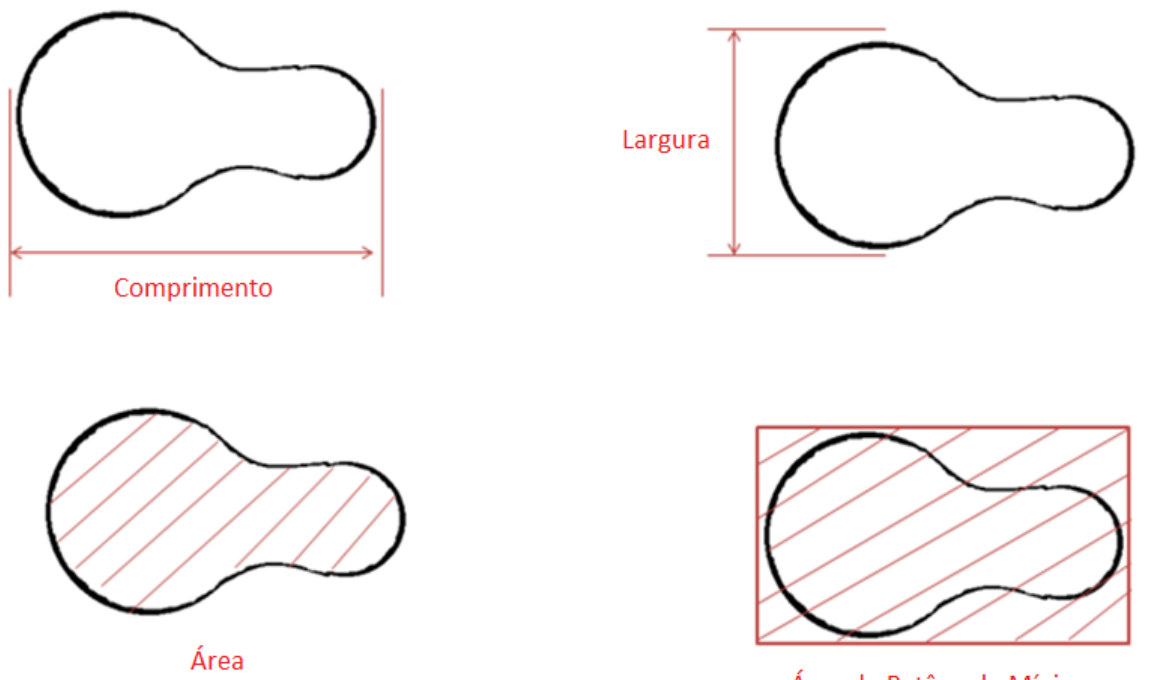

Área do Retângulo Mínimo

a) Comprimento: maior quantidade de pixels orientados horizontalmente em relação ao eixo do objeto.

b) Largura: maior quantidade de pixels orientados perpendicularmente ao comprimento.

c) Área: quantidade de pixels que fazem parte do objeto analisado.

d) Área do retângulo mínimo: quantidade pixels que fazem parte do menor retângulo que contém o objeto.

e) Excentricidade: é a relação entre o comprimento e a largura do objeto. Essa relação pode ser expressa pela equação (24). 


$$
\text { Excentricidade }=\frac{\text { Comprimento }}{\text { Largura }}
$$

- Atributos da imagem: Os atributos abaixo relacionados foram obtidos através dos atributos dos objetos analisado em relação à imagem como um todo.

a) Quantidade de Objetos: Corresponde ao número total de objetos identificados na imagem.

b) Maior comprimento: maior comprimento dentre todos os objetos da imagem.

c) Comprimento Médio: média aritmética do comprimento dos objetos em relação à quantidade de objetos da imagem.

d) \% de Continuidade: Corresponde ao valor percentual da somatória do comprimento dos objetos da imagem dividida pelo número total de colunas (comprimento) da imagem.

e) Largura Média: média aritmética da largura dos objetos em relação a quantidade de objetos da imagem.

f) Maior área: maior área dentre todos os objetos da imagem.

Nesta etapa, o algoritmo desenvolvido na primeira fase de implementação, foi modificado para que todos os atributos dos objetos e da imagem acima mencionados, fossem identificados, calculados e armazenados em arquivo texto. Os dados obtidos através desses atributos foram posteriormente analisados a fim de identificar regras que pudessem ser adotadas no processo de classificação das imagens nos respectivos graus de severidade da segregação central. Para a classificação do critério de continuidade foram utilizados os atributos de maior comprimento, comprimento médio e \% de continuidade. Para a classificação do critério de intensidade foram utilizados os atributos de maior área, maior comprimento e largura média. 


\subsection{Classificação}

A etapa de classificação visa determinar formas de mapeamento que sejam capazes de correlacionar os atributos extraídos das amostras com os rótulos ou classes analisadas. É importante ressaltar que as amostras que possuem atributos semelhantes devem ser mapeadas na mesma classe. Diversas abordagens podem ser adotadas para a realização deste mapeamento. Neste trabalho foi adotada a abordagem estatística, na qual cada amostra é representada em função de suas características ou atributos, expressas por meio de medidas.

O mapeamento foi definido através dos atributos extraídos das imagens do padrão de referência NSC. Para a obtenção destes atributos, foram submetidas ao algoritmo 30 imagens do padrão de referência, distribuídas nos diferentes graus de severidade. Todas as imagens foram corretamente segmentadas e o arquivo texto com as características acima foi gerado, visando à análise e o mapeamento dos atributos. A Figura 49 apresenta alguns exemplos de imagens do padrão de referência.

Figura 49 - Padrão de referência.

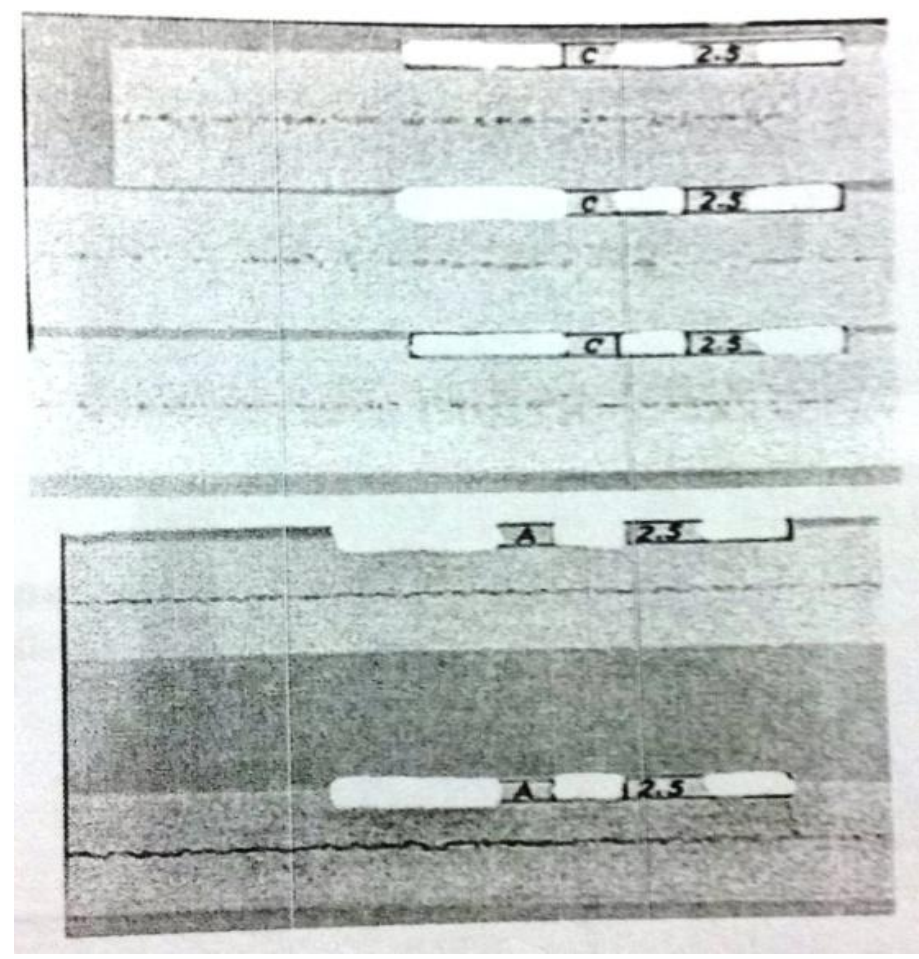

Fonte: FURTADO (2007). 
A segregação central é classificada em função de dois critérios: continuidade e intensidade. Estes critérios foram analisados separadamente. As seções seguintes detalham a análise realizada para o mapeamento dos atributos correlacionados a cada critério de classificação.

\subsubsection{Critério: Continuidade}

O critério de continuidade é classificado através das letras "A" (linha pronunciada uniforme e contínua), "B" (linha pronunciada, porém não uniforme disposta na forma de traços mais alongados) ou "C" (pontos não uniformes irregularmente formados). Em função das características dessas três classes, observou-se que o critério de continuidade está fortemente associado ao comprimento individual dos objetos (linha, traço ou ponto) em relação à imagem como um todo.

Durante a análise do atributo do objeto de maior comprimento em relação ao atributo da maior área dos objetos da imagem foi observada que as classes do critério de continuidade são separáveis. A Figura 50 apresenta a dispersão desses atributos em relação às imagens do padrão de referência processadas pelo algoritmo.

Figura 50 - Distribuição dos atributos dos objetos de maior comprimento e maior área.

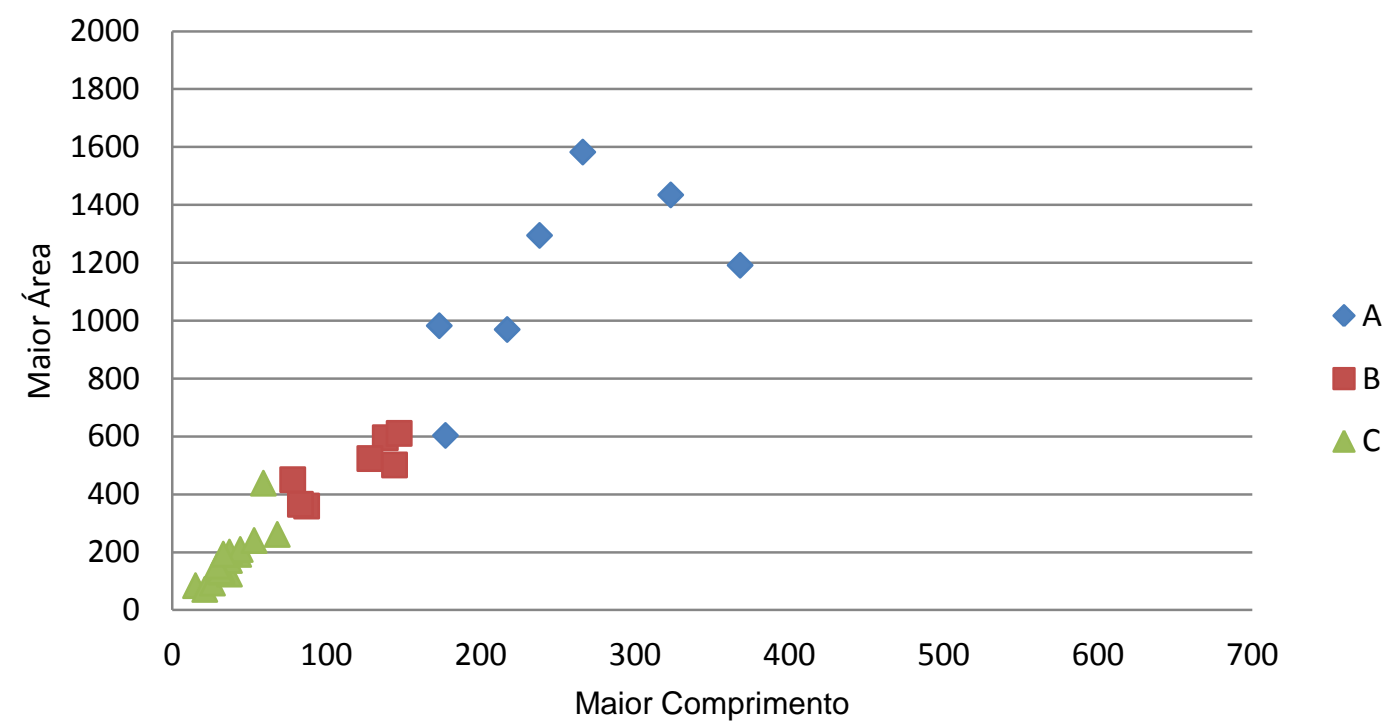


Nota-se que existe separabilidade entre as classes em função do atributo do objeto de "maior comprimento", entretanto a proximidade dos valores nas transições entre as classes de "A" para B" e "B" para "C", dificulta o processo de classificação, tornando necessária a existência de outros critérios que possam apoiar este processo.

Aprofundando na análise das características da segregação central nessas situações, sabe-se que as amostras classificadas como " $\mathrm{C}$ " tendem a possuir uma quantidade elevada de objetos com comprimento reduzido, em função de seu aspecto de "pontos não uniformes". A classe "B", por sua vez, apresenta-se com uma quantidade menor de objetos com comprimento maior, uma vez que se apresenta com aspecto de "traços mais alongados". Desta forma, o comprimento médio dos objetos de 11 pixels foi adotado como critério secundário de classificação, a fim de auxiliar a separação das amostras entre os critérios "B" e "C".

De forma similar, analisando as características da classe "A", sabe-se que essa classe é caracterizada por "linhas contínuas e uniformes", logo as imagens que apresentam o atributo de "maior comprimento" elevado são facilmente classificadas neste grau de severidade. Entretanto, ocorrem casos nos quais apenas um segmento da imagem apresenta um grau maior de severidade. Nestes casos prevalece para a imagem como um todo a classificação mais severa e são justamente essas situações que dificultam a classificação entre as classes "A" e "B", necessitando de um critério secundário.

A classe "B" é caracterizada por muitos segmentos contínuos (traços) não uniformes, fazendo com que do ponto de vista global da imagem o percentual de continuidade seja maior em relação ao comprimento total da imagem. A classe "A", por sua vez, no caso específico de classificação pelo segmento da imagem mais restritivo, possui poucos objetos contínuos, tornando o percentual de continuidade menor em relação ao comprimento total da imagem. Tendo em vista estas características, foi adotado como critério secundário de classificação o percentual de continuidade de $51 \%$ como critério de distinção entre essas duas classes. 
A Tabela 7 apresenta o critério principal e secundário, definidos para a classificação do critério da continuidade.

Tabela 7 - Mapeamento dos atributos no critério de continuidade.

\begin{tabular}{|c|c|c|}
\hline Faixa do Maior Comprimento & Critério secundário & Classificação \\
\hline Maior que $170 \mathrm{px}$ & - & $A$ \\
\hline \multirow{2}{*}{ De 156 à 170px } & $\%$ Continuidade $<=51 \%$ & $A$ \\
\hline & $\%$ Continuidade $>51 \%$ & $B$ \\
\hline De 98 à $156 p x$ & - & $B$ \\
\hline \multirow{2}{*}{ De 70 à 98 px } & Comprimento Médio > 11 px & $B$ \\
\hline & Comprimento Médio <= $11 \mathrm{px}$ & C \\
\hline Menor que $70 \mathrm{px}$ & - & $\mathrm{C}$ \\
\hline
\end{tabular}

A ausência ou presença mínima de segregação central é classificada com o grau "C". Caso o algoritmo não seja capaz de identificar e segmentar a linha segregada nas etapas de pré-processamento e segmentação, será atribuído o grau "C" para a imagem, uma vez que caracteriza a inexistência de segregação central. Em contrapartida, caso seja identificada a presença mínima de segregação certamente o atributo do maior comprimento será inferior a 70 pixels classificando a imagem com o grau "C";

\subsubsection{Critério: Intensidade}

O critério de intensidade é classificado de acordo com a dimensão da segregação central, medida em relação à espessura da linha segregada da placa com valores que variam de 0,0 a 3,0 em intervalos de 0,5. É importante ressaltar que as classes de continuidade "A" e "B" iniciam em 1,5, enquanto a classe "C" inicia em 0,0 .

Para a classe de severidade "C00", que indica o grau 0,0 de intensidade, ou seja, a ausência do defeito da segregação central foi considerado o mapeamento do atributo da largura média dos objetos menor ou igual a um pixel para a classificação da intensidade "00". 
Inicialmente, ao analisar os aspectos envolvidos para a classificação do critério de intensidade, acreditava-se que esta classificação estava relacionada aos atributos de largura dos objetos, de forma similar a influência exercida pelo atributo de comprimento no critério de continuidade. Entretanto, ao analisar os dados obtidos da etapa de extração de características, verificou-se que os atributos de largura não eram separáveis nas classes de severidade do critério de intensidade.

Em função deste cenário, os demais atributos da imagem foram analisados. Observou-se que, caso seja realizado o mapeamento prévio das imagens de acordo com a classificação adotada para o critério de continuidade, é possível realizar a separação aproximada do critério de intensidade através dos demais atributos. Descreve-se a seguir o mapeamento adotado para classificação do critério intensidade de acordo com cada classificação de continuidade.

\section{a) Classe "A"}

Ao analisar o comportamento dos atributos de "Maior comprimento" e "Maior área" das imagens classificadas com o critério de continuidade "A", foi possível identificar um comportamento em comum para cada classe de intensidade, conforme ilustra a Figura 51.

Figura 51 - Classe A: Distribuição dos atributos para o critério de intensidade.

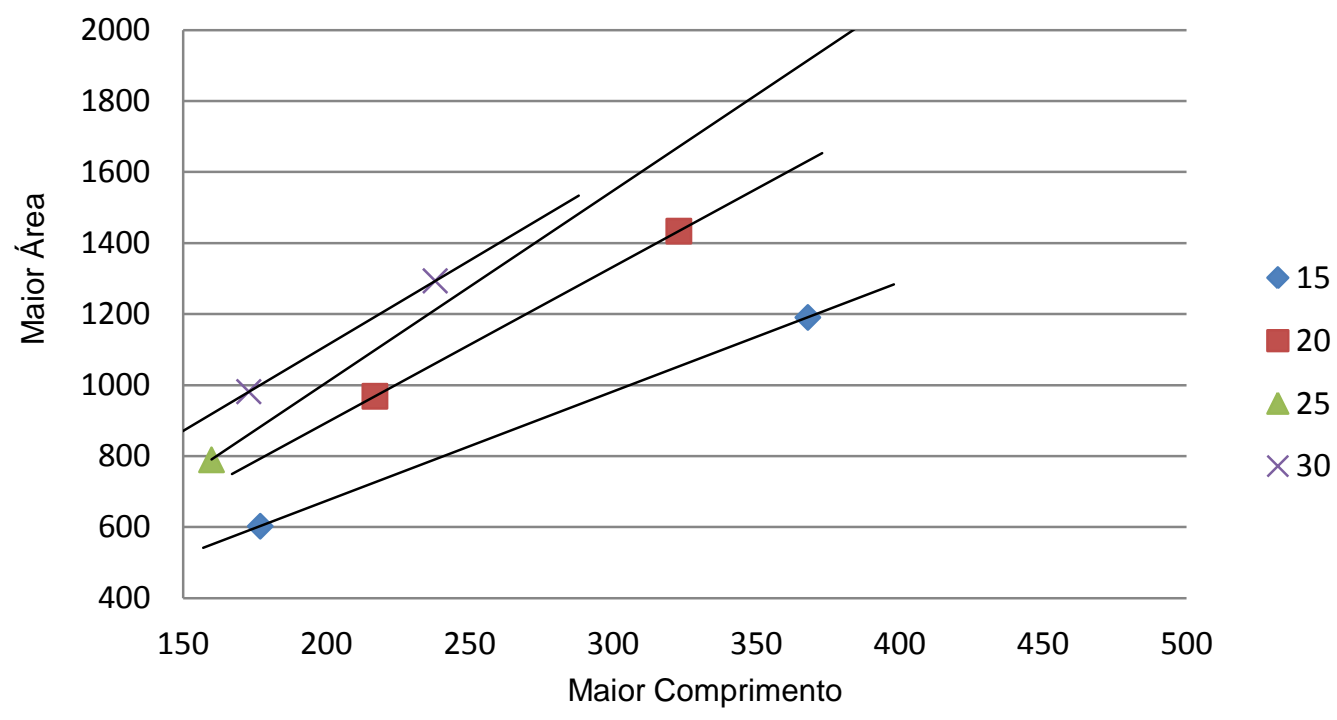


Este comportamento pode ser descrito para cada classe de intensidade através das equações lineares apresentadas na Tabela 8, na qual $x$ representa 0 atributo de maior comprimento e yo atributo de maior área.

Tabela 8- Classe A: Mapeamento dos atributos para o critério de intensidade.

\begin{tabular}{|cc|}
\hline Classe & Equação \\
\hline 15 & $y=3,0785 x+58,099$ \\
\hline 20 & $y=4,3868 x+17,066$ \\
\hline 25 & $y=5,4491 x-116,79$ \\
\hline 30 & $y=4,8 x+151,6$ \\
\hline
\end{tabular}

Desta forma, o mapeamento estimado do critério de intensidade é realizado através da aplicação dos atributos de maior comprimento e maior área de uma determinada imagem, em todas as equações relacionadas acima. A classificação de intensidade atribuída à imagem corresponde ao menor resultado absoluto das equações, obtido dentre todas as classes de intensidade.

\section{b) Classe "B"}

Ao analisar o comportamento dos atributos de "Largura média" e "Maior comprimento" das imagens classificadas com o critério de continuidade "B", foi possível identificar que as classes de intensidade são separáveis, como ilustra a Figura 52.

Figura 52 - Classe B: Distribuição dos atributos para o critério de intensidade.

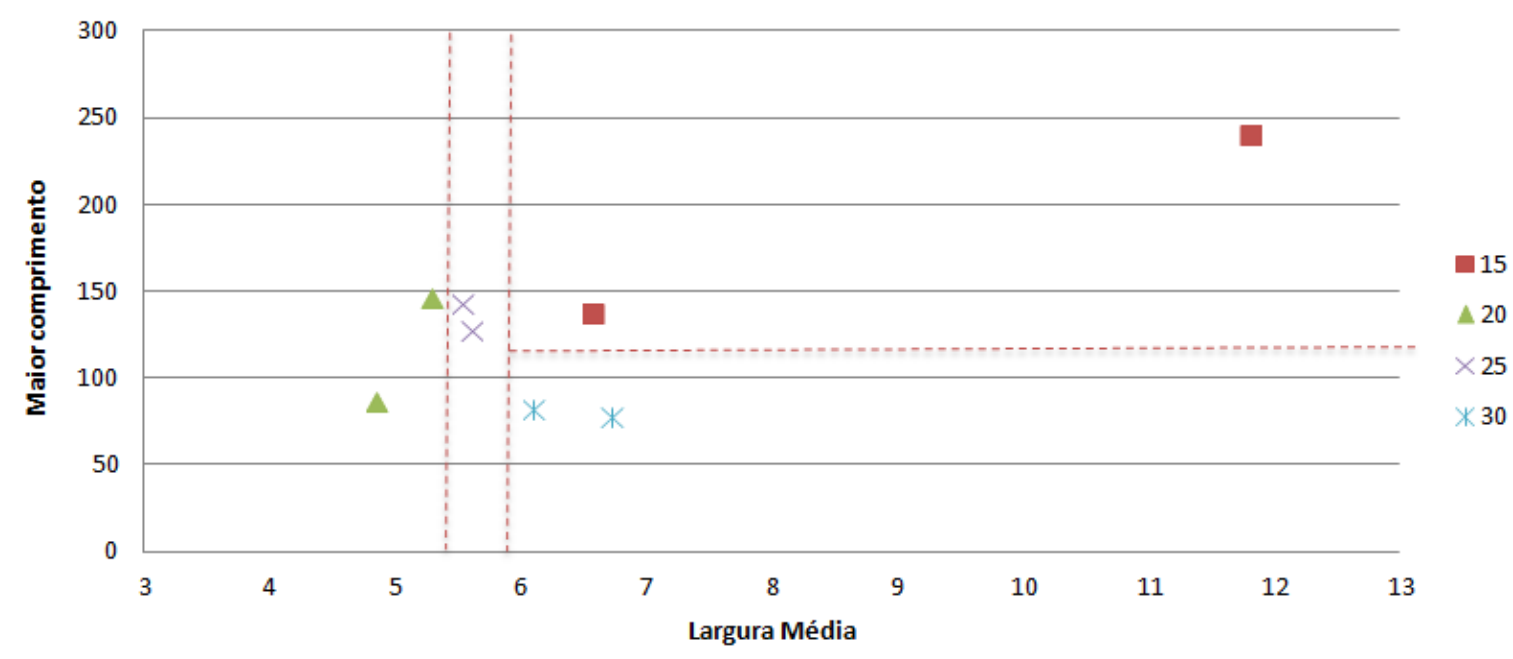


O critério primário para o mapeamento da imagem nas classes de intensidade está associado ao atributo da largura média, enquanto o atributo do maior comprimento está associado ao critério secundário, conforme Tabela 9.

Tabela 9- Classe B: Mapeamento dos atributos para o critério de intensidade.

\begin{tabular}{|clc|}
\hline Faixa Largura Média & Critério secundário & Classificação \\
\hline Menor que 5,5 px & - & 20 \\
\hline De 5,5 à 6 px & - & 25 \\
\hline \multirow{2}{*}{ Maior que 6 px } & Maior comprimento > 110 px & 15 \\
\cline { 2 - 3 } & Maior comprimento <= $110 \mathrm{px}$ & 30 \\
\hline
\end{tabular}

c) Classe "C"

Ao analisar o comportamento dos atributos de "Maior comprimento" e "Maior área" das imagens classificadas com o critério de continuidade "C", foi possível identificar a separabilidade para classes "05", "10" e "15". Para as classes "20","25" e "30" foi possível identificar um comportamento em comum, conforme ilustra a Figura 53.

Figura 53 - Classe C: Distribuição dos atributos para o critério de intensidade.

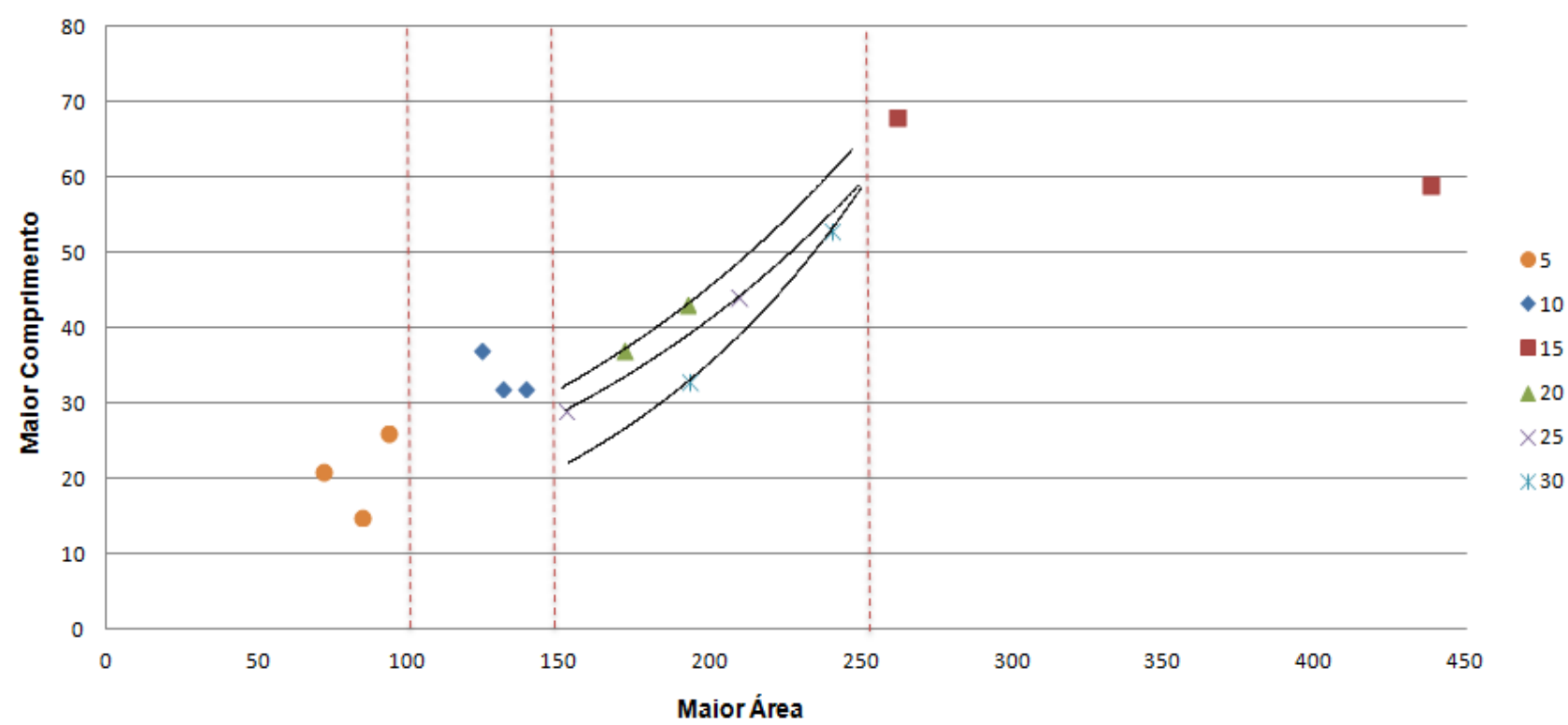


O critério primário para o mapeamento da imagem nas classes de intensidade está associado ao atributo da maior área. Para o critério secundário, foi adotado uma estimativa das classes "20", "25" e "30". O comportamento dessas classes pode ser descrito através das equações exponenciais apresentadas na Tabela 10, na qual $x$ representa o atributo de maior comprimento e $y$ o atributo de maior área.

Tabela 10- Classe C: Mapeamento dos atributos para o critério de intensidade.

\begin{tabular}{|clc|}
\hline Faixa do Maior Área & Critério secundário & Classificação \\
\hline Menor $\mathbf{1 0 0} \mathbf{p x}$ & - & 05 \\
\hline De $\mathbf{1 0 0}$ à $\mathbf{1 5 0} \mathbf{p x}$ & - & 10 \\
\hline \multirow{2}{*}{ De $\mathbf{1 5 0}$ à $\mathbf{2 5 0} \mathbf{p x}$} & $y=10,883 e^{0,0072 x}$ & 20 \\
\cline { 2 - 3 } & $y=9,5408 e^{0,0073 x}$ & 25 \\
\cline { 2 - 3 } & $y=4,716 e^{0,0101 x}$ & 30 \\
\hline Maior 250 px & - & 15 \\
\hline
\end{tabular}

A classificação da imagem é realizada pela faixa de classificação do critério primário. Nos casos onde também é necessária a classificação pelo critério secundário, o mapeamento estimado é realizado através da aplicação dos atributos de maior comprimento e maior área nas equações das classes de intensidade "20", "25" e "30". Para estes casos, a classificação de intensidade da imagem corresponde ao menor resultado absoluto obtido dentre as equações analisadas.

\subsection{Algoritmo de Classificação}

A implementação do algoritmo foi realizada na linguagem $\mathrm{C}++$ utilizando o compilador Visual C++ 2013 Express Edition (MICROSOFT, 2014) e a biblioteca OpenCV (Open Source Computer Vision Library) versão 2.4.11 (OpenCV, 2015). O algoritmo de classificação inclui os passos descritos no algoritmo 3 (para a etapa de pré-processamento e segmentação), a extração e quantificação dos atributos (conforme descritos no item 5.1) e as regras mapeadas para a atribuição da 
classificação, de acordo com o padrão de referência nos critérios de continuidade e intensidade estabelecidos para o algoritmo.

$\mathrm{Na}$ primeira validação do algoritmo de classificação foram submetidas 30 imagens digitalizadas do padrão de referência NSC, distribuídas nos diferentes graus de severidade ao algoritmo. O objetivo desta avaliação é a verificação do grau de aderência do algoritmo implementado ao padrão de classificação NSC. Na avaliação, o resultado da classificação atribuída pelo algoritmo foi comparado a classificação pré-existente do padrão de referência. Todas as imagens submetidas ao algoritmo foram classificadas corretamente.

É importante ressaltar que as imagens submetidas nesta validação, foram às mesmas imagens analisadas para o mapeamento dos atributos utilizados na definição das regras de classificação. Desta forma, a correta classificação de $100 \%$ das imagens (do padrão de referência) submetidas ao algoritmo era esperada e comprova a correta implementação do algoritmo em relação aos critérios de mapeamento pré-definidos.

Na sequência, foram submetidas ao algoritmo as 255 imagens das amostras de Baumann utilizadas anteriormente na validação da primeira fase de implementação (pré-processamento e segmentação). Nesta avaliação os critérios de classificação da segregação central (continuidade e intensidade) foram analisados separadamente. Ambos critérios foram avaliados através do método de contagem simples, no qual foi verificada a porcentagem de acerto na classificação, ou seja, a porcentagem de amostras nas quais o algoritmo foi capaz de indicar corretamente o grau de severidade em relação à classificação realizada pelo especialista.

No algoritmo foi obtida a correta classificação do critério de continuidade em $92 \%$ das amostras, enquanto $8 \%$ das amostras foram associadas às classes de severidade diferentes do esperado. Analisando as causas do desvio de $8 \%$ na classificação do critério de continuidade, observou-se que em $7 \%$ das amostras a linha segregada não foi identificada e segmentada corretamente pelo algoritmo na etapa de pré-processamento e segmentação, enquanto em $1 \%$ das amostras a linha 
segregada foi identificada, porém o critério de continuidade foi classificado incorretamente.

A Figura 54 apresenta os percentuais obtidos na classificação das amostras, em função de cada grau de severidade ("A", "B" e "C"), analisado para o critério de continuidade.

Figura 54 - Resultado do critério de continuidade.

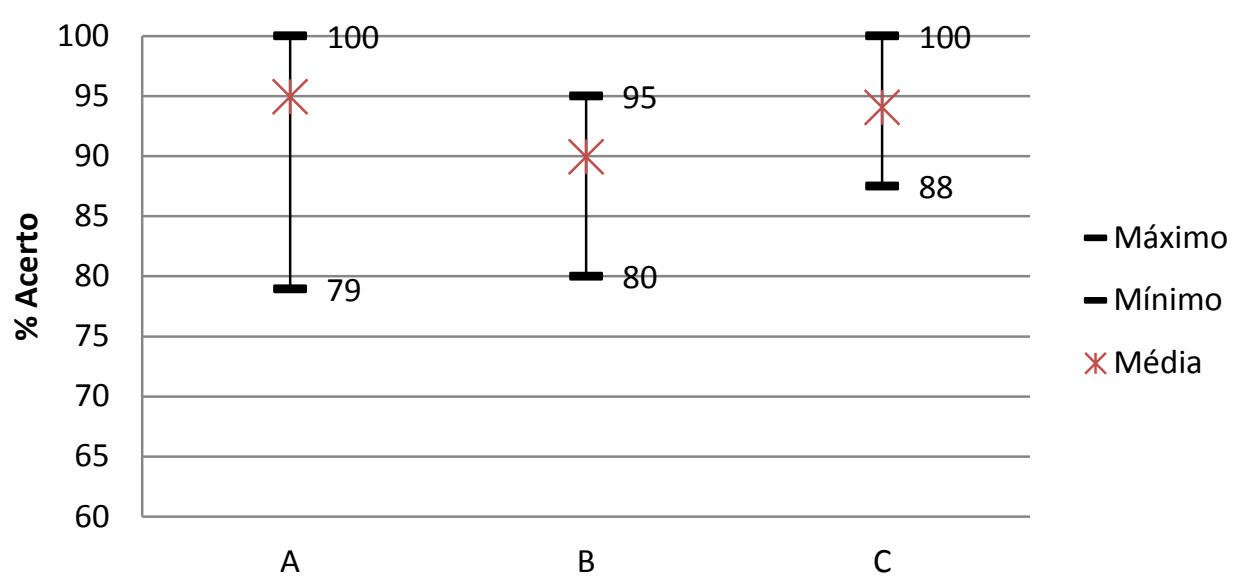

Os critérios "A" e "C" apresentam as melhores médias de acerto (95\% e 94\% respectivamente). Estes resultados estão diretamente relacionados as características bem definidas de cada grau de severidade, visto que a classe "A" caracteriza-se por uma "linha pronunciada uniforme e contínua", enquanto a classe "C" é caracterizada por "pontos não uniformes irregularmente formados". Desta forma, a segregação que se apresenta como linhas ou pontos são mais bem identificadas e classificadas pelo algoritmo.

A classe "B", por sua vez, possui uma média de acerto de $90 \%$, inferior as outras classes. Isso deve-se ao fato de que este grau de severidade tem como característica uma "linha pronunciada, porém não uniforme disposta na forma de traços mais alongados", o que dificulta a determinação na classificação da continuidade em relação as demais classes.

Em todas as classes de severidade, observou-se que os menores resultados de classificação estão relacionados a interferências de marcas (corte e lixamento) na 
imagem. Embora as interferências dessas marcas sejam minimizadas pelo algoritmo, há casos em que o elevado nível de interferência compromete a classificação. Isto ocorre quando as marcas estão situadas próximas (conectadas) aos elementos que compõe a linha segregada, como mostram as Figura 55 e Figura 56, fazendo com que o algoritmo interprete uma descontinuidade inexistente (para as marcas de lixamento) ou uma continuidade inexistente (para as marcas de corte). Tais interferências fazem com que as imagens sejam classificadas em classes distintas da classe correta. Desta forma, conclui-se que o desempenho da classificação pelo critério de continuidade está diretamente relacionado à qualidade da imagem resultante das etapas de pré-processamento e segmentação.

Figura 55 - Marcas de lixamento.

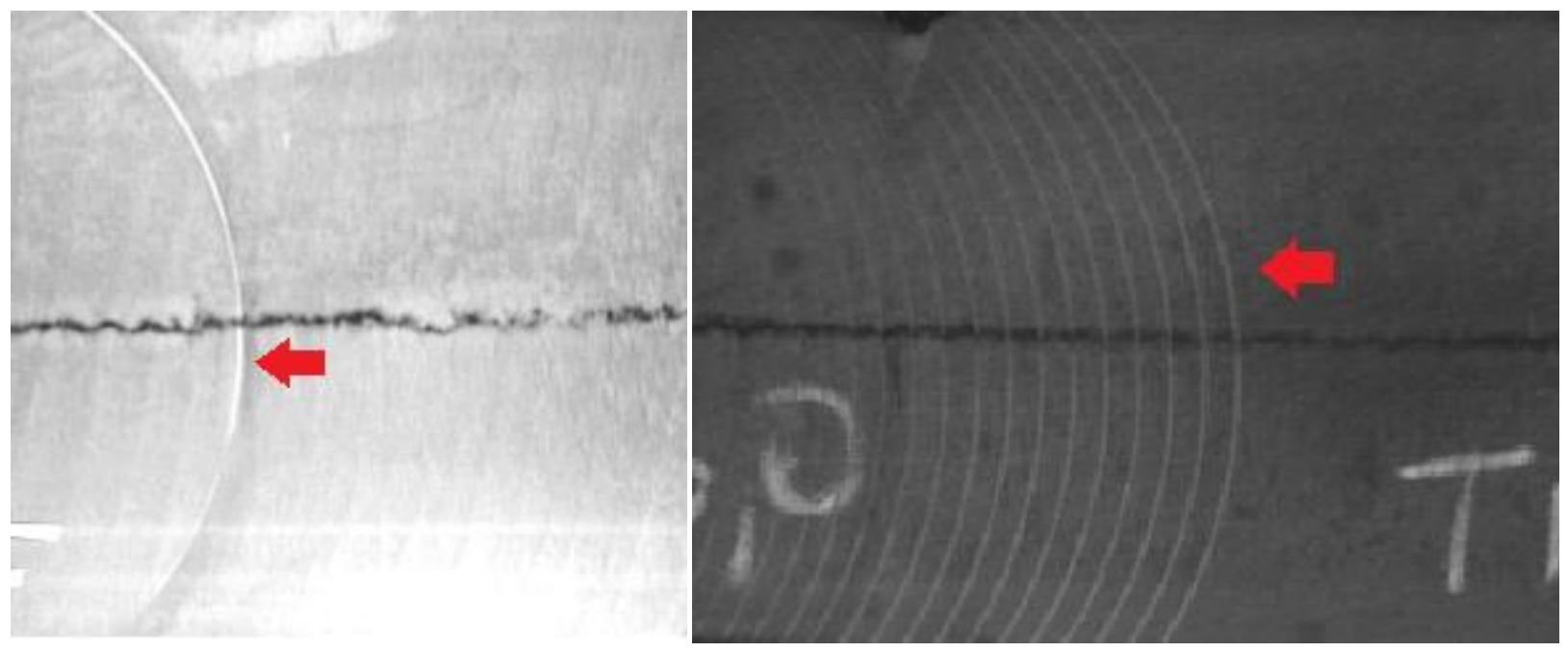

Figura 56 - Marca de corte

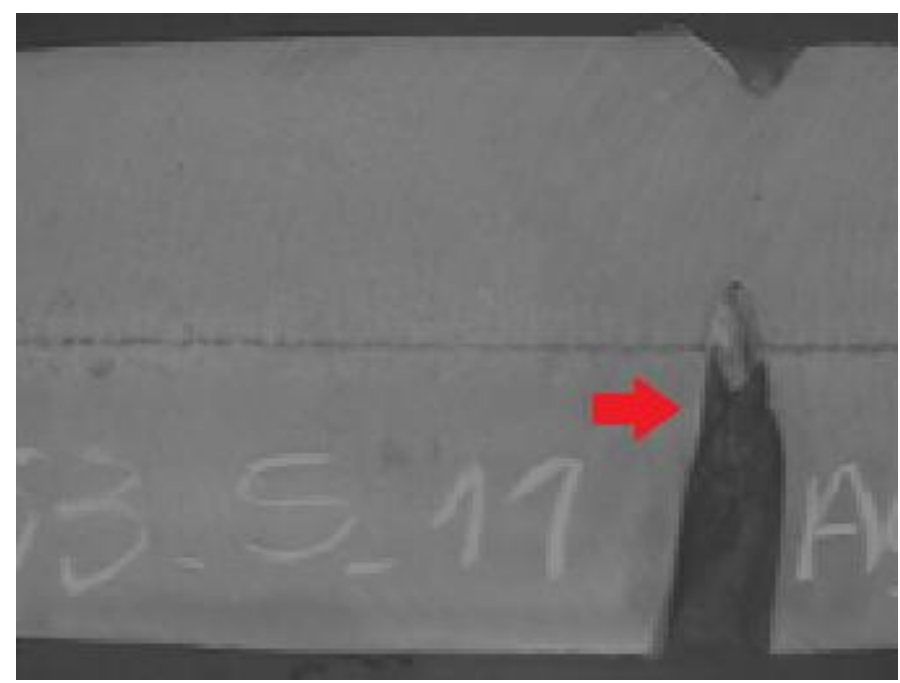


Em relação ao critério de intensidade foi avaliado o acerto global do algoritmo, considerando a porcentagem de acerto na classificação simultânea dos dois critérios (continuidade e intensidade). Em função da baixa separabilidade do critério de intensidade, o mapeamento estimado dos atributos para o critério de intensidade foi vinculado à classificação prévia do critério de continuidade, logo se torna irrelevante a análise individual do critério de intensidade.

No algoritmo foi obtida a correta classificação de $68 \%$ das amostras, considerando o acerto simultâneo nos critérios de classificação analisados. A Figura 57 apresenta os percentuais obtidos para cada grau de severidade.

Figura 57 - Resultados do critério de continuidade e intensidade.

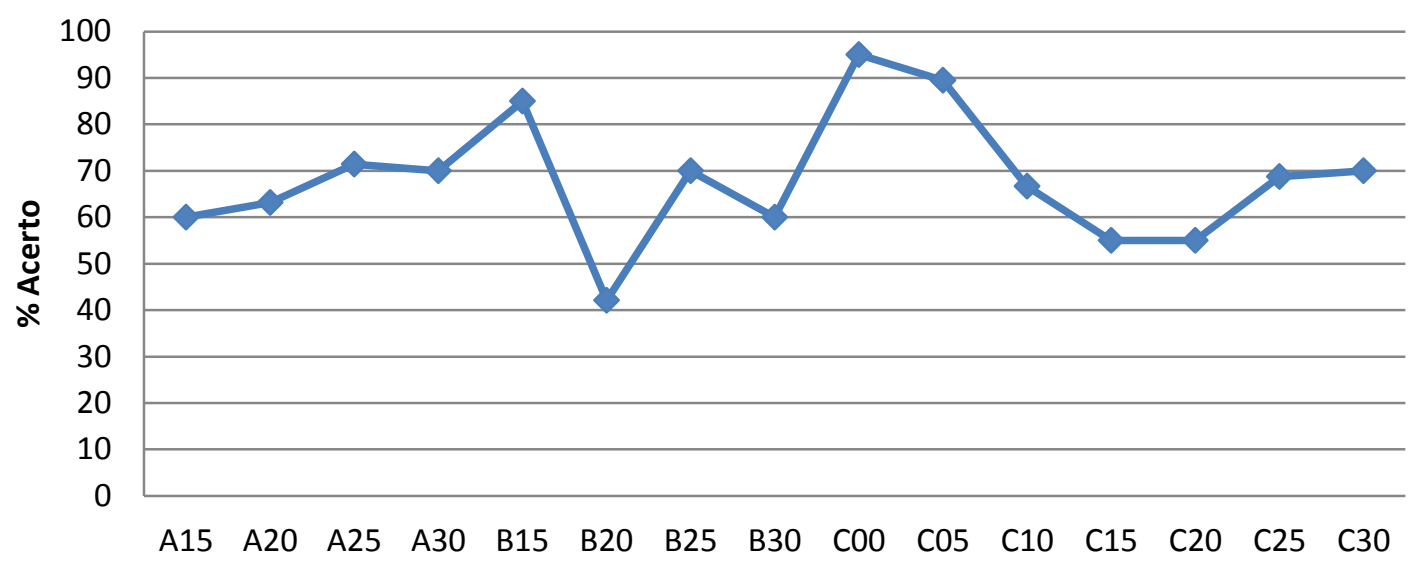

Observou-se que a baixa separabilidade entre os atributos dos objetos no critério de intensidade está relacionada a dois aspectos distintos. O primeiro referese à qualidade da imagem. As imagens disponibilizadas pelo sistema de aquisição, para a realização deste estudo, apresentam-se com baixa resolução (96 dpi), o que compromete a extração de informações da imagem para a classificação do critério intensidade. Apesar dos esforços implementados no algoritmo para preservação das características estruturais dos elementos que compõe a linha segregada, observouse que a baixa resolução das imagens compromete a qualidade das informações extraídas dos atributos.

No segundo aspecto, por sua vez, foi observado que a classificação do critério de intensidade realizada pelo especialista não considera somente as 
características dimensionais dos elementos segregados em sua avaliação. Outra característica que pode influenciar o resultado da avaliação realizada pelo especialista, é a composição química do material analisado. Em função deste cenário, os resultados obtidos neste trabalho para a aproximação do mapeamento dos atributos para a classificação do critério de intensidade são considerados satisfatórios. 


\section{CONCLUSÃO}

Uma proposta para classificação dos defeitos internos presentes nas amostras da impressão de Enxofre foi estudada, a partir da implementação de um algoritmo que agrega as técnicas de processamento digital de imagens e 0 conhecimento dos especialistas sobre o defeito da segregação central.

No algoritmo, a transformada de Hough e o limiar adaptativo foram utilizados para a identificação da linha segregada. Além disso, os conhecimentos sobre o defeito da segregação central, em conjunto com as características dos elementos segmentados, proporcionaram a construção no algoritmo do mapeamento entre as características extraídas da imagem e os graus de severidade do defeito. Este mapeamento foi utilizado pelo algoritmo na classificação dos critérios de continuidade e intensidade da segregação central, de acordo com o padrão de referência NSC.

O desempenho do algoritmo foi analisado em dois momentos específicos, de acordo com sua fase de implementação. Na avaliação, foram analisadas 255 imagens de amostras reais, oriundas de duas usinas siderúrgicas, distribuídas nos diferentes graus de severidade. Os resultados da primeira fase de implementação mostram que a identificação da linha segregada apresenta acurácia de $93 \%$. As classificações oriundas do mapeamento realizado para as classes de criticidade do defeito, na segunda fase de implementação, apresentam acurácia de 92\% para o critério de continuidade e $68 \%$ para o acerto simultâneo no critério de intensidade e continuidade.

Ao longo da implementação do algoritmo, observou-se que alguns aspectos associados aos procedimentos de preparação/manipulação das amostras e aspectos relacionados ao sistema de aquisição interferem no processamento das imagens. Dentre estes aspectos de preparação e manipulação das amostras destacam-se as marcas de corte, lixamento e giz. Tais marcas se apresentam como falhas do processo de preparação ou anotações operacionais, que podem ocorrer 
em qualquer região da amostra. Observou-se que essas marcas interferem na classificação, caso estejam situadas próximas (conectadas) aos elementos que compõe a linha segregada.

Em relação aos aspectos do sistema de aquisição das imagens, foram observadas interferências como a falha na concatenação das seções da amostra, iluminação irregular e inclinação do sistema de captura da imagem. Mesmo com todos os distúrbios mencionados, o algoritmo mostrou-se tolerante as interferências e capaz de minimiza-la, segmentando corretamente um número significativos de imagens no universo analisado.

Durante o desenvolvimento do algoritmo, observou-se que a extração das características foi prejudicada pela baixa qualidade da resolução da imagem (VGA 640 x 480 pixels com 96 dpi). Este fator resultou na perda de detalhes dos atributos que poderiam ser relevantes na separabilidade das classes de severidade do defeito. Desta forma, o mapeamento dos atributos e consequentemente o acerto na classificação pode ter sido afetado por esta condição da imagem. Em função desta limitação, os resultados obtidos pelo algoritmo para a classificação do critério de continuidade e intensidade são considerados satisfatórios.

Com base nos resultados obtidos, acredita-se que imagens com resolução HD (1280 x 720 pixels com 720 dpi) ou Full HD (1920 x 1080 pixels com 1080 dpi) sejam mais adequadas para a realização do mapeamento dos atributos e não comprometam os resultados do algoritmo de classificação.

A maior contribuição desse trabalho é a integração de diferentes técnicas computacionais em um único procedimento para a classificação da segregação central, em função das peculiaridades deste defeito. As dificuldades e as soluções encontradas no trabalho contribuem para o amadurecimento e evolução da integração de técnicas relacionadas ao processamento de imagens para a classificação de defeitos. 
Adicionalmente, o trabalho apresenta como contribuição para a área de aplicação, uma forma de retenção do conhecimento dos especialistas sobre o processo de classificação da segregação central. A representação desse conhecimento através de recursos computacionais contribui para a ampliação do entendimento sobre as características da segregação central que são analisadas durante o processo de classificação.

Os resultados obtidos no trabalho abrem oportunidades para 0 desenvolvimento de novos trabalhos que visem melhorar o mapeamento dos atributos e a classificação dos critérios de continuidade e intensidade. Essa melhoria pode ser alcançada por meio da análise de outros aspectos da amostra, como por exemplo a composição química do material, ou seja, aspectos não relacionados diretamente as características extraídas da imagem, mas que podem influenciar no processo de decisão do especialista durante a classificação. O desenvolvimento de uma solução automatizada da aquisição da imagem até a classificação da segregação central destaca-se como outra iniciativa que pode ser desenvolvida. 


\section{REFERÊNCIAS}

AGAIAN, S.; ALMUNTASHRI, A.; PAPAGIANNAKIS, A. T. An improved canny edge detection application for asphalt concrete. IEEE International Conference on Systems, Man and Cybernetics, San Antonio, TX, p. 3683 - 3687, 2009.

ALEKSIC, M.; SMIRNOV, M.; GOMA, S. Novel bilateral filter approach: Image noise reduction with sharpening. Proceedings of the SPIE, Digital Photography II, San Jose, CA, v. 6069, p. 141-147, 2006.

ALI, M.; CLAUSI, D. Using the Canny edge detector for feature extraction and enhancement of remote sensing images. IEEE Geoscience and Remote Sensing Symposium, Sydney, NSW, v.5, p. 2298-2300, 2001.

ALVES, W. A. L.; ARAUJO, S. A. de; LIBRANTZ, A. F. H. Reconhecimento de padrões de texturas em imagens digitais usando uma rede neural artificial híbrida. Exacta, São Paulo, v. 4, n. 2, p. 325-332, 2006.

AMERICAN SOCIETY FOR TESTING AND MATERIALS. ASTM E 340-00 (2006): Standard Test Method for Macroetching Metals and Alloys. Estados Unidos, 2006.

AMERICAN SOCIETY FOR TESTING AND MATERIALS. ASTM E 1180-08: Standard Practice for Preparing Sulphur Prints for Macrostructural Evaluation. Estados Unidos, 2008.

AURICH, V.; WEULE, J. Non-linear gaussian filters performing edge preserving diffusion. In: Proceedings of the DAGM Symposium, 1995.

BAE, S.; PARIS, S.; DURAND, F. Two-scale tone management for photographic look. ACM Transactions on Graphics (TOG) - Proceedings of ACM SIGGRAPH 2006, New York, v.25, n.3, p.637 - 645, 2006.

BALI, A.; SINGH, S. N. A Review on the Strategies and Techniques of Image Segmentation. IEEE Fifth International Conference on Advanced Computing \& Communication Technologies (ACCT), Haryana, p. 113 - 120, 2015.

BASAVAPRASAD, B.; RAVI, M. A Comparative Study on Classification of Image Segmentation Methods with a Focus on Graph Based Techniques. International Jounal of Research in Engineering and Technology (IJRET), India, v.3, n.3, p. 310315, 2014.

BASU, M. Gaussian-based edge-detection methods-a survey. IEEE Transactions on Systems, Man, and Cybernetics, Part C: Applications and Reviews, v.32, n.3, p. $252-260,2002$.

BENNETT, E. P.; MCMILLAN, L. Video enhancement using per-pixel virtual exposures. ACM Transactions on Graphics (TOG) - Proceedings of ACM SIGGRAPH 2005, New York, v.24, n.3, p. 845 - 852, 2005. 
BHATTACHARYA, S.; GUPTA, S.; SUBRAMANIAN, V. K. Localized image enhancement. IEEE Twentieth National Conference on Communications (NCC), Kanpu, p. 1 - 6, 2014.

BRITISH STANDARD. BS 6285: The macrographic examination of steel by sulphur print (Baumann method). Londres, 1982.

BOTELHO, G. S.; MARANA, A. N. HTS: A new shape descriptor based on Hough Transform. IEEE International Symposium on Circuits and Systems, Beijing, p. 974977, 2013 .

CALEB, P.; STEUER, M. Classification of surface defects on hot rolled steel using adaptive learning methods. IEEE Proceedings. Fourth International Conference on knowledge-Based Intelligent Engineering Systems and Allied Technologies, Brighton, v.1, p. 103-108, 2000.

CANNY, J. F. A computational approach to edge detection. IEEE Transactions on Pattern Analysis and Machine Intelligence, Vol. PAMI-8, n.6, p.679 - 698, 1986.

CAO, G.; CHEN, J.; JIANG, J. An adaptive approach to vehicle license plate localization. The 29th Annual Conference of the IEEE Industrial Electronics Society, Roanoke, Estados Unidos, p. 1786-1791, 2003.

CARVALHO,J.L. Lingotamento Contínuo de Placas de Aço. São Paulo: Associação Brasileira de Metais, 1988.

CHANG, C.; HSIAO J.; HSIEH C. An Adaptive Median Filter for Image Denoising. IEEE Second International Symposium on Intelligent Information Technology Application, Shanghai, v.2, p. $346-350,2008$.

CHENG, J., XUE, R., LU, W., JIA, R. Segmentation of medical images with Canny operator and GVF snake model. IEEE 7th World Congress on Intelligent Control and Automation, Chongqinp, p. 1777 - 1780, 2008.

COSIO, F. A.; FlORES, J. A. M.; CASTANEDA, M. A. P.; SOlANO, S. ; TATO, P. Automatic counting of immunocytochemically stained cells. IEEE Engineering in Medicine and Biology Society, Proceedings of the 25th Annual International Conference of the IEEE, v.1, p. $790-793,2003$.

CUNG, H. M.; COHEN, P.; BOULANGER, P. Multiscale edge detection and classification in range images. IEEE International Conference on Robotics and Automation, Cincinnati, v.3, p. 2038-2044, 1990.

DENG, C.; MA, W.; YIN Y. An edge detection approach of image fusion based on improved Sobel operator. IEEE 4th International Congress on Image and Signal Processing (CISP), Shanghai, v. 3, p. $1189-1193,2011$. 
DIAS, A.; SANCHO, L.; DIAZ, E.; LOPEZ, A.; SIRGO, J.A.; Application of Self Organizing Maps to predict centerline segregation in steel slabs. IEEE Industry Applications Conference, 41st IAS Annual Meeting, Tampa, v.1, p. 511 - 515, 2006.

DURAND, F.; DORSEY, J. Fast bilateral filtering for the display of high-dynamicrange images. ACM Transactions on Graphics (TOG) - Proceedings of ACM SIGGRAPH 2002, New York, v. 21, n. 3, p. 257-266, 2002.

EISEMANN, E.; DURAND, F. Flash photography enhancement via intrinsic relighting. ACM Transactions on Graphics (TOG) - Proceedings of ACM SIGGRAPH 2004, New York, v. 23, n. 3, p. 673-678, 2004.

EKSTROM, M. P. Digital Image Processing Techniques. Estados Unidos: Academic Press, p. 25, 1984.

$E L A D, M$. On the origin of the bilateral filter and ways to improve it. IEEE Transactions on Image Processing, v.11, n.10, p. 1141 - 1151, 2002.

ELAD, M. Retinex by two bilateral filters. Scale Space and PDE Methods in Computer Vision, $5^{\text {th }}$ Internation Conference Scale-Space conference, Hofgeismar, v. 3459, p. 217-229, 2005.

EMBLETON, K. V.; GIBSON, C. E.; HEANEY, S. I. Automated counting of phytoplankton by pattern recognition: a comparison with a manual counting method. Oxford Journals, Journal of Plankton Research, v. 25, n.6, p. 669-691, 2003.

FACO, R. J. Lingotamento contínuo do aço. In: Mourão M. B. Siderurgia para não siderurgistas, São Paulo: Associação Brasileira de Metalurgia e Materiais, p. 147, 2005.

FENG,Y.; RONG-BEN, W.; RONG-HUI, Z. Based on Digital Image Lane Edge Detection and Tracking under Structure Environment for Autonomous Vehicle. IEEE International Conference on Automation and Logistics, Jinan, p. $1310-1314$, 2007.

FLORES, A.; CRISÓSTOMO, P.; LOPEZ, J. Peruvian scallop larvae counting system using image processing techniques. IEEE 7th International Caribbean Conference on Devices, Circuits and Systems, Cancun, p.1 - 4, 2008.

FRAGA, C.; GONZALEZ, R.; CANCELAS, J.; ENGUITA, J. Camber measurement system in a hot rolling mill. IEEE Industry Applications Conference, 39th IAS Annual Meeting, v. 2, n. 2, p. 897-902, 2004.

FURTADO, H. S. Lingotamento Contínuo de Placas. São Paulo: Associação Brasileira de Metalurgia, 2007. 
GAJENDRAN, V.; RODRIGUEZ, J. J. Chromosome counting via digital image analysis. IEEE International Conference on Image Processing, v.5, p. 2929- 2932, 2004.

GARCIA, A.; SPIM,J. A.; SANTOS,C. A.; CHEUNG, N. Lingotamento Contínuo de Aços. São Paulo: Associação Brasileira de Metalurgia e Materiais, 2006.

GARCIA, M.; GARCIA, D.; DIAZ, J.; SUHREZ, F. Flatness defects detection in rolling products with real-time vision system. IEEE Second International Conference on Intelligent Systems Engineering, Hamburg-Harburg, p. 407-412, 1994.

GHOSH, A. Segregation in cast products. SADHANA - Academy Proceedings in Engineering Sciences, India, v.26, p.5-24, 2001.

GOMES, O. F. M. Processamento e Análise de Imagens Aplicados à Caracterização Automática de Materiais. Dissertação (Mestrado em Engenharia Metalúrgica e de Materiais). Pontifícia Universidade Católica do Rio de Janeiro, 2001.

GONZALEZ, R.C.; WOODS, R. E. Digital Image Processing. NewJersey: Prentice Hall, 2002.

HARDZEYEU, V.; KLEFENZ, F. On using the hough transform for driving assistance applications. IEEE 4th International Conference on Intelligent Computer Communication and Processing, Romênia, p. 91-98, 2008.

HOCENSKI, Z.; VASILIC, S.; HOCENSKI, V. Improved Canny Edge Detector in Ceramic Tiles Defect Detection. IEEE - 32nd Annual Conference on IEEE Industrial Electronics, Paris, p. $3328-3331,2006$.

HOUGH, P. V. C. A method and means for recognizing complex patterns. US 3069654, 1962.

INTERNATIONAL STANDARD ORGANIZATION. ISO 4968: Steel - Macrographic examination by sulphur print (Baumann method). Suíça, 1979.

JAIN, A.; DUIN, R. P.; MAO, J. Statistical pattern recognition: A review. IEEE Transactions on Pattern Analysis and Machine Inteligence, v. 22, n. 1, p.4-37, 2000.

JANAKIRAMAN, S.; DANIEL, J.; ABUDHAHIR, A. Certain studies on thresholding based defect detection algorithms for Magnetic Flux Leakage Images. IEEE International Conference on Emerging Trends in Computing, Communication and Nanotechnology (ICE-CCN), Tirunelveli, p. 507-512, 2013.

JANANI, V. DINAKARAN, M. Infrared image enhancement techniques - A review. IEEE $2^{\text {nd }}$ International Conference on Current Trends in Engineering and Technology (ICCTET), Coimbatore, p. 167-173, 2014. 
JARVINEN, J.; RAUHAMAA, J. Real-time inspection of steel strip. Helsinki, Finland, 2002.

KAUPPINEN, H.; SILVEN, O.; PIIRAINEN, T. Self-organizing map based user interface for visual surface inspection. Proceedings on 11th Scandinavvian Conference on Image Analysis, Kangerlussuaq, Greenland, p. 801-808, 1999.

KHARE, C.; NAGWANSHI, K. K. Implementation and Analysis of Image Restoration Techniques. International Journal of Computer Trends and Technology, India, p. 1 - 6, 2011.

KOTAS, P.; PRAKS, P.; ZELJKOVIC, V.; VALEK, L. Automated Region of Interest Retrieval of Metallographic Images for Quality Scoring Estimation. IEEE Industry Applications Society Annual Meeting (IAS), Texas, Estados Unidos, p. $1-4,2010$.

KOTAS, P.; PRAKS, P.; VALEK, L; ZELJKOVIC, V.; VONDRAK, V. Automated Region of Interest Retrieval of Metallographic Images for Quality Classification in Industry. Advances in Electrical \& Electronic Engeneering, v.10, n. 1, p.50-56, 2012.

KUMAGAI, H.; MORISHITA, S.; KUNIAKI, K.; ASAMA, H.;MISHIMA, T. Accuracy improvement of counting asbestos in particles using a noise redacted background subtraction. IEEE International Conference on Multisensor Fusion and Integration for Intelligent Systems, Seoul, p.74-79, 2008.

KUMAR, A.; SHEN, H. C. Texture inspection for defects using neural networks and support vector machines. IEEE International Conference on Image Processing, v. 3, p. III-353 - III-356, 2002.

KWAK, C.; VENTURA, J. A.; TOFANG-SAZI, K. A neural network approach for defect identification and classification on leather fabric. Journal of Intelligent Manufacturing, v.11, n.5, p. 485-499, 2000.

LI, H.; GUO, L. ; CHEN, T.; YANG, L.; WANG, X. The research of corner detector of teeth image based on the curvature scale space corner algorithm. IEEE International Conference on Computer, Mechatronics, Control and Electronic Engineering (CMCE), Changchun, v.5 p. 353-356, 2010.

LOPEZ, L. C.; HIRAKAWA, A. R. Classificação das amostras do ensaio de Baumann através do processamento digital de imagens. In: XV Seminário de Automação e TI Industrial, ABM - Associação Brasileira de Metalurgia, Materiais e Mineração, São Paulo, p. 134-146, 2011.

LOUKAS, C. G.; WILSON, G. D.; VOJNOVIC, B.; LINNEY, A. An image analysisbased approach for automated counting of cancer cell nuclei in tissue sections. Cytometry A, v. 55, p. 30-42, 2003. 
MA, C. ; SHEN, H. ; HUANG, T. Centerline segregation in continuous casting billets. IEEE Tsinghua Science and Technology, v.9, n.5, p.550-554, 2004.

MA, C.; GAO, W.; YANG, L.; LIU, Z. An improved Sobel algorithm based on median filter. IEEE $2^{\text {nd }}$ International Conference on Mechanical and Electronics Engineering, Kyoto, v. 1, p. V1-88-V1-92, 2010.

MACEDO, M. M. G.; JACKOWSKI, M. P. Extraction of Tubular Network From 3D Angiography Using Hough Transform. Sibgrapi Conference on Graphics, Patterns and Images, Arequipa, 2013.

MALL, V.; ROY, A.K. ; MITRA, S.K. ; SHUKLA, S. Detection of structural tampering in a digital image using Canny Edge Detector. IEEE International Conference on Informatics, Electronics \& Vision, Dhaka, p. 1-7, 2013.

MARINO, P.; DOMINGUEZ, M.; ALONSO, M. Inspection of steel sheets based on ccd image sensors. IEEE/SICE/RSJ International Conference on Multisensor Fusion and Integration for Intelligent Systems, Taipei, p. 68-73, 1999.

MARQUES, O. F.; VIEIRA, H. N. Processamento Digital de Imagens, Rio de Janeiro: Brasport, 1999. ISBN 8574520098.

MARTINS, L. A. O.; PÁDUA, F. L. C.; ALMEIDA, P. E. M. Automatic detection of surface defects on rolled steel using Computer Vision and Artificial Neural Networks. 36th Annual Conference on IEEE Industrial Electronics Society, Glendale, p. 1081-1086, 2010.

MICROSOFT. Visual C++ 2013 Express Edition. Disponível em: https://www.visualstudio.com/en-us/products/visual-studio-express-vs.aspx , 2014.

MORGENFELD, J.I; SOLARI, M.; OVEJERO-GARCIA, J. Technical Note: Metallographic Sulphur Determination by SEM in Austenitic Stainless Steel Weld Metal. Welding Research Supplement. American Welding Society, p.143-145, 1983.

MUTHUKRISHNAN, R.; RADHA, M. Edge Detection Technique for Image Segmentation. International Journal of Computer Science \& Information Technology (IJCSIT), v.3, n.6, p. 259-267, 2011.

NAKAGAWA, Y.; NAKAGAWA, S.; KANO, M.; TANIZAKI, T. Quality improvement of steel products by using multivariate data analysis. IEEE SICE Annual Conference, Japão, p. 2428 - 2432, 2007.

NAND, G. K.; NOOPUR; NEOGI, N. Defect Detection Of Steel Surface Using Entropy Segmentation. Annual IEEE India Conference (INDICON), Pune, p. 1-6, 2014. 
NASUTION, A.M.T. ; SURYANINGTYAS, E.K. Comparison of Red Blood Cells Counting using two Algorithms: Connected Component Labeling and Backprojection of Artificial Neural Network. IEEE PhotonicsGlobal@Singapore, Singapore, p. 1-4, 2008.

NAYAR, A. Testing of Metals. Nova Deli: McGraw-Hill, 2005.ISBN -10: 0-07058164-9.

NEELAMANI, R. N.; HYEOKHO, C.; BARNIUK, R. Forward: Fourier-wavelet regularized deconvolution for ill-conditioned systems. IEEE Transactions on Signal Processing, v. 52, n.2, p. 418-433, 2004.

NUNES, E. O.; CONCl, A. . Segmentação por Textura e Localização do Contorno de Regiões em Imagens Multibandas. Revista IEEE América Latina, v. 5, p. 185192, 2007.

OpenCV, Open Source Computer Vision. Disponível em: http://opencv.org, 2015.

OH,B. M.;CHEN, M.; DORSEY, J.; DURAND, F. Image-based modeling and photo editing. ACM Proceedings of the $28^{\text {th }}$ annual conference on Computer graphics and interactive techniques, New York, p. 433-442, , 2001.

PARIS, S.; KPRNPROBST, P.; TUMBLIN, J.; DURAND, F. A gentle introduction to bilateral filtering and its applications. ACM Proceeding SIGGRAPH, New York, n.1, p. 1-50, 2008.

PEDRINI, H.; SCHWARTZ, W. R. Análise de imagens digitais: princípios, algoritmos e aplicações. São Paulo: Thomson Learning, 2008. ISBN 978-85-2210595-3.

PETSCHNIGG, G.; AGRAWALA, M.; HOPPE, H.; SZELISKI, R.; COHEN, M.; TOYAMA, K. Digital photography with flash and no-flash image pairs. ACM Transactions on Graphics (TOG) - Proceedings of ACM SIGGRAPH 2004, New York, v.23, n.3, p. 664-672, 2004.

PRITHA, D.N.; SAVITHA, L.; SHYLAJA, S. S. Face Recognition by Feedforward Neural Network Using Laplacian of Gaussian Filter and Singular Value Decomposition. IEEE First International Conference on Integrated Intelligent Computing, Bangalore, p. $56-61,2010$.

QUEIROZ, L. C. L.; HIRAKAWA, A. R. Classificação das amostras do ensaio de Baumann através do processamento digital de imagens. Tecnologia em Metalurgia, Materiais e Mineração (Impresso), São Paulo, v. 10, p. 183-189, 2013.

RAJESHWARI, S.; SHARMILA, T.S. Efficient quality analysis of MRI image using preprocessing techniques. IEEE Conference on Information \& Communication Technologies (ICT), JeJu Island, p. 391-396, 2013. 
RIZZO, E. M. S. Introdução aos Processos de Lingotamento dos Aços. São Paulo: Associação Brasileira de Metalurgia e Materiais, 2006.

SABLE, A.H.; JOHNHALE, K.C. Modified Double Bilateral Filter for Sharpness Enhancement and Noise Removal. IEEE International Conference on Advances in Computer Engineering, Bangalore, Karnataka, India, p. 295 - 297, 2010.

SANCHO, L. F., DIAZ, A. M., SIRGO, J. A. New technique for centre line segregation measurement in steel slabs. La Revue de Métallurgie, Cambridge University Press, v. 103, n. 12, p. 546-551, 2006.

SANDHAR, R. K.; PHONSA, G. Distinctive feature mining based on varying threshold based image extraction for single and multiple objects. IEEE International Conference on Advanced Communication Control and Computing Technologies (ICACCCT), Ramanathapuram, p. 1537-1541, 2014.

SHANKAR, V..; GILL, T. P. S.; MANNAN, S. L.; SUNDARESAN, S. Solidification cracking in austenitic stainless steel welds. SADHANA - Academy Proceedings in Engineering Sciences, India, v.28, p.359-382, 2003.

SHARIFI, M. ;FATHY, M. ; TAYEFEH MAHMOUDI, M. A classified and comparative study of edge detection algorithms. IEEE International Conference on Information Technology: Coding and Computing, p. 117 - 120, 2002.

SHRIVAKSHAN, G. T.; CHANDRASEKAR, C. A Comparison of various Edge Detection Techniques used in Image Processing. IJCSI - International Journal of Computer Science Issues, v. 9, Issue 5, n.1, p.269-275, 2012.

SERVILHA, J. P. A metalografia no controle de qualidade. Máquinas \& Ferramentas, São Paulo, v.1, n. 12, p.27-29, 1980.

SIRGO, J.A.; CAMPO, R.; LOPEZ, A.; DIAZ, A.; SANCHO, L. Measurement of centerline segregation in steel slabs. IEEE Industry Applications Conference, $41 \mathrm{st}$ IAS Annual Meeting, Tampa, v.1, p. 516-520, 2006.

SMITH, S. M.; BRADY, J. M. SUSAN - a new approach to low level image processing. ACM International Journal of Computer Vision, Estados Unidos, v.23, n.1, p. 45-78, 1997.

SONAM, R. D. Review of Contrast Enhancement Techniques Based on Histogram Equalization. International Journal of Advanced Research in Education Technology (IJARET), India, v.2, n.2, p. 76-79, 2015.

SONKA, M.; HLAVAC, V.; BOYLE, R. Image processing, Analysis And Machine Vision. Estados Unidos: Cencage Learning, 2014. ISBN 978-1133593607.

SU, M.; WANG, Z.; ZHANG, H.; MA, Y. A new method for blood cell image segmentation and counting based on PCNN and autowave. IEEE 3rd International Symposium on Communications, Control and Signal Processing, St Julians, p. 6-9, 2008. 
SUVDAA, B.; AHN, J.; KO, J. Steel Surface Defects Detection and Classification Using SIFT and Voting Strategy. International Journal of Software Engineering and Its Applications, Austrália, v.6, n.2, 2012.

WU, G.; KWAK, H.; JANG, S.; XU, K. XU, J. Design of Online Surface Inspection System of Hot Rolled Strips. IEEE International Conference on Automation and Logistics (ICAL), Qingdao, p. 2291-2295, 2008.

TAMBUR, G. S. Metodologia de inspeção visual e automática de carga em vagões ferroviários. Dissertação (Mestrado em Engenharia Elétrica). Universidade Estadual de Campinas, 2007.

TANG, J. A Color Image Segmentation algorithm Based on Region Growing. IEEE 2nd International Conference on Computer Engineering and Technology (ICCET), Chengdu, v.6, p. 634-637, 2010.

$\mathrm{TOH}$, Y. H.; NG, T. M.; LIEW, B. K. Automated fish counting using image processing. IEEE International Conference on Computational Intelligence and Software Engineering, Wuhan, p. 1-5, 2009.

TOMASI, C.; MANDUCHI, R. Bilateral filtering for gray and color images. IEEE Sixth International Conference on Computer Vision, Bombay, p. 839 - 846, 1998.

VERNON, D. Machine Vision: Automated Visual Inspection and Robot Vision. United Kingdom: Prentice Hall, p.53, 1991.

VOORT, G. F. V. Metallography, principles and practices. New York: McGraw-Hill, p. 47-51, 2007.

WANG, B.; FAN, S. An Improved CANNY Edge Detection Algorithm. IEEE Second International Workshop on Computer Science and Engineering, Qingdao, v. 1 , p. $497-500,2009$.

WONG, Y.; SOH, V.C.-M. ; BAN, K.; BAU, Y. Improved Canny Edges Using Ant Colony Optimization. IEEE Fifth International Conference on Computer Graphics, Imaging and Visualisation, Penang, p.197 - 202, 2008.

XIANG, H.; YAN, B.; CAI, Q.; ZOU, G. An Edge Detection Algorithm Based-on Sobel Operator for Images Captured by Binocular Microscope. IEEE International Conference on Electrical and Control Engineering (ICECE), Yichang, p.980 - 982, 2011.

XIN-SHENG, W.; LIAN-ZHI, Q.; JUN, D. A New Method for Bar Code Localization and Recognition. IEEE $2^{\text {nd }}$ International Congress on Image and Signal Processing, Tianjin, p. 1-6, 2009.

XU, J.; WAN, Y.; ZHANG, X. A method of edge detection based on improved canny algorithm for the lidar depth image. Proceedings SPIE 6419, 
Geoinformatics 2006: Remotely Sensed Data and Information, Paginação irregular, 2006.

YANG, C.; ZHANG, C.J.; JI, G.; FU, Y.; HONG, X. Recognition of Defects in Steel Surface Image Based on Neural Networks and Morphology. IEEE Second Workshop on Digital Media and its Application in Museum \& Heritages, Chongqing, p. $72-77,2007$.

YANG, Q.; KANG, W. General Research on Image Segmentation Algorithms. International Journal of Image, Graphics and Signal Processing(IJIGSP), v.1, p.1-8. 2009.

YAZDCHI,M.; YAZDI,M.; MAHYARI,A.G. Steel Surface Defect Detection Using Texture Segmentation Based on Multifractal Dimension. IEEE International Conference on Digital Image Processing, Bangkok, p. 346-350, 2009.

YING, X.; WEI, X.; PEI-XIN, Y.; QING-DA, H.; CHANG-HAI, C. Research on an automatic counting method for steel bars' image. IEEE International Conference on Electrical and Control Engineering, Wuhan, p. 1644-1647, 2010.

YUN, J. P. et al. Development of real-time defect detection algorithm for highspeed steel bar in coil (bic). IEEE International Joint Conference SICE-ICASE, Busan, p. 2495-2498, 2006.

YUN, J. P.; CHOI, S.H., SEO, B.; PARK, C. H.; KIM, S. W. Defects Detection of Billet Surface Using Optimized Gabor Filters. Proceedings of the 17th International Federation of Automatic Control World Congress, Seoul, p. 77-82, 2008.

ZHAO, F.; deSILVA, C.J.S. Use of the Laplacian of Gaussian operator in prostate ultrasound image processing. IEEE Engineering in Medicine and Biology Society, Proceedings of the 20th Annual International Conference of the IEEE, Hong Kong, v.2, p. $812-815,1998$.

ZHOU, X.; XIAO, X.; MA, C. A study of automatic recognition and counting system of urine-sediment visual components. IEEE 3rd International Conference on Biomedical Engineering and Informatics (BMEI), Yantai, v.1, p. 78-81, 2010. 